\title{
Avaliação de atributos de testabilidade para sistemas de suporte à decisão
}



Assinatura:

\section{Marcos Fernando Geromini}

\section{Avaliação de atributos de testabilidade para sistemas de suporte à decisão}

Dissertação apresentada ao Instituto de Ciências Matemáticas e de Computação - ICMC-USP, como parte dos requisitos para obtenção do título de Mestre em Ciências - Ciências de Computação e Matemática Computacional. VERSÃO REVISADA Área de Concentração: Ciências de Computação e Matemática Computacional

Orientador: Prof. Dr. Adenilso da Silva Simão 
Ficha catalográfica elaborada pela Biblioteca Prof. Achille Bassi e Seção Técnica de Informática, ICMC/USP, com os dados fornecidos pelo(a) autor(a)

Geromini, Marcos Fernando
Avaliação de atributos de testabilidade para sis-
temas de suporte à decisão / Marcos Fernando Gero-
mini; orientador Adenilso da Silva Simão. - São
Carlos - SP, 2016.
107 p.
Dissertação (Mestrado - Programa de Pós-Graduação
em Ciências de Computação e Matemática Computacional)
- Instituto de Ciências Matemáticas e de Computação,
Universidade de São Paulo, 2016.
1. Testabilidade. 2. Fatores de testabilidade.
3. Sistemas de suporte à decisão - SSD. 4. Qualidade
da informação. 5. Tomada de decisão. I. Simão, Ade-
nilso da Silva, orient. II. Título.




\section{Marcos Fernando Geromini}

\section{Testability attributes assessment for decision support systems}

Master dissertation submitted to the Instituto de Ciências Matemáticas e de Computação - ICMCUSP, in partial fulfillment of the requirements for the degree of the Master Program in Computer Science and Computational Mathematics. FINAL VERSION

Concentration Area: Computer Science and Computational Mathematics

Advisor: Prof. Dr. Adenilso da Silva Simão

USP - São Carlos

April 2016 

Agradeço a Deus pelo dom da vida e por me dar forças em todos os momentos em que me sentia fraco diante das dificuldades.

À minha família, em especial a minha mulher Marcia, meus filhos Letícia e Gustavo que sempre estiveram ao meu lado com muito amor, carinho e paciência.

Ao meu orientador, Prof. Dr. Adenilso da Silva Simão, pela confiança, paciência, orientação e, sobretudo pela amizade construída ao longos desses anos.

Aos meus amigos e colegas, que de alguma forma contribuíram ou colaboraram para a realização deste trabalho: Alan, Allan Seolin, Camila Silveira, Camila Sundermann, Cezar Manechini, Cristiane Carneiro, Domenico, Draylson, Edna Vergilio, Eliane Ramos, Elias, Elisa, Flávio, João Porto, Julio Paulino, Lívia, Luiz Assis, Marcos Pereira, Otávio Lemos, Ricardo Ramos, Ricardo Reimão, Sérgio Yaegashi, Simone, Stevão e Valdemar Neto.

Agradeço também a todos os professores e funcionários do ICMC, em especial a Ana Carolina e Alexandre Reis da pós-graduação. 



\section{RESUMO}

GEROMINI, M. F.. Avaliação de atributos de testabilidade para sistemas de suporte à decisão. 2016. 107 f. Dissertação (Mestrado em Ciências - Ciências de Computação e Matemática Computacional) - Instituto de Ciências Matemáticas e de Computação (ICMC/USP), São Carlos - SP.

As organizações públicas e privadas são constantemente expostas a fatores internos e externos, que podem comprometer sua estabilidade diante das oscilações da economia e dos concorrentes. Nestas empresas, os tomadores de decisão são essenciais para analisar e avaliar todas as variáveis que envolvem estes fatores, com o objetivo de identificar o melhor caminho para os negócios. Entretanto, conseguir gerenciar os dados internos e externos à organização não é uma atividade simples. Neste contexto, os Sistemas de Suporte à Decisão (SSD) tornaram-se fundamentais para auxiliar os tomadores de decisão na solução de problemas mal estruturados ou sem nenhuma estruturação. Porém, a complexidade que envolve os projetos de implantação ou desenvolvimento de um SSD, geralmente compromete a efetividade dos testes que garantem a conformidade do sistema em relação às especificações previamente definidas. Uma solução para esse problema é considerar os atributos ou fatores de testabilidade nestes projetos, pois podem elevar o grau de eficácia e eficiência da atividade de teste e consequentemente contribuírem para redução do tempo e custos do projeto. Portanto, conseguir identificar esses atributos ou fatores que tenham influência na testabilidade dos SSD e algum método que permita analisar e avaliar o quanto estão presentes neste sistema, é essencial para aumentar a qualidade do sistema. Diante desta necessidade, este trabalho investigou e selecionou os principais fatores que podem influenciar no grau de testabilidade de um software e propôs um método para analisar e avaliar o quanto o SSD está considerando esses fatores em sua arquitetura. Com o objetivo de avaliar e validar o método de análise e avaliação, foram realizados testes de aplicabilidade em empresas de pequeno, médio e grande porte, bem como no meio acadêmico. Com os resultados obtidos nos testes, foi possível concluir que o método é específico para SSD, que pode ser usado como um guia durante o processo de desenvolvimento e auxiliar na classificação de SSD quanto a sua testabilidade.

Palavras-chave: Testabilidade, Fatores de testabilidade, Sistemas de suporte à decisão SSD, Qualidade da informação, Tomada de decisão. 



\section{ABSTRACT}

GEROMINI, M. F.. Avaliação de atributos de testabilidade para sistemas de suporte à decisão. 2016. 107 f. Dissertação (Mestrado em Ciências - Ciências de Computação e Matemática Computacional) - Instituto de Ciências Matemáticas e de Computação (ICMC/USP), São Carlos - SP.

Public and private organizations are constantly exposed to internal and external factors which could compromise their stability in the face of fluctuations in the economy and competitors. In these companies, decision makers are essential to analyze and evaluate all the variables regarding these factors, in order to identify the best way for business. However, managing internal and external data of the organization is not a simple activity. In this context, Decision Support Systems (DSS) have become essential to assist decision makers in solving unstructured problems or lock of structure. However, the complexity involved in the implementation of projects or development of a DSS usually compromises the effectiveness of tests that ensure compliance of the system in relation to previously defined specifications. One solution to this problem is to consider the attributes or testability factors in these projects, since they can raise the level of effectiveness and efficiency of testing activity and thus contribute to reducing the time and project costs. Therefore, the ability to identify these attributes or factors that influence testability of DSS and a process for analyzing and evaluating how much the present in this system, is essential to increase system quality. Given this need, this work investigated and selected the main factors that can influence the degree of testability of software and proposed a way to analyze and assess how the DSS is considering these factors in its architecture. In order to evaluate and validate the analysis and evaluation method, applicability tests were performed in small, medium and large companies, as well as in academy. As results obtained in the tests, it was concluded that the method is specific for DSS, which can be used as a guide during the development process and assist in the DSS classification regarding its testability.

Key-words: Testability, Testability Factors, Decision Support Systems - DSS, Quality of Information, Decision Making. 

Figura 1 - Recursos do Sistema de Informação. . . . . . . . . . . . . . . . . . 23

Figura 2 - Os componentes de um Sistema de Informação. . . . . . . . . . . . . . 24

Figura 3 - Classificação dos Sistemas de Informação. . . . . . . . . . . . . . . . 25

Figura 4 - Sistemas de informação de negócio e os problemas enfrentados. . . . . . 26

Figura 5 - Relação entre SPT e SIG. . . . . . . . . . . . . . . . . . 27

Figura 6 - Estrutura hierárquica de quatro camadas . . . . . . . . . . . . . . . . 29

Figura 7 - A relação entre os principais termos presentes em teste de software. . . 32

Figura 8 - As quatro fases do método GQM. . . . . . . . . . . . 36

Figura 9 - A estrutura do paradigma GQM. . . . . . . . . . . . . 37

Figura 10 - Modelo do GQM+Estratégias. . . . . . . . . . . . . . . . . 38

Figura 11 - Etapas do processo da pesquisa. . . . . . . . . . . . . . . . . . 43

Figura 12 - Representação da testabilidade como espinha dorsal. . . . . . . . . . . 45

Figura 13 - Representação do modelo de desenvolvimento de software testável. . . . 46

Figura 14 - Fatores de testabilidade. . . . . . . . . . . . . . . 47

Figura 15 - Diferentes fatores da capacidade de suporte ao teste. . . . . . . . . . 51

Figura 16 - Relação entre os fatores/atributos de QI. . . . . . . . . . . . . . . . 53

Figura 17 - Modelo da relação entre os fatores de QI e o impacto na tomada de decisão. . . . . . . . . . . . . . . . . . . . 55

Figura 18 - Modelo para avaliação e mapeamento dos pontos fortes e fracos do SSD. 60

Figura 19 - Modelo gráfico para avaliação dos SSD . . . . . . . . . . . . . . . . . 62

Figura 20 - Classificação por questão da primeira avaliação do sistema 1. . . . . . . 65

Figura 21 - Classificação por questão da segunda avaliação do sistema 1. . . . . . . 66

Figura 22 - Classificação por questão da terceira avaliação do sistema 1. . . . . . . 67

Figura 23 - Classificação por questão da avaliação do sistema 2 . . . . . . . . . . . 68

Figura 24 - Classificação por questão da avaliação do sistema 3. . . . . . . . . . . . 69

Figura 25 - Classificação por questão da avaliação do sistema 4. . . . . . . . . . . . 70

Figura 26 - Componentes da arquitetura do AGORA. . . . . . . . . . . . . . . 72

Figura 27 - Ilustração das camadas do AGORA-GeoDash, adaptado de (HORITA et al., 2014). . . . . . . . . . . . . . . . . . . . 73

Figura 28 - Classificação por questão da primeira avaliação do sistema 5. . . . . . . 74

Figura 29 - Classificação por questão da segunda avaliação do sistema 5 . . . . . . . 75

Figura 30 - Classificação geral obtidas nos testes. . . . . . . . . . . . . . . . 77 

$\overline{20}$

Tabela 1 - Artefatos da arquitetura dos SSD . . . . . . . . . . . . 29

Tabela 2 - Categorização de um modelo de desempenho para QI . . . . . . . . . . 52

Tabela 3 - Questões principais. . . . . . . . . . . . . 56

Tabela 4 - Atributos de testabilidade presentes nas subquestões. . . . . . . . . 58

Tabela 6 - Classificação do SSD conforme o nível de maturidade. . . . . . . . . . . 61

Tabela 7 - Classificação do nível de maturidade obtidos nos testes. . . . . . . . . . 76 

INTRODUÇÃo . . . . . . . . . . . . . . . . . . . 17

1.1 Contextualização e Motivação . . . . . . . . . . . . . . . 17

1.2 Objetivo . . . . . . . . . . . . . . . . . . . . . . 19

$1.3 \quad$ Organização . . . . . . . . . . . . . . . . . 20

2 REVISÃO BIBLIOGRÁFICA . . . . . . . . . . . . . 21

2.1 Considerações iniciais . . . . . . . . . . . . . . . . . 21

$2.2 \quad$ Sistemas de informação . . . . . . . . . . . . . . . . . 21

2.2.1 Sistemas de Suporte à Decisão (SSD) . . . . . . . . . . . . . . . 28

2.3 Testabilidade . . . . . . . . . . . . . . . . . . . 31

$2.4 \quad$ Goal Question Metrics (GQM) . . . . . . . . . . . . . . . . 35

$2.5 \quad$ Considerações finais . . . . . . . . . . . . . . . . . . 38

3 MÉTOdO PARA AVALIAÇÃO E ANÁLISE DA TESTABILIDADE DO SSD . . . . . . . . . . . . . . . . . 41

$3.1 \quad$ Considerações iniciais . . . . . . . . . . . . . . . . . . 41

3.2 Método e estratégia da pesquisa . . . . . . . . . . . . . 41

3.3 Fatores de testabilidade . . . . . . . . . . . . . . . . . . 44

3.4 Relação entre qualidade da informação e tomada de decisão . . . . 51

3.5 Desenvolvimento do questionário . . . . . . . . . . . . . . 55

$3.6 \quad$ Escala de classificação do SSD . . . . . . . . . . . . . . . 59

$3.7 \quad$ Considerações finais . . . . . . . . . . . . . . . . 62

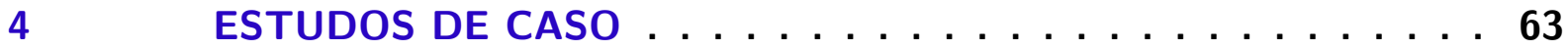

4.1 Considerações iniciais . . . . . . . . . . . . . . . 63

4.2 Teste de aplicabilidade do questionário . . . . . . . . . . . 63

4.2.1 Sistemas para empresas de médio e grande porte . . . . . . . . . . . 64

4.2.2 Sistemas para empresas de pequeno porte . . . . . . . . . . . . . . 68

4.2.3 Sistema no meio acadêmico . . . . . . . . . . . . . . . . . . 70

4.2.4 Resumo dos testes de aplicabilidade . . . . . . . . . . . . . 75

4.3 Considerações finais . . . . . . . . . . . . . . . 77

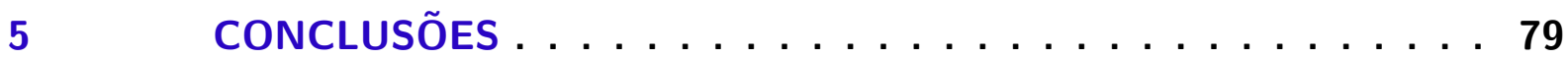

$5.1 \quad$ Dificuldades e Limitações . . . . . . . . . . . . . . . . . 80 


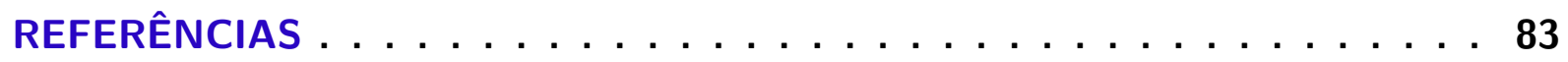

APÊNDICE A QUESTIONÁRIO PARA AVALIAR O NÍVEL DE MATURIDADE DO SSD . . . . . . . . . . . 91

APÊNDICE B QUESTIONÁRIO PARA DEFINIR O PERFIL DO PAR-

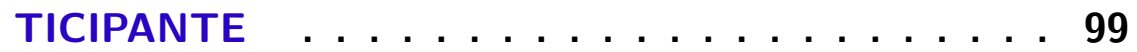

APÊNDICE C QUESTIONÁRIO PARA AVALIAR A QUALIDADE DO QUESTIONÁRIO DO NÍVEL DE MATURIDADE DO SSD $\ldots \ldots \ldots \ldots \ldots \ldots 10 \ldots \ldots \ldots$ 


\section{INTRODUÇÃO}

\subsection{Contextualização e Motivação}

As organizações públicas e privadas deparam-se todo dia com novos desafios, que necessitam de decisões rápidas frente ao dinamismo do mercado. Como previsto por Estender (2005), os desafios da concorrência simples baseada somente no preço quase não existem mais. Nos últimos anos, as organizações foram expostas não somente a situações internas, mas também aos reflexos da economia em nível mundial, como o possível enfraquecimento da economia, tanto em países desenvolvidos como nos países emergentes (LAGARDE, 2015) e a desaceleração na atividade econômica que vem comprometendo a estabilidade financeira de muitas empresas no Brasil, no qual metade delas estão inadimplentes (GONCALVES, 2015).

Para estas empresas conseguirem se manter diante desta instabilidade e não perderem sua competitividade no mercado, é necessário se antecipar aos acontecimentos e concorrentes. Para isto, os tomadores de decisão assumem um papel de grande importância nas organizações, pois os resultados obtidos no processo de decisão podem guiar os negócios frente a esta instabilidade (ADLA; ZARATE, 2006). No entanto, o crescente volume de dados e a complexidade das relações comerciais estão comprometendo a efetividade do processo de decisão e aumentando o tempo de resposta aos problemas.

Nesse contexto, alcançar formas de gerenciar esse volume de dados e extrair a partir deles informações relevantes para a tomada de decisão, são ações fundamentais para responder rapidamente às oscilações do mercado. Diante disso, os Sistemas de Suporte à Decisão (SSD) tornaram-se uma ferramenta decisiva no processo de tomada de decisão.

Os SSDs são soluções de software empresarial de administração, projetados para dar suporte na solução de problemas mal estruturados ou sem nenhuma estruturação previamente conhecida. Possuem ferramentas que permitem flexibilidade na interação com 
o tomador de decisão (TURBAN, 1995; BEUREN; MARTINS, 2001; LI; PENG, 2004; ADLA; ZARATE, 2006; STAIR; REYNOLDS, 2011).

Estes sistemas são utilizados em diversos segmentos do mercado, normalmente em conjunto ou integrados a outros sistemas de informação. Devido a essa abrangência, na literatura existem vários estudos relacionados ao uso dos SSD, na tentativa de obter suporte para solução de problemas, tais como: de logística na rede de transporte (SANTOS; COUTINHO-RODRIGUES; ANTUNES, 2011); no planejamento de planos diretores de áreas residenciais e industriais (RUIZ et al., 2012); e no setor da saúde (KELLY et al., 2012).

Entre as opções disponibilizadas a uma organização que deseja implantar um SSD, duas são mais comuns: (i) desenvolver o seu próprio sistema; ou (ii) comprar de empresas especializadas. Entretanto, existem vantagens e desvantagens nas duas opções (LAUDON; LAUDON, 2010; STAIR; REYNOLDS, 2011). Independentemente da opção escolhida, surgem dúvidas sobre o SSD por parte da organização, tais como: é confiável, permite integração, tem suporte, tem documentação, permite importação de dados e outras. Uma forma de responder a estas dúvidas é realizando testes no sistema.

Um outro fator importante que deve ser verificado na aquisição de um SSD é a qualidade agregada ao produto final, que pode ser identificada pelos atributos de qualidade previstos na (ISO/IEC 25010, 2010): adequabilidade funcional, eficiência do desempenho, compatibilidade, usabilidade, confiabilidade, segurança, manutenibilidade e portabilidade, que também podem ser verificados por meio de testes no SSD.

Entre esses atributos, Sommerville (2011) considera a manutenibilidade como um atributo crítico, porque em ambiente de negócio as mudanças são inevitáveis. Assim, é fundamental desenvolver em conformidade com as normas relacionadas à ela, empregando os principais fatores que influenciam esse atributo de qualidade: modularidade, reusabilidade, analisabilidade, modificabilidade e testabilidade (ISO/IEC 25010, 2010).

Neste trabalho, é dada ênfase à testabilidade, que é definida como o grau de eficácia e eficiência com o qual é possível estabelecer critérios de teste de um sistema, produto ou componente, bem como os testes que possam ser realizados para determinar se esses critérios foram cumpridos (ISO/IEC 25010, 2010). Isto significa que quanto maior for o grau de testabilidade de um sistema, mais fácil será testá-lo e consequentemente identificar mais erros que possam comprometer suas funcionalidades.

Diante do alto grau de complexidade que envolve os projetos de implantação ou desenvolvimento de um SSD, os quais exigem pesquisa, desenvolvimento, projeto de instalação e principalmente testes para garantir que o sistema esteja em conformidade com as especificações (ARCHIBALD, 2003; PEZZè; YOUNG, 2008), conseguir elevar o grau de testabilidade deste sistema pode reduzir o tempo e os custos da atividade de teste, bem 
como elevar o grau de eficácia e eficiência na detecção de erros, uma vez que o custo da atividade de teste é considerado alto em relação às outras etapas do projeto (DELAMARO; MALDONADO; JINO, 2007).

Entretanto, conseguir avaliar o grau de testabilidade de um software não é uma tarefa trivial, pois envolve os fatores ou atributos internos e externos que influenciam no grau da testabilidade dentro de um domínio específico, tais como controlabilidade e observabilidade (ISO/IEC 25010, 2010). Na tentativa de identificar estes fatores e meios de mensurá-los, vários esforços foram identificados (FREEDMAN, 1991; BINDER, 1994; VOAS; MILLER, 1995; KAROUI; GHEDAMSI; DSSOULI, 1999; GAO; JACOB; WU, 2003; AIZENBUD-RESHEF et al., 2006; NAZIR; KHAN, 2009).

Apesar dos vários estudos identificados na literatura, nenhum deles tinha relação direta com os fatores ou atributos de testabilidade para o domínio dos SSDs. Essa lacuna no conhecimento sobre esses fatores ou atributos específicos de testabilidade e formas de mensurá-los motiva o desenvolvimento desta pesquisa, cujo objetivo é descrito a seguir.

\subsection{Objetivo}

O principal objetivo deste trabalho é a identificação dos fatores ou atributos que possam aumentar o grau de testabilidade dos Sistemas de Suporte à Decisão e pelo desenvolvimento de um método para análise e avaliação do nível de maturidade deste sistema em relação a sua testabilidade. Com esses dois elementos definidos e relacionados, espera-se como resultado:

- Um conjunto de fatores ou atributos de testabilidade específicos para SSD;

- Um método que possibilite a análise e avaliação do SSD em relação a sua testabilidade; e

- Um guia a ser considerado no processo de desenvolvimento do SSD, que auxilie no aumento do grau de testabilidade do sistema.

Para tanto, foi desenvolvida neste trabalho uma revisão da literatura, a qual permitiu identificar cinco fatores que podem alterar o grau de testabilidade de um software, são eles: compreensibilidade, observabilidade, rastreabilidade, controlabilidade e capacidade de suporte ao teste. Com o propósito de verificar se os princípios destes fatores influenciam na testabilidade dos Sistemas de Suporte à Decisão, foi elaborado um mapa com os possíveis elementos que podem afetar a tomada de decisão, a partir dos estudos identificados na literatura. 
Com base nestes elementos e de algumas das principais exigências dos órgãos públicos em licitações envolvendo softwares com módulo de suporte à decisão, foi desenvolvido um método de análise e avaliação do nível de maturidade do SSD em relação à sua testabilidade. Para avaliar a aplicabilidade do método, foram realizados estudos de casos em empresas de pequeno, médio e grande porte, bem como no meio acadêmico.

Os resultados obtidos dos testes de aplicabilidade do método permitiram verificar que os colaboradores que possuem conhecimento sobre SSD e sobre os conceitos básicos de teste de software conseguem extrair mais informações sobre o status atual do SSD. Também foi observado que o método desenvolvido é aplicável somente para este tipo de sistema.

\subsection{Organização}

Este capítulo apresentou o contexto e a motivação para o desenvolvimento deste trabalho, e o objetivo a ser alcançado. No Capítulo 2 é feita uma revisão bibliográfica sobre os principais assuntos abordados neste trabalho. No capítulo 3 é apresentado o processo de desenvolvimento que definiu uma forma de analisar e avaliar os SSD em relação a sua testabilidade. No Capítulo 4 são realizados vários testes de aplicabilidade da ferramenta definida no Capítulo 3 em SSD já consolidados no mercado. O Capítulo 5 apresenta as contribuições deste trabalho e possíveis trabalhos futuros relacionados a este tema. Nos Apêndices A, B e C são apresentados os questionários utilizados para avaliar o nível de maturidade dos SSD em relação a sua testabilidade. 


\section{REVISÃO BIBLIOGRÁFICA}

\subsection{Considerações iniciais}

Neste Capítulo, são apresentados os conceitos básicos sobre os principais tópicos deste trabalho. Inicialmente, na Seção 2.2 é ressaltada a importância dos Sistemas de Informação na sociedade e as principais diferenças entre dados, informação e conhecimento. Ainda nessa seção, são apresentados em mais detalhes os Sistemas de Suporte à Decisão, um dos focos do presente trabalho. Em seguida, na Seção 2.3 são feitas considerações sobre a importância dos testes em softwares e sua relação com o atributo testabilidade que está inserido no modelo de qualidade da (ISO/IEC 25010, 2010). Finalmente, na Seção 2.4 é apresentado o conceito sobre o paradigma Goal Question Metric (GQM), utilizado para definir métricas a partir de metas previamente estabelecidas.

\subsection{Sistemas de informação}

Na última década, o produto software assumiu um papel de grande importância na sociedade, apoiando com rapidez e segurança diversas atividades desenvolvidas pelo ser humano. Entre essas, uma das principais atividades em que empresas, governo e o ser humano podem obter destes sistemas, são informações com confiabilidade e rapidez.

Para Pressman (2010), "Software" é um conjunto composto por programas, dados e sua respectiva documentação, o qual realiza procedimentos previamente definidos em prol de um objetivo. Com base no propósito do software e nas características do ambiente, é possível classificá-los em: software de tempo real, software comercial, software embutido e outros.

Entre esses softwares, têm-se os Sistemas de Informação (SI), com os quais interagese diariamente, por meio de caixas eletrônicos, máquinas de autoatendimento em órgãos 
públicos ou privados e outros. Nas organizações privadas, os Sistemas de Informação são considerados um diferencial, que pode elevar o nível de competitividade perante os concorrentes, alcançar uma gestão com excelência, desenvolver novos produtos, estreitar o relacionamento com os clientes e fornecedores, bem como fornecer apoio nas tomadas de decisão, de tal forma a antecipar as necessidades do mercado (LAUDON; LAUDON, 2010; PARENTE, 2009; STAIR; REYNOLDS, 2011).

A funcionalidade básica dos SI é gerar informações relevantes que atendam seus objetivos a partir do processamento de dados. Os dados podem ser entendidos como elementos brutos, registros, fatos, representações do mundo real e que sozinhos não conduzem a nenhuma compreensão (SOMMERVILLE, 2011; REZENDE, 2003; BEAL, 2004). A transformação desses dados por combinações lógicas e significativas, permite aumentar a consistência dos dados, dotando-os de relevância e propósito. O resultado dessa transformação é chamado de informação. No entanto, se essas transformações não adicionarem nenhum valor novo ou significado aos dados processados para quem a interprete, ela não é considerada informação (STAIR; REYNOLDS, 2011; REZENDE, 2003; BEAL, 2004). Consequentemente, conforme Hoffmann (2009), essa informação analisada, processada e aplicada se transforma em conhecimento. Para Stair e Reynolds (2011), o conhecimento é a análise e compreensão das informações e como utilizá-las em uma tarefa específica.

As principais diferenças entre dados, informação e conhecimento estão relacionadas às características de cada um. Os dados são simples observações do mundo real, que podem ser obtidos por máquinas e estruturados de forma a permitir seu compartilhamento e serem quantificados. A informação depende do homem para analisar e mensurar esses dados, para torná-los relevantes ao propósito a ser alcançado. Por fim, o conhecimento está diretamente ligado à mente humana e sua capacidade de explorar, vincular e relacionar essas informações com outras. Por isso é difícil capturar, estruturar e transferi-lo a outra pessoa usando máquinas (DAVENPORT; PRUSAK, 1998).

Na literatura existem várias definições sobre o termo "Sistema". Entre essas, a mais abrangente é de Chiavenato (2006). Para o autor, Sistema é a combinação de componentes ligados ou interdependentes que interagem formando uma unidade complexa e organizada, de forma a atingir um propósito. De modo geral, esses sistemas podem ser classificados quanto a suas características; assim, considerando as organizações de médio a grande porte, os Sistemas de Informação são classificados em (STAIR; REYNOLDS, 2011):

- Complexo, devido aos vários elementos altamente relacionados e interconectados;

- Aberto, pela capacidade de interagir com o seu ambiente externo;

- Dinâmico, por sofrer constantes mudanças em curtos intervalos de tempo; 
- Adaptável, pela capacidade de mudar em resposta as mudanças do ambiente externo; e

- Permanente, quando realizadas as devidas manutenções e adaptações.

A partir dos anos 60, os SIs começaram a assumir novos papéis, agregando recursos ao longo do tempo e consequentemente novas funções, voltadas ao usuário final e principalmente para gestão das organizações. Entretanto, foi nos anos 80 que ficou caracterizada a maior expansão dos SIs, devido ao avanço das tecnologias específicas para o usuário final. A partir dessa década, os SIs também começaram a oferecer suporte para o processo de tomadas de decisão, planejamento de recursos e inteligência de negócios (O’BRIEN, 2011).

Atualmente, os Sistemas de Informação são formados por um conjunto organizado de pessoas, software, hardware, redes de comunicação, procedimentos e recursos de coleta de dados que se transforma e dissemina informações na organização, conforme ilustrado na Figura 1 (O'BRIEN, 2011).

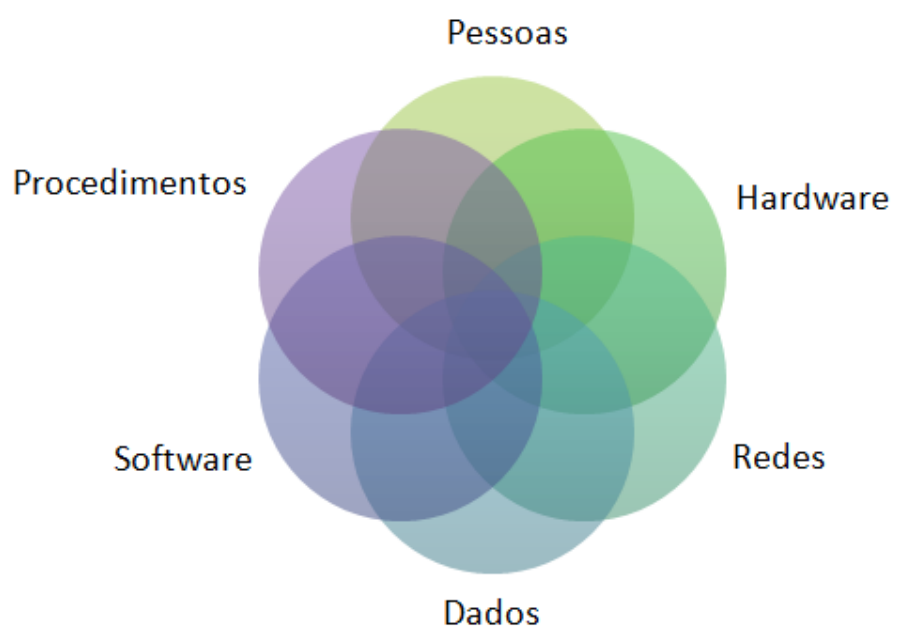

Figura 1 - Recursos do Sistema de Informação, adaptado de (O'BRIEN, 2011).

Outra definição muito citada na literatura descreve um SI como um conjunto de elementos ou componentes inter-relacionados que coleta determinada entrada de dados, realiza um processamento, dissemina uma saída com informações significativas e fornece um mecanismo de realimentação para correções dessa saída em prol de seus objetivos, conforme ilustrado na Figura 2 (STAIR; REYNOLDS, 2011; LAUDON; LAUDON, 2010). 


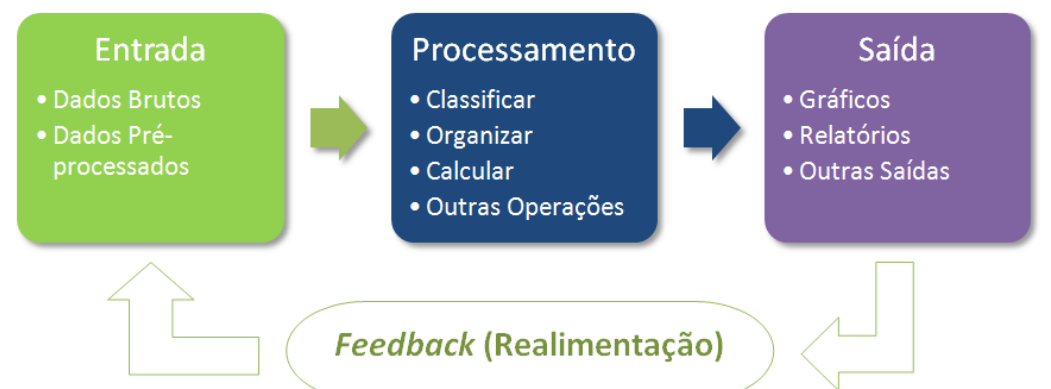

Figura 2 - Os componentes de um Sistema de Informação, adaptado de (LAUDON; LAUDON, 2010; STAIR; REYNOLDS, 2011).

A atividade de entrada é responsável por captar dados brutos da organização, como as vendas efetuadas, despesas com folha de pagamento, situação do estoque e dados do seu ambiente externo, por exemplo: bolsa de valores, prazos de fornecedores, valores da concorrência (STAIR; REYNOLDS, 2011; LAUDON; LAUDON, 2010).

O maior desafio nessa atividade é gerenciar o grande volume de dados distintos, mantendo a integridade do seu significado, o sigilo dos dados e principalmente a confiabilidade para geração de informação, assim evitando análises distorcidas da situação real (TAYI; BALLOU, 1998). Segundo Salvador et al. (2013), a falta de qualidade dos dados tem um impacto negativo nas organizações, gerando retrabalho e reprocessamento de certas tarefas, causando prejuízo financeiro e perda de oportunidades de negócios.

$\mathrm{Na}$ atividade de processamento, os dados brutos são trabalhados de forma a retornar informações significativas e úteis para decisão dos negócios. Para isso, o processamento pode integrar métodos estatísticos, armazenamento de dados para uso futuro, comparações e agrupamentos de dados (STAIR; REYNOLDS, 2011; LAUDON; LAUDON, 2010).

No processamento também é considerado o conhecimento adquirido do domínio, a cultura ou um conjunto de premissas que definem prioridades durante o processamento, gerando, assim, informações realmente relevantes ao contexto da organização. Entretanto, os tomadores de decisão devem equilibrar o custo/benefício de uma informação ao produzi-la (STAIR; REYNOLDS, 2011; LAUDON; LAUDON, 2010).

A saída envolve a transferência das informações produzidas para os membros da organização, geralmente na forma de relatórios ou gráficos, organizados de maneira a facilitar a visualização do status atual da organização (STAIR; REYNOLDS, 2011; LAUDON; LAUDON, 2010). Essa visão da saída muda quando um SI é decomposto em vários subsistemas. As saídas geradas por um subsistema podem ser a entrada de vários subsistemas ou dele mesmo, por isso é importante definir a estrutura de integração entre esses subsistemas para evitar perda de informação ou semântica (REZENDE; ABREU, 2003). 
A atividade de FeedBack é fundamental nesse ciclo para corrigir ou avaliar os dados de entrada, com o propósito de aumentar a confiabilidade das informações produzidas. A realimentação depende da ação adotada pelos membros da empresa. Um exemplo desse processo é a utilização das previsões de vendas futuras para alimentar a entrada do sistema; dessa forma, o módulo de gerenciamento do estoque poderia gerar pedidos aos fornecedores para atender esse novo consumo (STAIR; REYNOLDS, 2011; LAUDON; LAUDON, 2010).

Segundo O'Brien (2011), os SIs podem ser classificados conceitualmente em operacionais e gerenciais, conforme ilustrado na Figura 3, a qual destaca as principais funções desempenhadas pelos sistemas de apoio às operações nas áreas funcionais e dos sistemas gerenciais na administração de uma organização.

\section{Sistemas de Informação}

\section{Sistemas de Apoio às Operações}
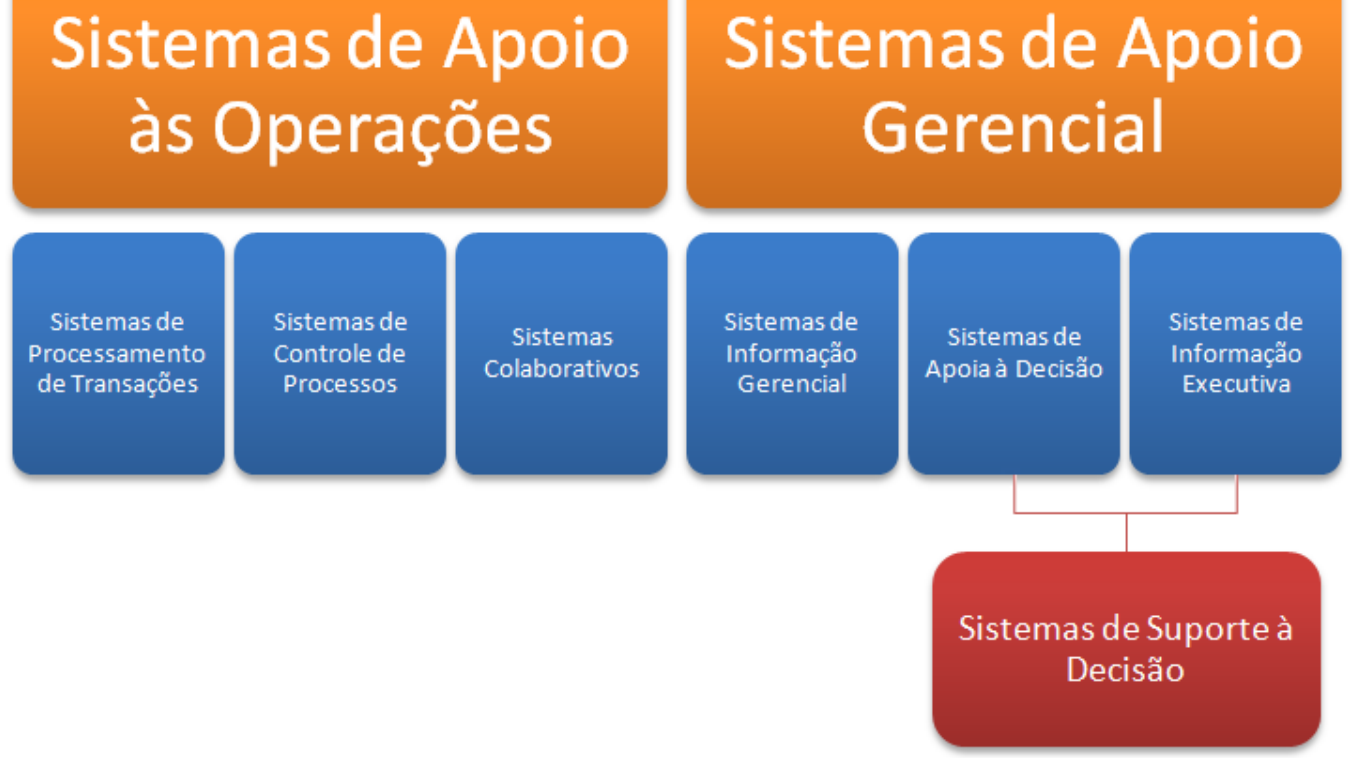

Figura 3 - Classificação dos Sistemas de Informação, adaptado de (O’BRIEN, 2011).

Esses sistemas podem ser vistos nos três níveis principais da hierarquia dentro da organização e, para melhores resultados, a integração entre eles é fundamental. A Figura 4 ilustra esses níveis, tendo na base da pirâmide os sistemas operacionais, que são voltados para apoiar e controlar as transações funcionais da empresa, como sistema de controle de estoque/vendas, sistema de recursos humanos. No meio da pirâmide encontra-se a gerência média, responsável pelas tomadas de decisão que envolvem as atividades operacionais e no topo da hierarquia está a gerência sênior ou executiva, na qual as decisões referem-se não 
somente à empresa, mas ao ambiente de negócios (STAIR; REYNOLDS, 2011; LAUDON; LAUDON, 2010).

Nesse ambiente de negócios, os sistemas operacionais e gerenciais contribuem para solução de inúmeros problemas enfrentados por uma organização, do mais complexo ao mais básico. Na Figura 4, a pirâmide invertida dos problemas faz uma relação com a outra pirâmide. No topo dessa pirâmide estão concentrados os problemas mais complexos e relevantes para a sobrevivência da organização, exigindo atenção constante da alta gerência (REZENDE; ABREU, 2003; LAUDON; LAUDON, 2010).

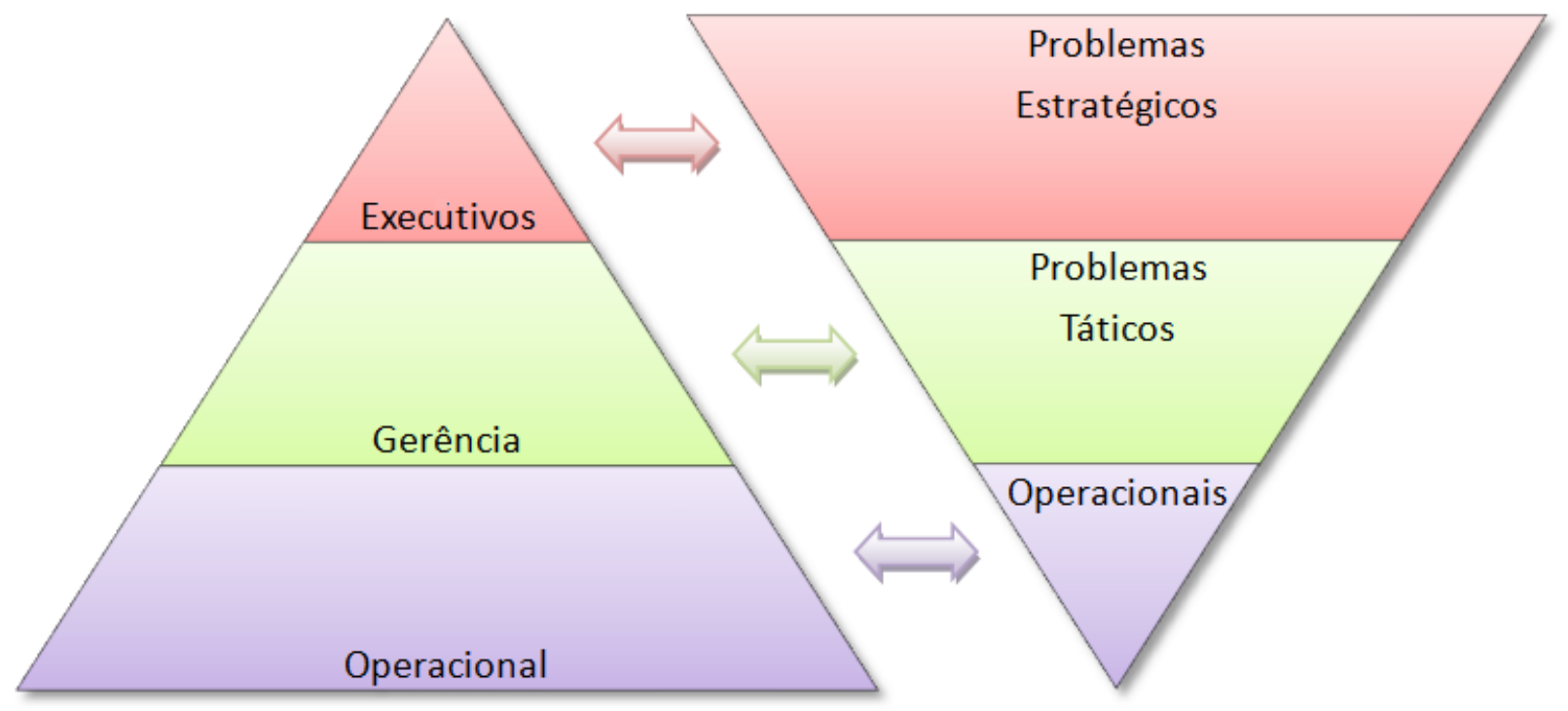

Figura 4 - Sistemas de informação de negócio e os problemas enfrentados (LAUDON; LAUDON, 2010).

Nessas organizações, as necessidades mudam conforme o nível de hierarquia e especialidades. Sendo assim, as informações necessárias para atender as exigências desses setores são específicas. Um único SI não seria suficiente e completo a ponto de atender todos os setores. Por isso, identificar os SI e sua área de atuação pode ser um fator importante no momento de decidir em qual SI deve-se investir. Para auxiliar nessa identificação Laudon e Laudon (2010) e Stair e Reynolds (2011), relacionaram alguns tipos de Sistemas de Informação, conforme o nível organizacional de atuação.

- No nível operacional, o mais baixo dessa hierarquia, atuam os Sistemas de Processamento de Transação (SPT), largamente utilizados nas atividades diárias da organização e também considerados os mais antigos dos sistemas computadorizados. Um dos seus propósitos é fornecer saídas que auxiliem o corpo técnico dos setores a responder perguntas relacionadas a estoque, fluxo de caixa e outros. Um ponto importante desses sistemas é a vantagem de automatizar as atividades repetitivas e funções imprescindíveis ao funcionamento de uma organização, como: financeiro, 
recursos humanos, contabilidade, controle do estoque, entre outros (REZENDE; ABREU, 2003).

- O nível da gerência média é dividido em duas áreas: a do conhecimento voltada para trabalhos de engenharia e administrativos, os quais são assistidos pelos Sistemas de Automação de Escritório (SAE) e os Sistemas de Trabalhadores do Conhecimento (STC); e a área gerencial, que utiliza os Sistemas de Informações Gerenciais (SIG), voltados às atividades de gestão, fornecendo informações consolidadas sobre o desempenho da organização para serem utilizadas na estrutura decisória e proporcionar subsídios para previsões futuras, com o objetivo de otimizar os resultados esperados (REZENDE; ABREU, 2003; LAUDON; LAUDON, 2010; OLIVEIRA, 2011). A Figura 5 ilustra esse conceito e a relação entre os SPT fornecendo informação para os SIG.

Sistemas de Processamento de Transações (SPT)

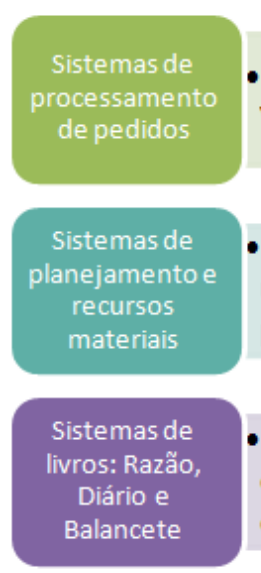

-Dados das Vendas

- Dados de custo unitário de produtos

- Dados contabeis, como despesas, caixa e outros
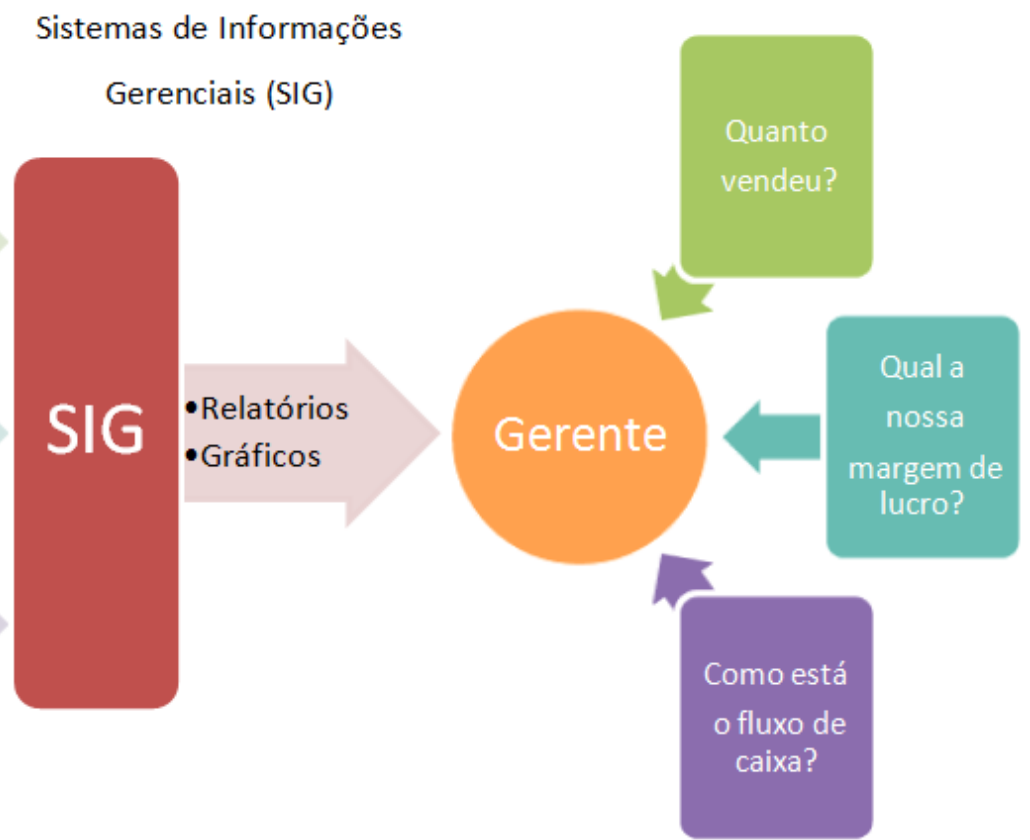

Figura 5 - Relação entre SPT e SIG, adaptado de (LAUDON; LAUDON, 2010).

- No nível mais alto, atuam os Sistemas de Apoio à Decisão (SAD), que têm como objetivo fornecer ao administrador alternativas com mais qualidade para solução de um determinado problema. Em geral, são ad hoc, ou seja, podem ser desenvolvidos para uma única situação ou para situações que ocorrem periodicamente. Mas, para problemas de alto nível e não-estruturados, são indicados os Sistemas de Informações Executivas (SIE), que permitem a exploração das informações externas, como novos concorrentes, balança comercial e outros, a fim de fornecer resultados personalizados e integrados sobre desempenho, fatores críticos e informações do ambiente externo que atingem de forma direta ou indireta a organização. A combinação 
destes dois sistemas originou os Sistemas de Suporte à Decisão (SSD), que serão abordados na Subseção 2.2.1 (REZENDE; ABREU, 2003; LAUDON; LAUDON, 2010; STAIR; REYNOLDS, 2011).

Nesse contexto, os sistemas de gestão mais comuns que integram todos os dados e processos de uma organização em um único sistema de software, são: (i) o sistema integrado de gestão empresarial (do inglês, Enterprise Resource Planning - ERP), que se propõe a planejar e controlar todos os recursos da empresa, tais como finanças, contabilidade, apoio a tomadas de decisão e outros (GUERRINI; BELHOT, 2008); (ii) o sistema de gestão da cadeia de suprimento (do inglês, Supply Chain Management - SCM), utilizado para gerenciar a cadeia de suprimentos desde uma promessa de pedido até a entrega do produto; e (iii) os sistemas de gestão do relacionamento com o cliente (do inglês, Customer Relationship Management - CRM), cujo objetivo é aproximar o consumidor da organização de forma inteligente, criando e mantendo um vínculo entre cliente e empresa, além de procurar sempre perceber e antecipar as necessidades destes clientes (LAUDON; LAUDON, 2010).

\subsubsection{Sistemas de Suporte à Decisão (SSD)}

Os Sistemas de Suporte à Decisão (SSD) foram projetados a partir da combinação do SIE e o SAD, para dar suporte na solução de problemas mal estruturados ou sem nenhuma estruturação previamente conhecida, os quais necessitam da intuição e experiência do tomador de decisão para identificar qual solução é a mais apropriada (ADLA; ZARATE, 2006; LI; PENG, 2004; STAIR; REYNOLDS, 2011).

A interação entre o SSD e o tomador de decisão normalmente ocorre por ferramentas que permitem ao tomador adequar as saídas conforme suas necessidades e oferece recursos para analisar fatos não previsíveis à organização. Entre essas ferramentas tem-se: as de simulação, gerador de relatórios e gráficos (TURBAN, 1995; BEUREN; MARTINS, 2001).

Essas ferramentas fazem parte de uma arquitetura que permite combinar diferentes artefatos para melhorar a eficácia da tomada de decisão. A Tabela 1 relaciona alguns trabalhos e os artefatos utilizados: (i) as bases de dados tanto internas quanto externas, (ii) base de modelos contendo representações do mundo real e outros, (iii) base de conhecimento com as regras de negócios e outros, (iv) interface de simulação/interação com o tomador de decisão, (v) base de métodos com fórmulas matemáticas, procedimentos e outros, e (vi) módulos de gestão, adaptação e mineração de dados (ZHENGLI; XIAOFENG, 2011; TAO; HUIFENG, 2010; HORITA; ALBUQUERQUE, 2013). 
Tabela 1 - Artefatos da arquitetura dos SSD

\begin{tabular}{|l|c|c|c|c|c|c|c|}
\hline \multicolumn{1}{|c|}{ Trabalhos } & \multicolumn{2}{c|}{ Base de Dados } \\
Interna & Externa & $\begin{array}{c}\text { Base de } \\
\text { Modelos }\end{array}$ & $\begin{array}{c}\text { Base de } \\
\text { Conhecimento }\end{array}$ & $\begin{array}{c}\text { Simulador } \\
\text { Interação }\end{array}$ & $\begin{array}{c}\text { Base de } \\
\text { Métodos }\end{array}$ & $\begin{array}{c}\text { Mineração } \\
\text { de Dados }\end{array}$ \\
\hline Li e Peng (2004) & $\bullet$ & $\bullet$ & $\bullet$ & $\bullet$ & & $\bullet$ & \\
\hline Adla e Zarate (2006) & $\bullet$ & $\bullet$ & $\bullet$ & $\bullet$ & $\bullet$ & $\bullet$ \\
\hline Jianjun e Zhishu (2009) & $\bullet$ & $\bullet$ & $\bullet$ & $\bullet$ & & $\bullet$ \\
\hline Luo et al. $(2009)$ & $\bullet$ & $\bullet$ & $\bullet$ & $\bullet$ & $\bullet$ & $\bullet$ \\
\hline Tao e Huifeng (2010) & $\bullet$ & $\bullet$ & $\bullet$ & $\bullet$ & $\bullet$ & $\bullet$ \\
\hline Stair e Reynolds (2011) & $\bullet$ & $\bullet$ & $\bullet$ & & $\bullet$ & $\bullet$ \\
\hline Zhengli e Xiaofeng (2011) & $\bullet$ & $\bullet$ & $\bullet$ & & $\bullet$ & $\bullet$ \\
\hline Lin et al. (2012) & $\bullet$ & $\bullet$ & $\bullet$ & $\bullet$ & $\bullet$ & $\bullet$ \\
\hline Horita e Albuquerque (2013) & $\bullet$ & $\bullet$ & $\bullet$ & $\bullet$ & $\bullet$ & $\bullet$ \\
\hline
\end{tabular}

Esses artefatos são organizados nessa arquitetura normalmente pelo tipo e sua função, a princípio formados por quatro camadas: (i) das bases de dados, (ii) de préprocessamento ou gestão dos dados, (iii) dos aplicativos, e (iv) das ferramentas de interação com o tomador (HORITA; ALBUQUERQUE, 2013; LIN et al., 2012; TAO; HUIFENG, 2010).

A Figura 6 apresenta uma ilustração desta arquitetura e a disposição dos artefatos em cada camada. Esta arquitetura é resultado do trabalho dos autores Luo et al. (2009), que abordaram os Sistemas de Informações Geográficas (GIS) e SSD, com o propósito de apoiar na prática o planejamento urbano em relação a distribuição e expansão da rede de energia.

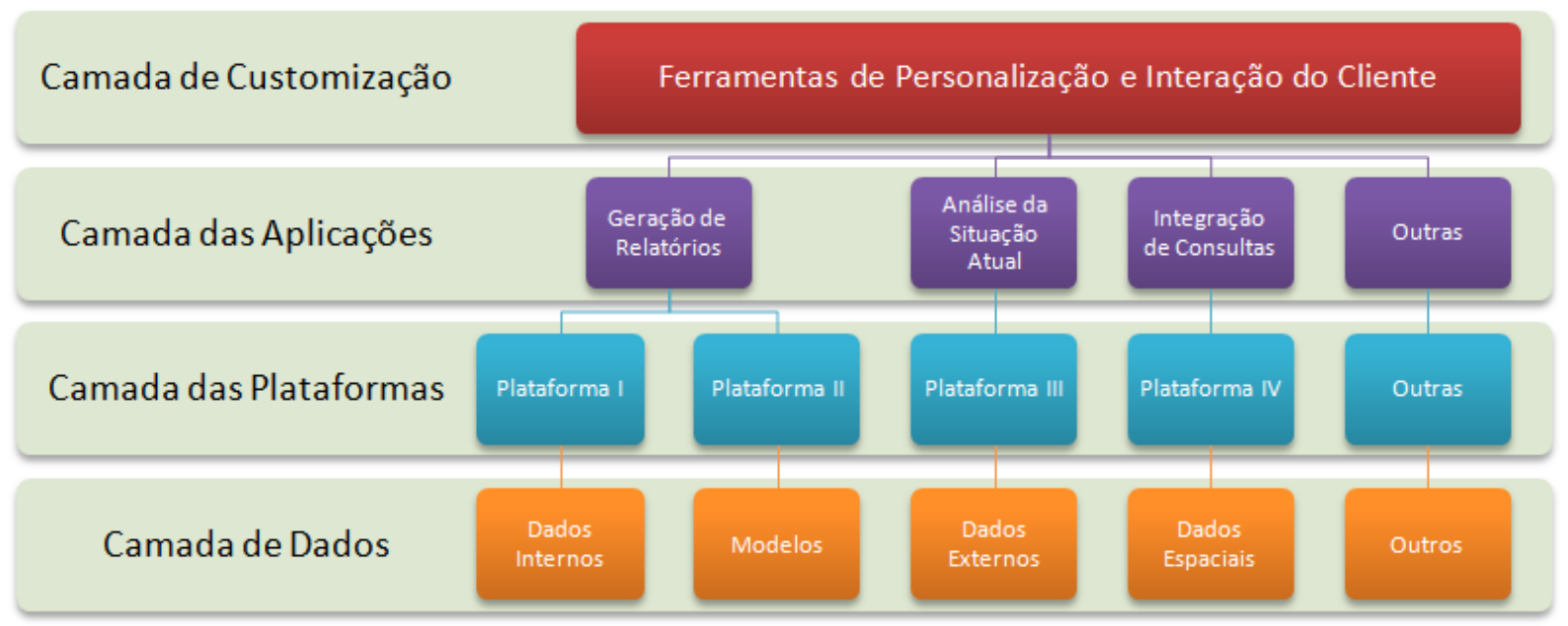

Figura 6 - Estrutura hierárquica de quatro camadas, adaptado de (LUO et al., 2009).

Os Sistemas de Informações Geográficas (GIS) abordados no trabalho dos autores Luo et al. (2009), é uma vertente dos SIs, que oferece ferramentas para solucionar problemas de logística, engenharia de tráfego e outros. Também possibilitam integrar dados de mapas, fotos aéreas, geoprocessamento de imagens, armazenamento em banco de dados, além de 
proporcionar formas para análise e a manipulação espacial desses dados geo-referenciados (LAUDON; LAUDON, 2010; STAIR; REYNOLDS, 2011).

Essas funcionalidades dos GIS, quando utilizadas como dados de entrada nos Sistemas de Suporte à Decisão (SSD), auxiliam nas atividades de vários setores como do urbanismo, apoiando no planejamento, projeto e construção de áreas residenciais e industriais. Nesse segmento, o trabalho dos autores Ruiz et al. (2012) sugere um modelo de avaliação multi-critério que visa garantir a viabilidade das zonas industriais com os seus arredores.

$\mathrm{Na}$ engenharia de tráfego esses sistemas ajudam na geração de rotas otimizadas de veículos voltados a problemas de logística que envolvem a demanda localizada ao longo dos arcos de uma rede de transporte (SANTOS; COUTINHO-RODRIGUES; ANTUNES, 2011).

Kelly et al. (2012) ressaltam a importância do GIS e do SSD no setor da saúde, apoiando a soluções que dependem da necessidade de vigilância baseada em localização, na detecção de pontos que necessitam de intervenções para prevenção e tratamento, por exemplo, no apoio ao controle da malária e da sua erradicação.

Outra área relevante em que o GIS e o SSD estão sendo fundamentais é na gestão de risco de desastres, auxiliando todas as fases dessa estrutura: mitigação, preparação, desastre, resposta, recuperação e as fases de reconstrução com informações que ajudam a identificar e mapear os pontos de risco geograficamente. Com esses dados espaciais é possível determinar rotas de fugas em caso de emergência, uso indevido do solo e pontos de monitoramento (JHA; MINER; STANTON-GEDDES, 2013).

A partir dos conceitos estudados sobre SI e principalmente SSD, vale ressaltar que existem duas opções oferecidas a uma organização no momento em que se deseja adquiri-lo: (i) desenvolver o seu próprio SSD; ou (ii) comprar de empresas especializadas o pacote de SSD (LAUDON; LAUDON, 2010; STAIR; REYNOLDS, 2011). De acordo com Stair e Reynolds (2011), há vantagens e desvantagens nas duas opções. Em ambas existe uma característica que deve ser considerada ao escolher qualquer uma das duas opções: a qualidade agregada ao produto final, que pode ser identificada pelos seus atributos, como confiabilidade, manutenibilidade, testabilidade e outros. Essa característica pode ser percebida em alguns aspectos, tais como:

- Software proprietário: desenvolvido pela própria organização.

- Vantagem: proporciona um nível maior de controle sobre os resultados (controlabilidade).

- Desvantagem: possível falta de tempo para alcançar o nível requerido de manutenção e suporte (manutenibilidade). 
- Software de prateleira: desenvolvido por empresas especializadas.

- Vantagem: alta qualidade, pois diversos clientes o testaram e ajudaram a identificar defeitos (confiabilidade).

- Desvantagem: modificações ou adaptações futuras, podem afetar a confiabilidade do produto (falta de confiabilidade).

Diante destas opções, vale ressaltar que os projetos envolvendo SSD apresentam alto grau de complexidade técnica, exigem pesquisa, desenvolvimento, projetos de instalações e testes para garantir a sua confiabilidade (ARCHIBALD, 2003).

\subsection{Testabilidade}

A cada dia os softwares estão mais presentes na vida do ser humano, auxiliando nos mais diversos setores, como economia, comunicação, comércio e outros. Entretanto, desenvolver softwares para atender às necessidades de cada setor com eficiência é uma tarefa difícil e complexa, pois vários fatores podem comprometer a confiabilidade do produto final apresentando um comportamento diferente do especificado (DELAMARO; MALDONADO; JINO, 2007; SOMMERVILLE, 2011; LAUDON; LAUDON, 2010). Para minimizar problemas desse tipo, o teste de software é fundamental, pois tem como objetivo principal revelar a presença de erros no software e a falta de conformidade com a especificação, a fim de serem corrigidos, melhorando dessa forma, qualidade no produto final (MYERS, 1978).

As atividades de teste podem ser aplicadas em quase todas as fases de um projeto, como por exemplo, no projeto arquitetural, projeto detalhado, codificação, implantação e manutenção. Para cada fase do projeto existe uma técnica, método ou ferramenta para auxiliar na inspeção de falhas no processo, código e produto final, obtendo assim uma melhoria contínua no ciclo de desenvolvimento e, consequentemente, um software com vários atributos de qualidade (PEZZè; YOUNG, 2008; SOMMERVILLE, 2011; PRESSMAN, 2010).

No domínio de teste de software é importante definir alguns termos para evitar ambiguidade ou viés em sua aplicabilidade, pois vários problemas podem ser classificados com base nesses termos. Por isso, a IEEE (1990) definiu no manual IEEE 610.12 os seguintes termos:

- Defeito (do inglês, fault) é um passo, processo ou definição de dados incorretos, por exemplo uma variável declarada errada; 
- Engano (mistake) é a ação humana que ocasiona uma inconsistência no sistema, por exemplo a implementação de uma instrução obtida por uma ambiguidade presente na especificação do sistema;

- Erro (error) ocorre na execução do sistema/programa, o qual pode interromper a execução de um estado intermediário, devido ao resultado inesperado ou propagar esse resultado incorreto até a saída do sistema, como por exemplo, em um procedimento que aguarda uma entrada de valores do tipo inteiro e recebe valores do tipo caractere; $\mathrm{e}$

- Falha (failure) é o comportamento inesperado do sistema, baseado na produção de uma saída divergente da esperada.

A Figura 7 ilustra a relação entre os termos definidos, na qual mostra-se que um "engano" introduz um "defeito" no software, esse quando ativado, pode produzir um "erro" no estado atual ou propagar-se até a saída do sistema, ocasionando uma "falha". Com base nessa relação, o "engano" é um dos principais fatores para o aumento de "erros", por isso construir uma especificação do sistema utilizando métodos formais pode reduzir as ambiguidades, evitando assim, a inserção de instruções inconsistentes.

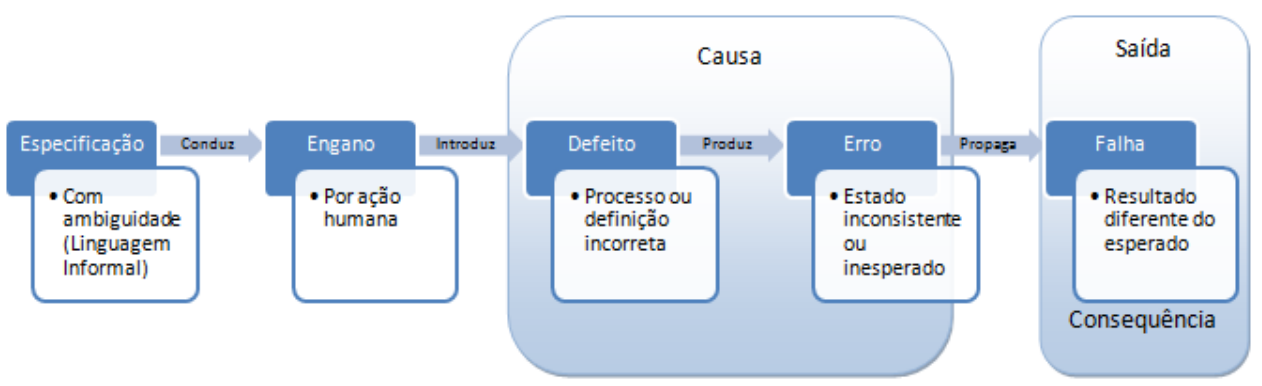

Figura 7 - A relação entre os principais termos presentes em teste de software.

Dentro da área de teste, existem outros termos importantes, como "domínio de entrada" de um programa $\mathbf{P}$, chamado de $D(P)$. Trata-se do conjunto de todos os elementos possíveis de entrada para executar $\mathbf{P}$. Nesse contexto, tem-se o domínio de saída, que é o conjunto de todos os possíveis resultados produzidos pelo sistema. A combinação desses dois termos dá origem ao termo "caso de teste" representado por (um valor de entrada, um valor de saída esperada) e vários casos de teste denotam um "conjunto de casos de teste" (DELAMARO; MALDONADO; JINO, 2007).

Aplicar testes usando todo domínio de entrada é inviável na maioria dos softwares. Devido ao número excessivo de elementos, esse procedimento é conhecido como teste exaustivo. A inviabilidade do teste exaustivo é motivador de várias pesquisas na área de teste com objetivo de identificar meios de extrair um subconjunto $D^{\prime}(P)$ reduzido e eficiente 
de $D(P)$, possibilitando, assim, reduzir o tempo e custo na fase de teste (DELAMARO; MALDONADO; JINO, 2007; PEZZè; YOUNG, 2008).

Em uma perspectiva mais específica, são definidas três fases de testes para sistemas de software comercial (PRESSMAN, 2010; SOMMERVILLE, 2011):

Testes em desenvolvimento: são testes aplicados durante a etapa de desenvolvimento para descobrir bugs e defeitos. Um teste frequentemente utilizado nesse estágio é o teste de unidade, que tem como foco a menor unidade do sistema de software implementada, chamada de componente ou módulo. Nesse estágio podem ser incluídos programadores e projetistas de sistemas na execução dos casos de teste.

Testes de release: são testes realizados com o propósito de verificar se o sistema atende aos requisitos para que foi desenvolvido, geralmente aplicado no sistema completo por equipes de teste independentes antes de ser liberado em produção para o usuário final.

Teste de usuário: é um processo que envolve testes no sistema instalado em seu próprio ambiente, executados pelos possíveis usuários finais. Esses testes tem como objetivo expor o sistema como um todo, incluindo testes de segurança, demanda e outros.

Embora o teste de software tenha se mostrado relevante para elevar o grau de confiabilidade do software, seu custo para ser aplicado é visto como alto nas organizações em relação às outras etapas do projeto (DELAMARO; MALDONADO; JINO, 2007). Por isso, cada organização deve elaborar uma abordagem adequada ao seus objetivos, invariavelmente com diversas técnicas de teste e análise para conseguir maior abrangência na detecção de erros (PEZZè; YOUNG, 2008). Com essa abordagem definida, deve-se criar casos de teste abrangentes, com o propósito de serem mais eficazes em atender as definições; na sequência aplica-se cada caso de teste na respectiva fase do desenvolvimento, para o qual foi definido, de tal forma que as falhas ou erros detectados sejam removidos o mais cedo possível, reduzindo assim custos nas fases posteriores do projeto (PERRY, 2000; PEZZè; YOUNG, 2008).

O desafio de identificar formas de selecionar elementos significativos do $D(P)$, contribuiu para o surgimento de novos critérios de seleção e otimização dos já existentes. A principal função de um critério de teste é usar "regras" para geração de um conjunto de casos de teste reduzido e suficiente, a ponto de ativar o maior número de erros de um programa, outro uso é avaliar um conjunto de casos de teste já existente (FRANKL; WEYUKER, 2000; DELAMARO; MALDONADO; JINO, 2007).

Nesse contexto, existem técnicas e métodos mais apropriados para apoiar na criação de casos de teste. Tomando como base as informações utilizadas para derivar os requisitos de teste, tem-se: (i) técnica funcional, os critérios e casos de teste são elaborados a partir da especificação do software, também conhecidos como teste da caixa-preta; (ii) técnica estrutural, os requisitos de teste são obtidos a partir do código-fonte, também chamado 
como caixa-branca; e (iii) técnica baseado em defeitos, usa de forma direta para criar os critérios e os requisitos sobre defeitos potenciais no programa que está sendo testado (PERRY, 2000; DELAMARO; MALDONADO; JINO, 2007; PEZZè; YOUNG, 2008).

Mesmo com o avanço das técnicas e métodos para tornar a atividade de teste mais eficiente, ele ainda não é suficiente para atender os projetos de desenvolvimento de software, que normalmente são limitados ao tempo de conclusão e aos recursos financeiros. Essas limitações podem ocasionar a necessidade de reduzir tempo e custos do projeto. Quando isto ocorre, a fase de teste é uma das primeiras a sofrer com essa redução, por ser considerada uma das mais custosas do projeto (DELAMARO; MALDONADO; JINO, 2007).

Diante desta deficiência, investigar formas de reduzir o tempo gasto com testes sem perder qualidade, pode contribuir para minimizar os efeitos causados por essas limitações do projeto. Segundo Zhao (2006), Nazir e Khan (2009), Pressman (2010), uma das formas de diminuir o tempo da atividade de teste é aumentar a capacidade do software em atender um critério de testes com mais facilidade de forma eficiente, essa aptidão é denominada testabilidade.

Testabilidade é considerada um atributo de qualidade de software, o qual expressa o efeito dos testes de software sobre a eficácia de determinado critério (ZHAO, 2006). Nesse contexto, conseguir relacionar todos os potenciais fatores que possam demonstrar qualitativamente e quantitativamente o quanto um software é testável e o nível de inferência desses fatores em diferentes domínios de testes, pode contribuir na redução de esforço no processo de testes e elevar o grau de qualidade no produto de software (ZHAO, 2006; NAZIR; KHAN, 2009).

Nas últimas décadas, vários autores pesquisaram fatores, atributos, métricas e formas de como desenvolver um software com alto grau de testabilidade (FREEDMAN, 1991; GUPTA; SINHA, 1994; VOAS; MILLER, 1995; ZHAO, 2006; JARING; KRIKHAAR; BOSCH, 2008; NAZIR; KHAN, 2009; LAMBA, 2010). Nesta mesma vertente, a Associação Brasileira de Normas Técnicas (ABNT) traduziu a norma (ISO/IEC 9126-1, 2001), a qual concentrou e classificou características para identificar atributos-chave de qualidade de software (PRESSMAN, 2010). Recentemente, a ISO/IEC 9126-1 (2001) foi substituída pela ISO/IEC 25010 (2010).

O modelo de qualidade do produto de software da ISO/IEC 25010 (2010) é constituído por oito características: adequabilidade funcional, eficiência do desempenho, compatibilidade, usabilidade, confiabilidade, segurança, manutenibilidade e portabilidade. Nessa mesma norma, a testabilidade foi incluída como uma subcaracterística de manutenibilidade e pode ser medida por meio de métricas externas e internas. Outras subcaracterísticas como modularidade, reusabilidade, analisabilidade e modificabilidade fazem parte juntamente com testabilidade, de um conjunto de atributos que evidenciam o esforço necessário 
para fazer alterações no produto de software, sempre em conformidade com as normas relacionadas à manutenibilidade (ISO/IEC 25010, 2010):

- Manutenibilidade é o grau de eficácia e eficiência com que um produto ou sistema pode ser modificado, conforme ocorrem correções, melhorias ou adaptações do software.

- Modularidade é o grau em que um programa de computador ou sistema é composto por componentes discretos, de tal modo que a alteração em um componente tenha impacto mínimo sobre os outros.

- Reusabilidade é o grau em que um ativo pode ser utilizado em mais do que um sistema, ou na construção de outros ativos.

- Analisabilidade é o grau de eficácia e eficiência com a qual é possível avaliar o impacto sobre um produto ou sistema de uma alteração, ou permitir o diagnóstico de deficiências ou causas de falhas, ou a identificação de partes a serem modificadas.

- Modificabilidade é o grau com que um produto ou sistema pode ser modificado de forma eficaz e eficiente sem a introdução de defeitos ou perda da qualidade do produto existente.

- Testabilidade, é grau de eficácia e eficiência com a qual é possível estabelecer critérios de teste de um sistema, produto ou componente, bem como os testes que possam ser realizados para determinar se esses critérios foram cumpridos.

\subsection{Goal Question Metrics (GQM)}

Na literatura existem vários trabalhos relacionados a métricas no contexto de desenvolvimento de software. Entre esses, destacam-se as pesquisas que utilizam métricas definidas a partir de metas previamente estabelecidas. Uma das principais abordagens que apresenta esse conceito é o Goal Question Metric (GQM) (SOLINGEN; BERGHOUT, 1999). Considerando as características deste trabalho e para alcançar os objetivos propostos, o conceito GQM foi utilizado no processo de desenvolvimento do questionário e na definição de métricas.

O GQM foi desenvolvido pelos pesquisadores Victor R. Basili e Dr. David Weiss, para avaliar os defeitos de um conjunto de projetos no Ambiente NASA Goddard Space Flight Center (BASILI; WEISS, 1984). O paradigma GQM é uma abordagem sistemática que favorece a unificação das metas do processo de desenvolvimento de software, incluíndo os modelos de processo, bem como os de qualidade, com base nas necessidades específicas do projeto e da organização (SOLINGEN et al., 2002). O resultado ao aplicar o método 
GQM é um protocolo de avaliação abordando metas específicas e o conjunto de questões, regras para a interpretação dos dados usados para medição. Essa abordagem tem como fundamento duas suposições (SOLINGEN; BERGHOUT, 1999):

1. Que um projeto de medição não deve ser baseado em métricas (estrutura BottomUp) mas baseado em objetivos (estrutura Top-Down); e

2. Que a definição das metas e medidas precisam ser adaptadas a cada necessidade em particular, tanto organizacional quanto pessoal.

A vantagem em assumir essas duas hipóteses é a flexibilidade, que permite estabelecer as métricas conforme cada necessidade e suas particularidades. No entanto, elas tornam o processo mais complexo, pois exige do usuário definir suas próprias metas e processos (BASILI; WEISS, 1984; BASILI, 1992; SOLINGEN; BERGHOUT, 1999). Essa atividade é feita de forma sistemática, seguindo as quatro fases propostas pelo método GQM (BASILI; CALDIERA; ROMBACH, 1994), ilustrado na Figura 8.

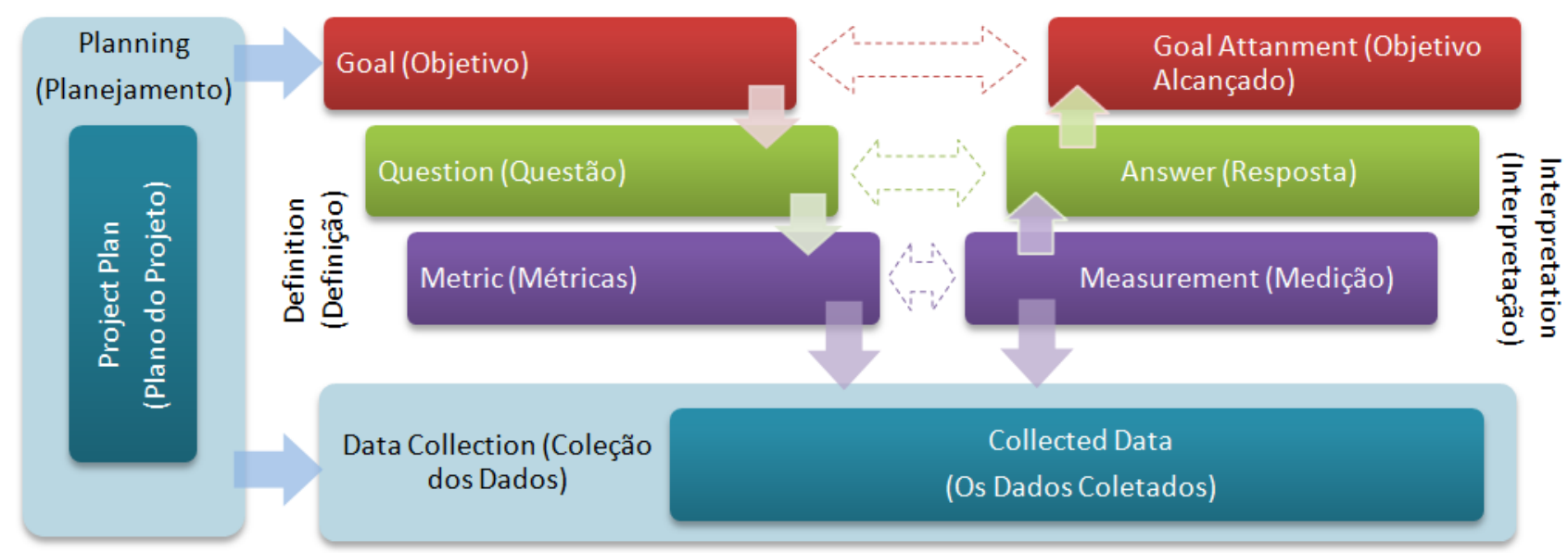

Figura 8 - As quatro fases do método GQM, adaptado de (SOLINGEN; BERGHOUT, 1999).

1. Goal - é uma fase de planejamento a nível conceitual, na qual é definido um plano de projeto considerando as metas e modelos de qualidade a partir de vários pontos de vista em domínio específico. Nesta fase, são considerados os seguinte objetos de medição:

- Produtos: São os artefatos produzidos durante o processo de desenvolvimento de um software;

- Processos: Em geral são as atividades de software que envolvem contagem do tempo para realiza-las; e

- Recursos: São os elementos utilizados por processos, que contribuem para alcançar os seus resultados, entre esses temos: equipamentos, estrutura física, software e outros. 
2. Question - é a fase operacional, na qual será definido e documentado o protocolo de medição, com base nas metas estabelecidas. São documentados nesse protocolo as metas, as questões que caracterizam a forma de avaliação, as métricas e hipóteses.

3. Metric - (nível quantitativo) é a fase da coleta de dados reais, associados a todas as perguntas. Em geral esses dados podem ser:

- Objetivo: quando as medições dependem apenas do objeto que está sendo medido. Um exemplo desse tipo de dados seriam as horas de trabalhadas em uma tarefa.

- Subjetiva: dependem tanto do objeto a ser medido quanto de outros fatores. Um exemplo desse tipo de dados seria o grau de satisfação do usuário.

4. Interpretation - $\mathrm{Na}$ fase de interpretação, ocorre o processamento dos dados coletados com base nas métricas definidas, com o objetivo de fornecer respostas às perguntas estabelecidas no protocolo e, assim, alcançar as metas podem ser avaliadas.

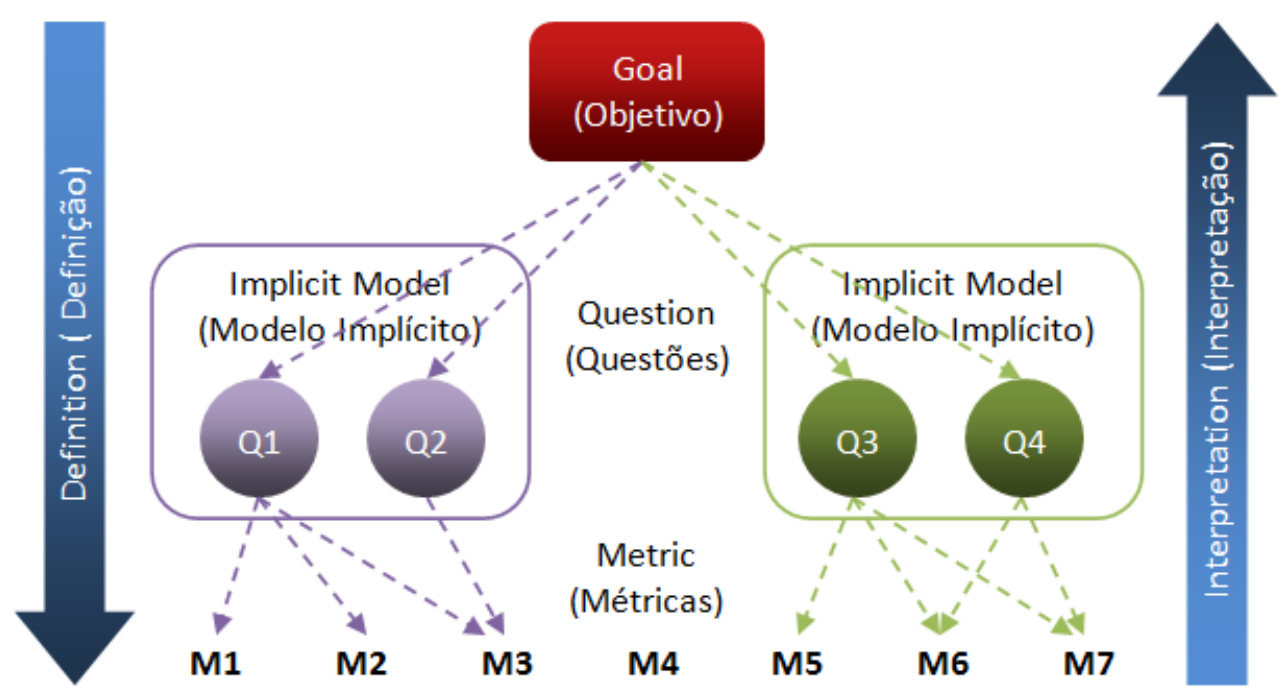

Figura 9 - A estrutura do paradigma GQM, adaptado de (BASILI; WEISS, 1984).

A Figura 9 ilustra como funciona o GQM na definição das métricas. O início se dá em uma estrutura de cima para baixo (Top-Down) e, após o processo de definição ocorre a análise dos dados e interpretação da medição em uma estrutura de baixo para cima (Bottom-Up).

Top-Down: o modelo GQM tem início com definição da meta de medição, de forma clara, sem dúvidas ou ambiguidades. Esta meta passa por um processo de refinamento por meio de perguntas, até se alcançarem os seus principais componentes. Estas perguntas são analisadas e transformadas em métricas com o propósito de fornecer informações relevantes que respondam a essas perguntas. 
Bottom-Up: após a coleta dos dados de medição, ocorre a interpretação e análise das informações fornecidas pelas métricas, sempre com foco na meta definida no início.Um diferencial para o sucesso do método GQM é utilizar a base de conhecimento já existente na organização, a participação do especialistas, desenvolvedores e outros envolvidos no processo. Dessa forma, os modelos implícitos serão mais relevantes ao programa de medição.

Após o surgimento do método GQM, várias extensões foram publicadas na literatura. Entre essas, a extensão GQM + Estratégias de negócio proposta pelos autores Basili et al. (2007), representado na Figura 10. Esse modelo apresenta ligações entre cada meta estabelecida a nível do software com as estratégias em nível de negócios. Nessa mesma linha de pesquisa, Heidrich e Kowalczyk (2012) apresentam um modelo baseado em GQM + Estratégias que permite o alinhamento entre as metas e estratégias em diferentes níveis de negócio, tanto organizacional quanto individual.

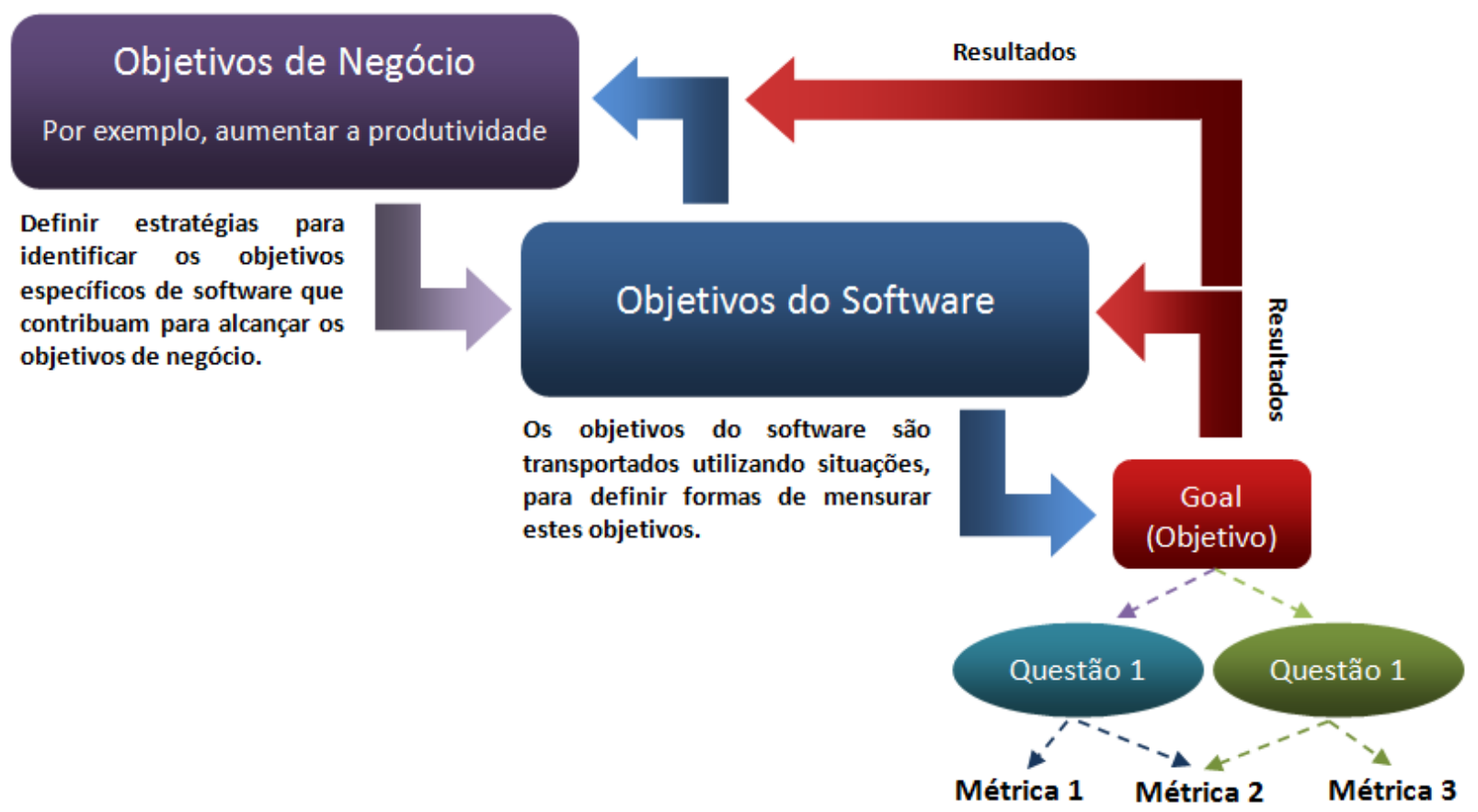

Figura 10 - Modelo do GQM+Estratégias, adaptado de (BASILI et al., 2007).

\subsection{Considerações finais}

Foi apresentado neste capítulo um embasamento necessário para ressaltar a importância dos Sistemas de Informação e principalmente dos Sistemas de Suporte à Decisão em organizações dos setores públicos e privados, como: indústria, comércio, área da saúde e urbanismo, bem como os conceitos sobre dados, informação e conhecimento aplicados nesse domínio. 
Em seguida, na Seção 2.3 foram introduzidos conceitos básicos a respeito da atividade de teste e da sua importância no processo de desenvolvimento de software. Também foi descrito como o atributo de testabilidade pode contribuir na execução desta atividade, com base na norma ISO/IEC 25010 (2010) e sobre a visão de alguns autores mais conhecidos na literatura. Além disso foi apresentado o conceito sobre o paradigma Goal Question Metric (GQM) e alguns estudos que propuseram extensões para este paradigma.

No próximo Capítulo serão apresentados o método, a estratégia necessária para seu desenvolvimento e as métricas definidas para análise e avaliação de um SSD. 

CAPÍTULO

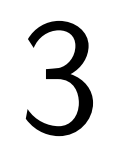

(2)

\section{MÉTODO PARA AVALIAÇÃO E ANÁLISE DA TESTABILIDADE DO SSD}

\subsection{Considerações iniciais}

São apresentados neste capítulo o método considerado na pesquisa, a estratégia para identificar os fatores ou atributos de testabilidade e o processo de desenvolvimento de uma ferramenta para análise e avaliação de um SSD em relação a sua testabilidade, considerando as expectativas do cliente.

Inicialmente, na Seção 3.2 é apresentado o método adotado para mapear os pontos fortes e fracos do SSD e as etapas necessárias para o seu desenvolvimento. Na sequência, na Seção 3.3 é realizada uma investigação na literatura com o propósito de identificar e selecionar fatores e atributos de testabilidade que possam influenciar no domínio dos SSD.

Devido a abrangência dos SSD nos mais diversos segmentos, apoiando a solução de problemas críticos ou não, é ressaltada na Seção 3.4 a importância da informação com qualidade e os fatores que a comprometem. Em seguida, na Seção 3.5 é apresentado o questionário que servirá para a análise e avaliação de um SSD, considerando os conceitos e elementos vistos nas seções anteriores. Finalmente, na Seção 3.6 são definidas as métricas que permitem avaliar o resultado do questionário e as formas gráficas de apoio à análise deste resultado.

\subsection{Método e estratégia da pesquisa}

Nesta seção, é apresentado o método utilizado para identificar e mapear os pontos que podem influenciar no processo de tomada de decisão e no grau de testabilidade do Sistema de Suporte à Decisão (SSD), tendo como foco as expectativas do cliente em relação 
ao sistema.

Para isso, o método escolhido para esta avaliação foi um questionário que agregasse em suas perguntas algumas das principais exigências dos clientes e que estivessem diretamente ou indiretamente vinculadas aos atributos de testabilidade.

Foi adotado o questionário como ferramenta de avaliação devido à flexibilidade de poder elaborar questões que fornecessem respostas tanto qualitativas quanto quantitativas; sua facilidade de ser aplicado no domínio, e principalmente, quando bem elaborados podem produzir informações valiosas. Isto, mesmo com as dificuldades enfrentadas no momento de aplicá-lo, por exemplo, a resistência das pessoas em responder certas questões, pois temem que as respostas possam lhes gerar problemas (VIEIRA, 2009).

Um exemplo de que essas dificuldades são minímas em relação aos benefícios alcançados por este instrumento é a sua utilização nas mais diversas áreas de pesquisas, como na área de saúde e engenharia civil. Outro fator a considerar é seu baixo custo de desenvolvimento e execução, além de ser o meio mais direto de obter informações em determinadas situações (VIEIRA, 2009).

Considerando estes fatores, o questionário é um protocolo ou guia para que as empresas possam avaliar o nível de maturidade de um SSD em relação às expectativas do cliente, permitindo classificar o sistema e mapear os pontos que necessitam de melhorias, a fim de elevar o grau de testabilidade e da qualidade do SSD.

Nesta classificação, quanto maior for a maturidade do SSD, maior poderá ser o seu grau de testabilidade, o qual pode facilitar a atividade de testes e consequentemente identificar mais falhas no SSD, a fim de serem corrigidas. Com isto, pode-se elevar a qualidade da informação que tem influência direta no processo de tomada de decisão, como será visto em mais detalhes na Seção 3.4.

O desenvolvimento do questionário foi realizado em oito etapas, começando com a revisão da literatura e terminando com as conclusões sobre o trabalho, conforme ilustrado na Figura 11. 

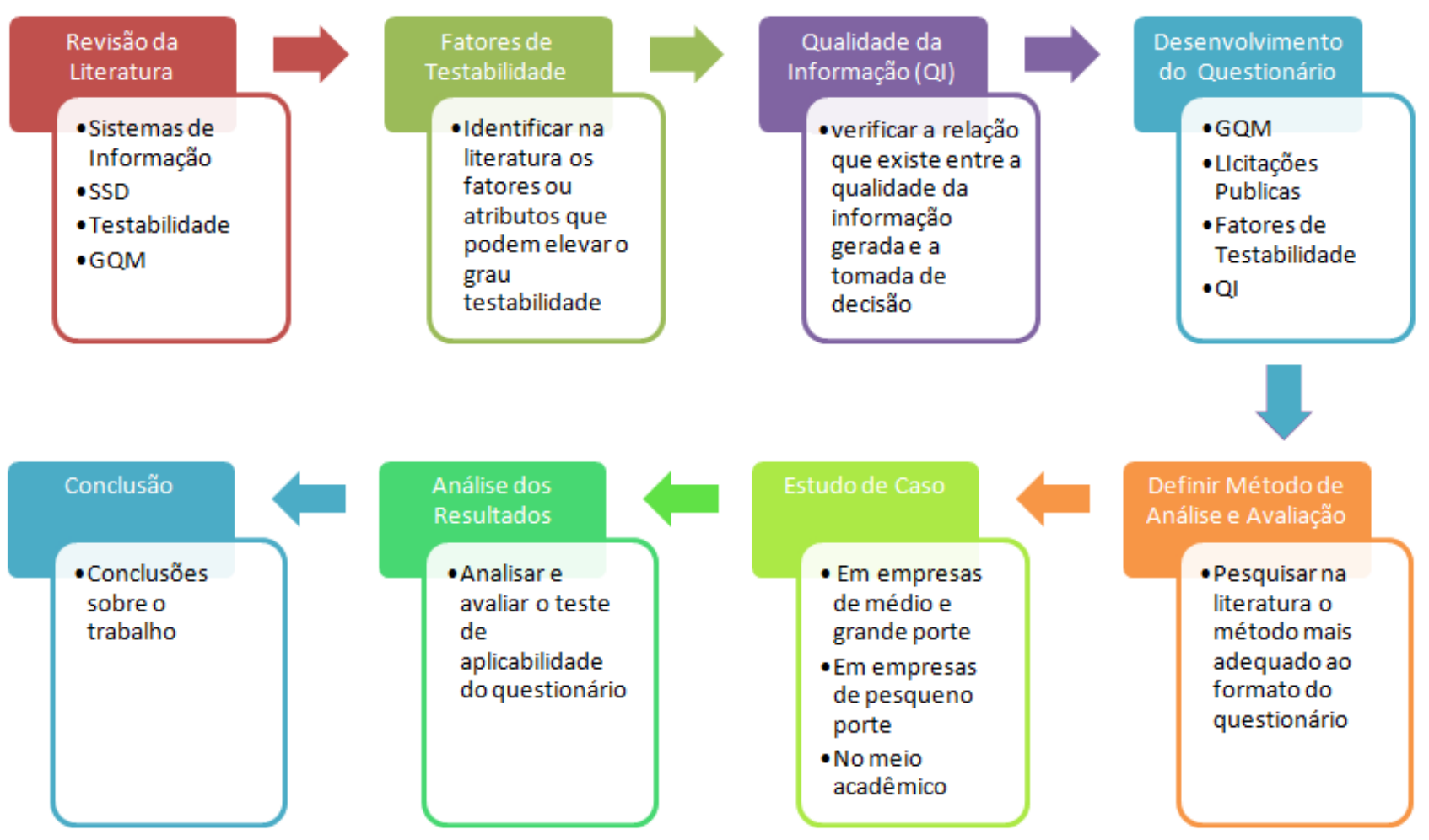

Figura 11 - Fluxo do processo da pesquisa.

1. Revisão da Literatura: Nesta etapa foi realizada a revisão da literatura sobre os principais assuntos abordados neste trabalho e métodos utilizados, como: sistemas de informação e sua vertente SSD, conceitos sobre teste de software e testabilidade, bem como sobre o método Goal Question Metrics (GQM). Estes assuntos estão descritos com maiores detalhes no Capítulo 2.

2. Levantamento dos Fatores de Testabilidade: Nesta etapa foram selecionados trabalhos da literatura que abordassem o conceito de testabilidade em seus conteúdos, com o propósito de identificar fatores ou atributos que pudessem elevar o grau de testabilidade.

3. Relação entre Qualidade da Informação (QI) e a Tomada de Decisão: O principal objetivo desta etapa foi verificar a relação que existe entre a qualidade da informação gerada e a tomada de decisão.

4. Desenvolvimento do Questionário: Foi aplicado o método GQM no desenvolvimento do questionário, considerando: os conceitos sobre SSD, atributos ou fatores de testabilidade, qualidade da informação no processo de tomada de decisão e as expectativas dos clientes sobre o sistema. 
5. Definição do Método de Análise e Avaliação: Para definir o método que pudesse fornecer meios de analisar o SSD e depois classifica-lo, foi adotado como base os métodos utilizados nos trabalhos dos autores (HOFACKER et al., 2008; OLIVEIRA et al., 2010; VIEIRA; SOUZA; AMARAL, 2012).

6. Realização dos Estudos de Caso: Foi realizado o teste de aplicabilidade do questionário em SSD já consolidados no mercado, em empresas de pequeno, médio e grande porte. Contudo, para extrair o máximo do questionário também foram realizados testes no meio acadêmico.

7. Análise dos Resultados: Após a aplicação do método definido na Seção 3.6, o qual fornece os meios para análise e também o método de classificação do SSD, verificou-se a aplicabilidade do questionário.

8. Conclusão: Conclusões sobre o trabalho.

\subsection{Fatores de testabilidade}

A ISO/IEC 25010 (2010) considera testabilidade como uma característica que pode ser medida por meio de métricas que utilizam atributos externos e internos. No entanto, esta norma não deixa evidente quais destes fatores devem ser considerados para obter melhores resultados e elevar o grau de testabilidade do produto. Neste contexto, várias pesquisas foram realizadas com o objetivo de identificar estes fatores.

No trabalho realizado por Freedman (1991) foram definidos formalmente dois fatores: observabilidade e controlabilidade no domínio de testabilidade de softwares. Para o autor, observabilidade refere-se à facilidade de determinar se as entradas especificadas afetam as saídas produzidas pelo componente em teste e controlabilidade se refere à facilidade de produzir uma saída a partir de uma entrada específica, submetida ao componente em teste. Ressalta que um programa no domínio testável é observável e controlável. Definiu métricas para serem aplicadas a programas e especificações funcionais.

Nessa mesma linha, Binder (1994) ressalta a importância dos fatores de controlabilidade e observabilidade no teste de um componente. No entanto, destaca que existem obstáculos ao empregar esses fatores, e tais obstáculos resultam do fato de um componente em teste ser incorporado em outro sistema. Por isso, a remoção desses obstáculos para conseguir controlar a entrada e observar a saída é a principal preocupação no design para testabilidade. Na prática, a testabilidade deve fazer parte do processo de desenvolvimento, assim a capacidade de processamento tem a mesma importância dos outros dois fatores.

A Figura 12 utiliza o diagrama de Ishikawa [espinha de peixe], a fim de demonstrar a influência das fases de um processo de desenvolvimento na testabilidade do software. 
Cada espinha representa o impacto desses fatores sobre a testabilidade (ISHIKAWA, 1990; BINDER, 1994).

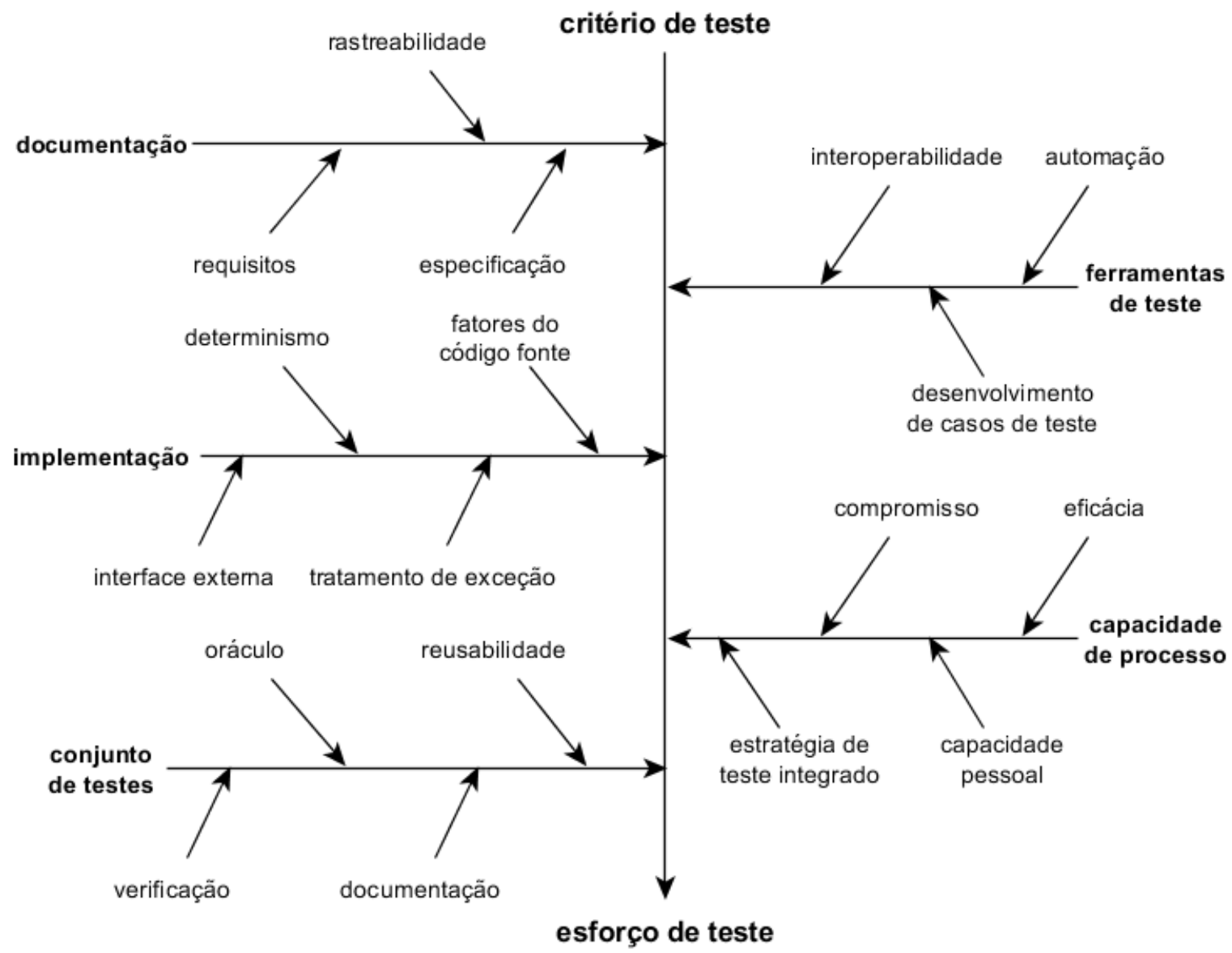

Figura 12 - Representação da testabilidade como espinha dorsal, adaptado (BINDER, 1994).

Gupta e Sinha (1994) propõem um modelo para incorporar medidas de testabilidade no processo de desenvolvimento de software. Para isso, utilizam como base o modelo cascata para ilustrar seu conceito, como exemplificado na Figura 13. As fases dos modelos são: s especificação, d - design do documento, dd - detalhamento do design do documento e c desenvolvimento do código. O elemento st é o plano de teste da especificação, os outros dt, ddt e ct são respectivamente o plano de teste de cada fase do modelo. Na Figura 13, o Modelo 2 - Testável se mostra interativo, em que os artefatos produzidos em uma fase anterior servem como entrada de informação para a próxima fase, principalmente o plano de teste, que no Modelo 1 - Tradicional fica restrito na sua respectiva fase.

Com base nesse conceito, os autores verificam os fatores observabilidade e controlabilidade através do comportamento de um componente de software. Assim, concluem que um componente de software é observável quando seu comportamento externo e interno puderem ser verificados em tempo real ou armazenados para análise, e controlável 
quando, através de sua interface de comandos conseguir inicializá-los em diferentes estados, conforme requerido pelos testes (GUPTA; SINHA, 1994).
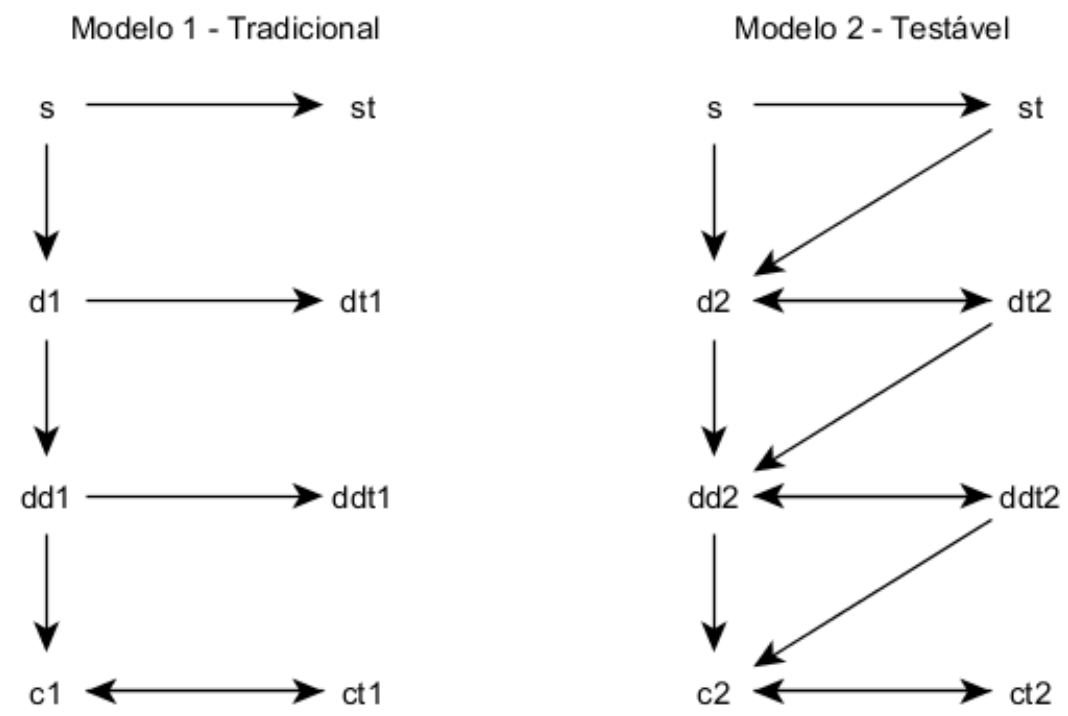

Figura 13 - Representação do modelo de desenvolvimento de software testável, adaptado de (GUPTA; SINHA, 1994).

Outro trabalho importante é de Voas e Miller (1995), que desenvolveram um modelo que quantifica a capacidade de teste com base em uma análise de sensibilidade. Para isso, adotaram duas suposições:

- A suposição de que o programa contém uma única falha, não múltiplas falhas distribuídas por todo o programa.

- A suposição de que existe a falha em um único local, e não distribuída por todo o programa, ou seja, é a mesma probabilidade dessa falha estar em qualquer lugar do programa.

A suposição desse erro único é uma variação sobre a hipótese do programador competente, que vai implementar o código quase que correto. Essa técnica de análise de sensibilidade e as métricas baseadas nas definições de observabilidade e controlabilidade de Freedman (1991) são a base de vários trabalhos relacionados à testabilidade.

Para Karoui, Ghedamsi e Dssouli (1999), a facilidade de diagnosticar pode ser vista como um critério de testabilidade, caracterizado pelos requisitos específicos em nível de design. Dessa forma, foi investigada a ligação entre a influência de alguns fatores de testabilidade na atividade de diagnóstico, baseada em Máquina de Estados Finitos (MEFs). Após analisar alguns exemplos de implementações com falhas nas MEFs, constatou-se que os testes e os processos de diagnóstico são influenciados por fatores relacionados 
diretamente com as falhas, os quais são difíceis de analisar. Entretanto, fatores como o número de falhas, o tipo de falhas e a distribuição de falhas na aplicação, devem ser considerados ao realizar os testes ou os processos de diagnóstico.

Entre essas pesquisas que contribuíram para identificar os fatores que inferem na testabilidade do software, Gao, Gupta e Gupta (2000) discutem testabilidade considerando cinco fatores, que para eles podem ser usados para verificar e mensurar a testabilidade de software. Os fatores considerados são: (i) compreensibilidade; (ii) observabilidade; (iii) rastreabilidade; (iv) controlabilidade; e (v) capacidade de suporte ao teste, ilustrado na Figura 14.

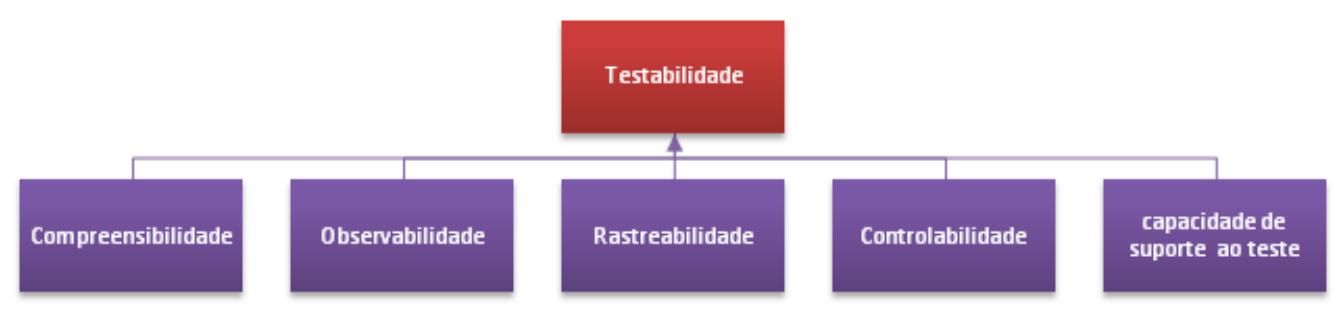

Figura 14 - Fatores de testabilidade, adaptado de (GAO; GUPTA; GUPTA, 2000).

A compreensibilidade (em inglês, understandability) do software, depende de dois fatores: a disponibilidade de informações sobre o componente a ser testado, e a compreensão dessas informações. Normalmente, essas informações estão disponibilizadas em um conjunto de documentos, tais como: o manual de referência do usuário sobre a função dos componentes, especificações de interface, especificações de projeto, código fonte, documentos de teste e relatório de qualidade (GAO; JACOB; WU, 2003).

A compreensibilidade é um fator essencial para a testabilidade, pois quanto maior for o conhecimento sobre os componentes a serem testados, mais fácil será definir critérios de teste e obter casos de teste mais eficientes, consequentemente elevando a qualidade dos testes. Esses componentes altamente compreensíveis proporcionam aos usuários explorar o máximo dos recursos oferecidos (GAO; JACOB; WU, 2003).

Observabilidade (em inglês, observability) do software, como visto anteriormente. é um dos fatores mais discutidos, juntamente com a controlabilidade. Esses dois fatores são considerados, por profissionais da área e pesquisadores, os principais entre os cinco, e o mínimo a ser atendido para que se tenha alguma testabilidade (NAZIR; KHAN, 2009).

Como já visto, observabilidade de software indica quão fácil é observar as entradas especificadas e o quanto afetam as saídas produzidas pelo componente em teste (FREEDMAN, 1991). Permite observar o comportamento externo e interno desse componente em tempo real ou oferecer formas de armazenar os resultados desse processo para posterior análise (GUPTA; SINHA, 1994). Nesse processo, caso ocorra resultado incorreto ou erros 
internos, esses devem ser facilmente identificados (PRESSMAN, 2010).

De acordo com Gao, Jacob e Wu (2003), observabilidade refere-se ao grau em que os componentes são projetados para facilitar o monitoramento e visualização das suas funções e o comportamento dos testes aplicados a eles. Para os autores, a observabilidade pode ser alcançada de duas formas:

1. Realizar um mapeamento entre as entradas e as saídas correspondentes para cada teste, revisando o projeto de teste para verificar tais correspondências, e tentar localizar as entradas e saídas ocultas e as relações de mapeamento incorretas entre entradas e saídas. Na fase de teste do componente, a verificação dos resultados é outra parte importante. O uso de uma ferramenta de teste eficaz poderia ser uma solução ideal para apoiar de forma sistemática essa tarefa.

2. Rastreamento e monitoramento de todos os testes de componentes e seus resultados. Para isso, ter uma base eficaz para teste de componente seria a solução ideal. No entanto, são altos os custos para a criação de uma base específica de teste para cada componente. Uma forma de reduzir esse custo é investigar métodos eficazes para a construção de componentes testáveis com boa observabilidade.

O fator rastreabilidade (em inglês, traceability) do software é muito importante na prática de engenharia de componentes, pois afeta a capacidade de teste (GAO; JACOB; WU, 2003). Uma das primeiras definições sobre a rastreabilidade no domínio de desenvolvimento de software, foi a capacidade de rastrear requisitos por trás do código fonte, conhecida como rastreabilidade de gerenciamento de requisitos, definida da seguinte forma pelos autores (GOTEL; FINKELSTEIN, 1994):

\begin{abstract}
"A capacidade de descrever e seguir a vida de um requisito, tanto à frente quanto na direção contrária, ou seja, desde a sua origem, através de seu desenvolvimento e especificação, para ser usado na sua implantação posterior e na iteração em qualquer destas fases para refinamento das tarefas".
\end{abstract}

Aizenbud-Reshef et al. (2006) definem rastreabilidade de forma mais ampla, considerando qualquer relacionamento existente entre os artefatos envolvidos no processo de vida da engenharia do software. Os autores ressaltam que essa definição inclui, mas não se limita ao seguinte:

- Ligações explícitas ou mapeamentos que são gerados como resultado de transformações, tanto para a frente (por exemplo, geração de código) e para trás (por exemplo, engenharia reversa); 
- Ligações que são computadas com base nas atuais informações (por exemplo, análise de dependência de código); e

- Ligações estatisticamente inferidas, que são computadas com base no histórico do gerenciamento das mudanças realizadas no sistema.

Segundo Gao, Jacob e Wu (2003), a rastreabilidade de um componente de software refere-se à capacidade de incorporar uma extensão de recursos que rastreia as operações funcionais, atributos de componentes e seus comportamentos. A rastreabilidade do componente pode ser verificada e avaliada em dois aspectos diferentes:

- Rastreabilidade caixa-preta (em inglês, Black-box traceability): refere-se à capacidade interna do componente de facilitar o rastreamento do seu comportamento em uma visão caixa-preta, incluindo as interfaces externas desse componente, o comportamento das funções acessíveis, os estados de objetos visíveis externamente e dos eventos. Isto é importante durante o teste desses componentes, para avaliação dos usuários sobre o componente, na integração desses componentes e validação do sistema.

- Rastreabilidade caixa-branca (em inglês, White-box traceability): refere-se à capacidade interna do componente de facilitar o rastreamento do seu comportamento em uma visão caixa-branca, incluindo o comportamento das funções internas do componente, lógica de negócios, estados do objeto e a estrutura do programa. Isto é muito útil durante o teste desses componentes e para correção de erros.

A rastreabilidade de software vem a cada ano mostrando-se importante no processo de desenvolvimento, apoiando principalmente a fase de teste, com reduções na série de testes de software e redução nos custos com manutenção (GAO; JACOB; WU, 2003).

Um estudo realizado pelos autores Nazir e Khan (2009) entre profissionais da área e pesquisadores selecionou o fator controlabilidade (em inglês, controllability) como essencial para testabilidade de software. O fator observabilidade como já visto, também foi selecionado pelos participantes. No entanto, Freedman (1991) ressalta que a observabilidade não é exigida para que se tenha controlabilidade do software, pois componentes de software sem dados de entrada podem ser controláveis, mas não observáveis. O autor definiu formalmente controlabilidade como a facilidade de produzir uma saída específica a partir de uma entrada específica, submetida ao componente em teste, considerando a cobertura eficaz do domínio de saída que foi declarado no domínio de entrada.

Para Gupta e Sinha (1994), um componente de software é controlável quando, por meio de sua interface de comandos conseguir inicializá-los em diferentes estados, conforme requerido pelos testes. Gao, Jacob e Wu (2003) estendem esse conceito, olhando para a controlabilidade de um componente de software a partir de três aspectos: (i) controle do 
comportamento do componente; (ii) característica da personalização do componente; e (iii) instalação e implantação do componente. A pesquisa sobre esses três aspectos define uma extensão em que, para construir um componente com o objetivo de proporcionar uma capacidade de controle, deve-se incluir cinco tipos de controle:

1. Controle da execução do componente;

2. Controle do ambiente do componente;

3. Controle do comportamento do componente baseado no estado;

4. Controle do teste ao componente através de interfaces; e

5. Controle do recurso funcional.

A Figura 15 apresenta fatores de capacidade de suporte ao teste (em inglês test suport capability) do software (GAO; JACOB; WU, 2003):

- Capacidade de geração de teste, refere-se ao grau em que os scripts de teste e os testes de componentes podem ser gerados utilizando métodos sistemáticos de geração e por ferramentas, tanto para testes caixa-preta quanto para testes caixa-branca.

- Capacidade de gerenciamento do teste, que define o quanto uma solução sistemática fornece apoio à gestão de vários tipos de informações de teste.

- Capacidade de suporte ao conjunto de teste, refere-se ao quão fácil é para os engenheiros e desenvolvedores de teste criarem, manterem e executarem os scripts de teste.

- Capacidade de análise de cobertura de teste, refere-se o quanto a cobertura do teste pode ser facilmente medida, monitorada e relatada. Para isso, pode-se usar um conjunto bem definido de critérios de cobertura e normas, bem como funções de análise de cobertura em ferramentas de teste. 


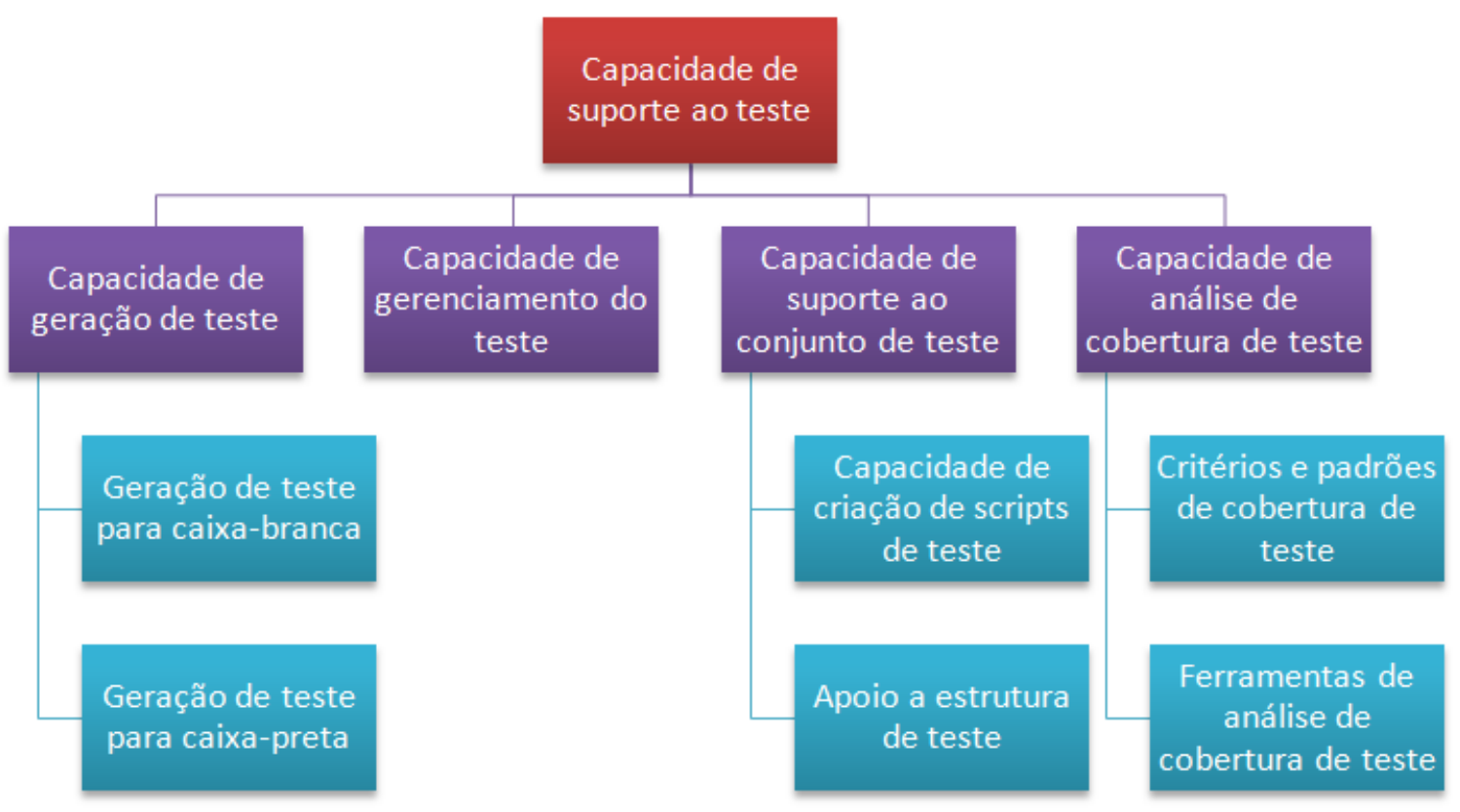

Figura 15 - Diferentes fatores da capacidade de suporte ao teste, adaptado de (GAO; JACOB; WU, 2003).

\subsection{Relação entre qualidade da informação e tomada de decisão}

Visto a importância dos SSD nos mais diversos cenários, críticos ou não, surge a preocupação com a qualidade das informações fornecidas pelo sistema, se estão corretas e livres de ambiguidade. Neste contexto, Lee e Haider (2013), Inderapermana e Suhardi (2013), Gorla, Somers e Wong (2010) e Salmela (1997) investigaram o que pode impactar na qualidade da informação e se o impacto pode distorcer seu entendimento ao ponto de levar a uma decisão equivocada. Para os autores, as informações e sua qualidade são afetadas por inúmeras fontes internas e externas, bem como por fatores dinâmicos.

Nestes trabalhos foram relacionados vários estudos com contribuições significativas para este tema, entre eles o realizado por Wang e Strong (1996), em que identificaram 179 fatores/atributos diferentes de qualidade da informação (QI) e reduziram esse conjunto, agrupando-os em 15 subconjuntos, formando quatro categorias principais: intrínseco, contextuais, representacional e acessibilidade.

A maioria das pesquisas sobre QI citadas por Lee e Haider (2013), possui uma característica em comum; tentam reduzir o número de atributos por categorização. A Tabela 2 mostra uma dessas, que é a categorização de um modelo de desempenho para QI voltado para produtos e serviços. 
Tabela 2 - Categorização de um modelo de desempenho para QI

\begin{tabular}{|c|c|c|c|}
\hline \multirow{16}{*}{$\begin{array}{l}\text { Atributos para } \\
\text { melhoria da } \\
\text { Qualidade de } \\
\text { Informação }\end{array}$} & Categorias & Perspectiva da Qualidade & Atributos de QI \\
\hline & \multirow{6}{*}{$\begin{array}{l}\text { Em Conformidade } \\
\text { com as } \\
\text { Especificações }\end{array}$} & \multirow{4}{*}{$\begin{array}{l}\text { Qualidade das } \\
\text { Informações sobre o } \\
\text { Produto }\end{array}$} & Precisão \\
\hline & & & Concisão \\
\hline & & & Plenitude \\
\hline & & & Consistência \\
\hline & & \multirow{2}{*}{ QI sobre o Serviço } & Pontualidade \\
\hline & & & Segurança \\
\hline & \multirow{9}{*}{$\begin{array}{l}\text { Atende ou Excede } \\
\text { as Expectativas } \\
\text { do Cliente }\end{array}$} & \multirow{5}{*}{$\begin{array}{l}\text { Qualidade das } \\
\text { Informações sobre o } \\
\text { Produto }\end{array}$} & Adequação \\
\hline & & & Relevância \\
\hline & & & Fácil Entendimento \\
\hline & & & Interpretabilidade \\
\hline & & & Objetividade \\
\hline & & \multirow{4}{*}{$\begin{array}{l}\text { Qualidade das } \\
\text { Informações sobre o } \\
\text { Serviço }\end{array}$} & Credibilidade \\
\hline & & & Acessibilidade \\
\hline & & & Facilidade de Operação \\
\hline & & & Reputação \\
\hline
\end{tabular}

Para esclarecer as relações dos fatores/atributos de QI, os autores criaram um mapa, ilustrado na Figura 16, com base na literatura e na importância relativa dos fatores aplicados na prática em um estudo de caso real. Assim, foi possível visualizar como os fatores e atributos são ligados uns aos outros e a importância de considerar intensamente esses fatores nos processos de negócios. Contudo, a gestão imprópria da QI pode ser extremamente negativa ao processo de negócio. 


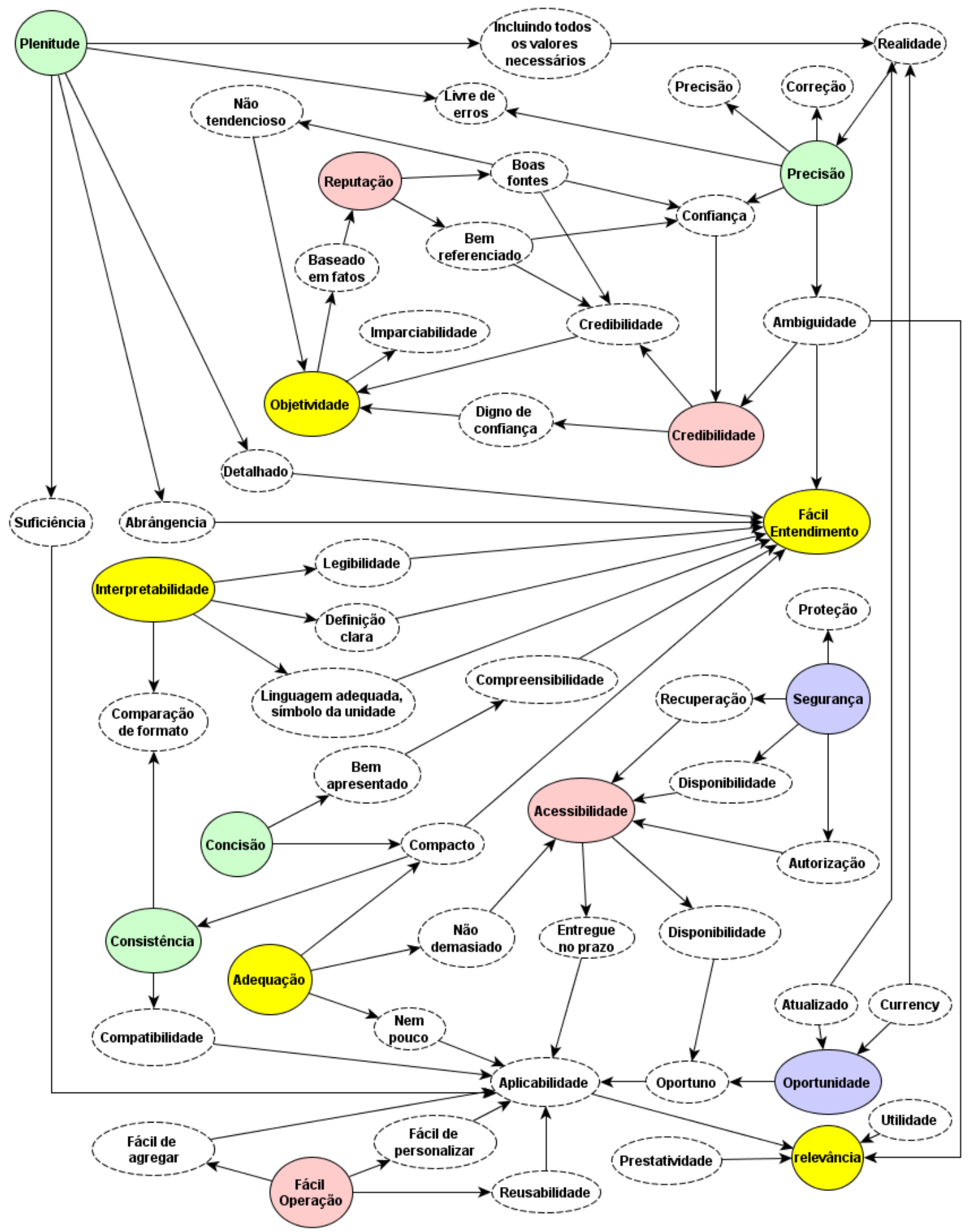

Figura 16 - Relação entre os fatores/atributos de QI, adaptado de (LEE; HAIDER, 2013).

Com base no mapa da Figura 16 e nos trabalhos de Inderapermana e Suhardi (2013) e Gorla, Somers e Wong (2010), foi elaborado um modelo da relação entre os fatores de QI e tomada de decisão, conforme a Figura 17. Desta forma, é possível verificar as dependências diretas e indiretas dos fatores de QI sobre o processo de tomada de decisão. Para Inderapermana e Suhardi (2013), o grau em que estes fatores são considerados na geração da informação tem reflexo na performance da tomada de decisão. Entre estes 
fatores, alguns são considerados mais relevantes, tais como:

Precisão: trata da regularidade do valor da informação, implica o quanto a informação está correta, confiável e "livre de erros", ou seja, é o grau de exatidão do valor registrado em relação ao valor real. De um modo geral, a precisão pode ser classificada como precisão sintática e precisão semântica (LEE; HAIDER, 2013):

- Precisão sintática: é a proximidade de um novo valor em um domínio particular. Se o novo valor é o valor aceitável no domínio e se o valor está correto ou não, o valor pode ser considerado como sintaticamente correto.

- Precisão semântica: é a proximidade de um novo valor com o valor verdadeiro.

- Imprecisão: envolve a precisão semântica e precisão sintática, pode ser interpretada como um mapeamento incorreto do resultado ou a geração de um valor errado em relação ao valor real. O resultado da imprecisão pode causar a escolha do estado errado, devido ao aumento da ambiguidade causada pela falta de precisão. A ambiguidade afeta a relevância da precisão e dificulta na atividade de tomada de decisão.

Plenitude significa que todas as informações necessárias para descrever um conceito com um nível de detalhe suficiente é apresentado (BEHKAMAL et al., 2014).

Relevância é definida como a informação aplicável e útil para determinado objetivo ou como um padrão para determinar informações significativas para a resolução de questões de negócios. Ela pode ser classificada em critérios e medida pelo usuário em uma avaliação contínua (LEE; HAIDER, 2013).

Concisão é a informação compactada sem perder sua relevância e semântica. Pode ser categorizada por classe representacional e pragmática (toma o valor prático como critério para análise), bem como ser medido pela avaliação subjetiva (depende de um oráculo com conhecimento do domínio) (LEE; HAIDER, 2013).

Fácil Entendimento é a capacidade de representar as informações de forma clara e sem ambiguidade. O grau dessa capacidade está relacionada com o uso da linguagem apropriada, símbolos, unidade e definição clara (LEE; HAIDER, 2013). 


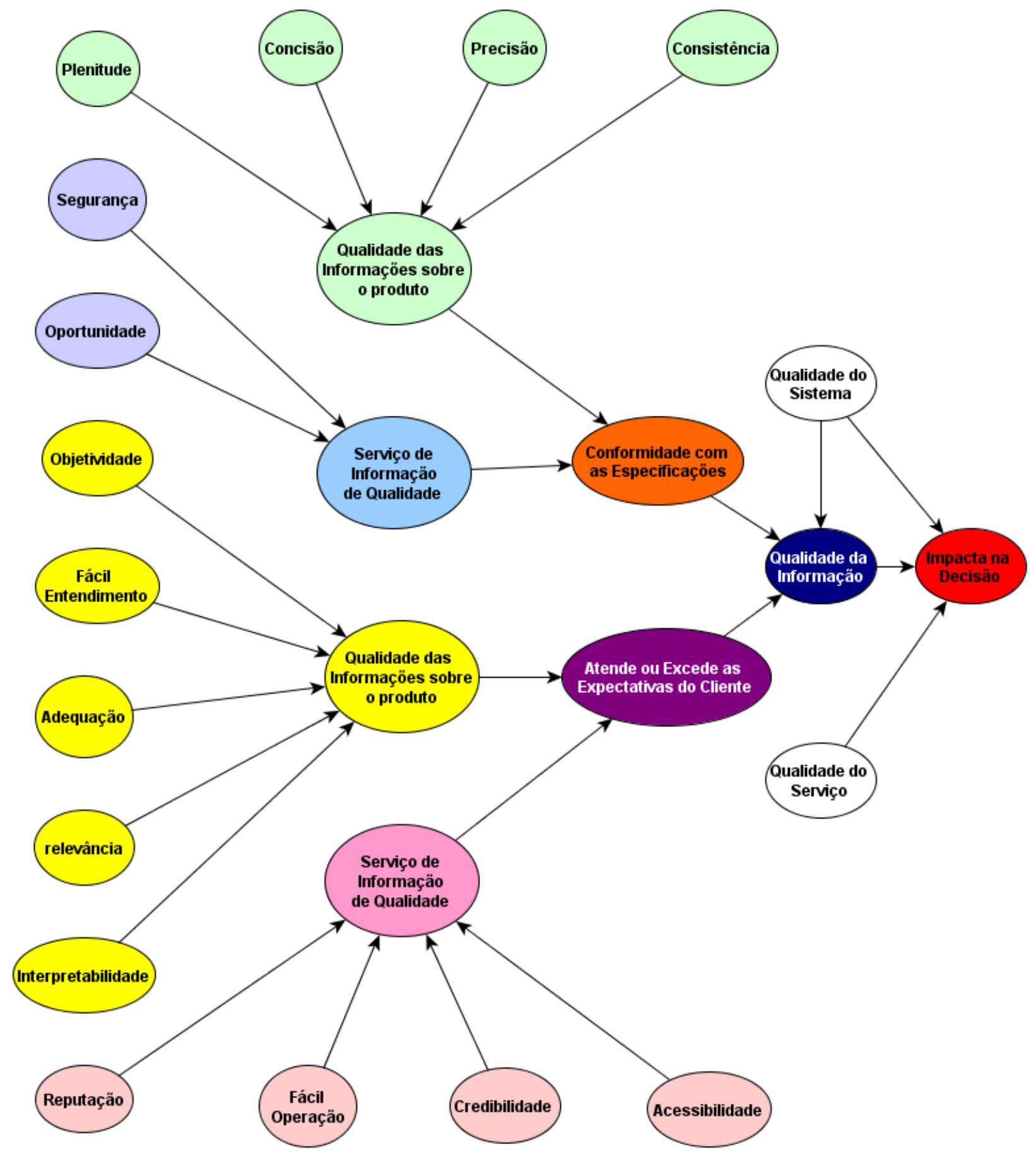

Figura 17 - Modelo da relação entre os fatores de QI e o impacto na tomada de decisão, adaptado de (LEE; HAIDER, 2013; INDERAPERMANA; SUHARDI, 2013; GORLA; SOMERS; WONG, 2010).

\subsection{Desenvolvimento do questionário}

Entre os principais objetivos deste trabalho está o levantamento dos fatores que possam aumentar o grau de testabilidade dos Sistemas de Suporte à Decisão, o qual foi realizado na Seção 3.3. Entretanto, é necessário o desenvolvimento de um método para 
análise e avaliação do nível de maturidade desses sistemas em relação aos fatores e o grau de testabilidade do sistema como um todo.

Para essa análise e avaliação, foi elaborado um questionário que poderá ser usado como um guia no processo de desenvolvimento de um SSD, com o objetivo de atender às expectativas do cliente ou poderá ser usado para avaliar o quanto um SSD já desenvolvido atende tais expectativas e principalmente determinar o nível de maturidade do SSD em relação a sua testabilidade.

Para elaborar um questionário que fosse abrangente em relação aos objetivos deste trabalho e ao mesmo tempo de fácil entendimento, utilizou-se o conceito Goal Question Metric (GQM) visto na Seção 2.4, mais especificamente duas extensões do GQM que agregam em seu modelo as estratégias de negócio (BASILI et al., 2007; HEIDRICH; KOWALCZYK, 2012).

Usando estes modelos como referência, foram elaboradas as questões principais do questionário, que tem como característica uma linguagem mais voltada ao cliente. A composição das questões é resultado de uma pesquisa feita em licitações públicas do Brasil, na qual, o objeto das licitações era voltado para a compra ou desenvolvimento de software na linha dos Sistemas de Informação e que tivesse algum módulo de suporte à decisão. As fontes das licitações foram os sites (RCC, 2015; CNM, 2015).

No processo de análise das licitações, o principal objetivo foi identificar as exigências da contratante (cliente), quanto às funcionalidades, plataformas, segurança, qualidade do sistema e principalmente as que tinham relação direta ou indireta com os fatores ou atributos de testabilidade, vistos em mais detalhes na Seção 3.3.

Com as questões principais definidas na Tabela 3, deu-se início ao desenvolvimento das subquestões, cujo propósito foi fornecer por meio de seus resultados a resposta da questão principal. As subquestões são mais técnicas e foram elaboradas com base nos princípios dos fatores ou atributos de testabilidade, vistos na Seção 3.3 e dos atributos que influenciam de forma direta ou indireta o processo de tomada de decisão, vistos em mais detalhes na Seção 3.4.

Tabela 3 - Questões principais.

Questão

$1 \quad$ O SSD é customizável em relação ao perfil do tomador de decisão? esperado? 
Questão

3

O serviço de mobilidade atende às expectativas do tomador de decisão sem limitar a abrangência da informação?

A documentação disponibilizada sobre o SSD, como o processo de desenvolvi-

4 mento, os testes nele realizados e suas funcionalidades é suficiente para descrever o seu ciclo de vida?

O SSD atende às expectativas do tomador de decisão em tempo hábil com

5 qualidade, ou seja, a informação é apresentada em "Real time" ou "deadline" muito curto?

6

O SSD possui flexibilidade para conexão com outros sistemas internos e externos à sua plataforma?

$7 \quad$ As regras ou modelos de negócios do SSD atendem o propósito original?

8

As transformações realizadas nos dados pelo SSD até serem apresentados como informação de apoio a tomada de decisão foram corretas?

$9 \quad$ O SSD permite a utilização de rotinas de teste automatizadas?

Para desenvolver as subquestões, foram utilizados os conceitos e definições sobre testabilidade, vistos em mais detalhes na Seção 3.3 e 2.3. Em cada subquestão, teve-se o cuidado de considerar pelo menos um atributo de testabilidade na sua composição, bem como o propósito da questão principal. A Tabela 4 mostra os atributos de testabilidade presentes em cada subquestão, das vinte e uma que foram elaboradas. 
Tabela 4 - Atributos de testabilidade presentes nas subquestões.

\begin{tabular}{|c|c|c|c|c|c|}
\hline \multirow{2}{*}{ Sub. } & \multicolumn{5}{|c|}{ Atributos de Testabilidade } \\
\hline & Controlabilidade & Observabilidade & Rastreabilidade & Compreensibilidade & $\begin{array}{l}\text { Suporte } \\
\text { ao Teste }\end{array}$ \\
\hline 1.1 & $\bullet$ & & & & \\
\hline 1.2 & & $\bullet$ & & $\bullet$ & \\
\hline 2.1 & $\bullet$ & & & & \\
\hline 2.2 & & $\bullet$ & & & $\bullet$ \\
\hline 2.3 & & & $\bullet$ & $\bullet$ & \\
\hline 3.1 & & $\bullet$ & & $\bullet$ & \\
\hline 3.2 & $\bullet$ & & & & \\
\hline 3.3 & & $\bullet$ & & $\bullet$ & \\
\hline 4.1 & & & $\bullet$ & $\bullet$ & \\
\hline 4.2 & & & $\bullet$ & $\bullet$ & \\
\hline 4.3 & & & & $\bullet$ & \\
\hline 4.4 & & $\bullet$ & $\bullet$ & $\bullet$ & \\
\hline 4.5 & $\bullet$ & & & $\bullet$ & \\
\hline 4.6 & & & & $\bullet$ & \\
\hline 4.7 & $\bullet$ & & $\bullet$ & $\bullet$ & \\
\hline 5.1 & & $\bullet$ & & $\bullet$ & \\
\hline 6.1 & $\bullet$ & & & $\bullet$ & \\
\hline 6.2 & $\bullet$ & $\bullet$ & & & \\
\hline 7.1 & & $\bullet$ & & $\bullet$ & \\
\hline 8.1 & $\bullet$ & $\bullet$ & $\bullet$ & $\bullet$ & \\
\hline 9.1 & & & & & $\bullet$ \\
\hline
\end{tabular}

$\mathrm{Na}$ fase de estabelecer o formato das respostas para as subquestões, alguns pontos foram levados em consideração, tais como oferecer maior flexibilidade na escolha da resposta e ser aplicável a todas subquestões. Após uma busca na literatura, o modelo conhecido como escala de Likert (1932) foi o que melhor se adaptou ao formato do questionário e atendeu os pontos desejados. Conforme exemplo abaixo, extraído do questionário que se encontra no Apêndice A, que mostra como ficou a formatação de uma questão e suas respectivas subquestões.

\section{Exemplo de uma questão do questionário para avaliação do nível de} maturidade do SSD.

\begin{tabular}{|l|l|c|}
\hline Questão 1 & $\begin{array}{l}\text { O SSD é customizável em relação ao perfil do tomador de } \\
\text { decisão? }\end{array}$ & Nível de Maturidade \\
\hline
\end{tabular}

1.1 É possível desabilitar ou habilitar módulos do SSD?

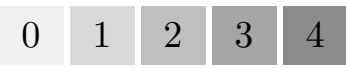


Nota Explicativa: Deve-se verificar se os recursos disponibilizados pelo SSD são dinamicamente ajustáveis conforme o usuário, exemplo: a mesma informação visualizada na forma de gráfico pela gerência, pode ser analisada na forma de tabela pela contabilidade.

1.2 A informação que foi adequada pela customização perma-

$\begin{array}{llllll}0 & 1 & 2 & 3 & 4\end{array}$
nece sem distorção?

Nota Explicativa: Deve-se verificar se informações apresentadas em mais de um formato ou dispositivos diferentes permanecem sem alterações sintáticas ou semânticas.

\subsection{Escala de classificação do SSD}

Para que o avaliador do SSD tivesse meios de analisar o resultado obtido através do questionário, foi adotada uma classificação escalar, que permite posicionar o sistema com base no seu status atual, bem como mapear os pontos fortes e fracos do SSD sobre as expectativas do cliente e do grau de testabilidade.

Com isto, é possível definir estratégias junto ao grupo de desenvolvimento, com objetivo de melhorar os pontos fracos e por tratar-se de uma medida escalar é possível reavaliar o SSD quantas vezes for necessário, a fim de verificar se com as melhorias aplicadas houve um aumento no nível de maturidade. Outro uso seria no momento de uma possível aquisição de um SSD pronto.

Para análise pontual de cada questão do questionário, foi considerada a média aritmética dos resultados obtidos nas suas subquestões. Sendo: $(q)$ a questão a ser analisada, $x_{1}, x_{2}, x_{3}, \cdots, x_{n}=$ o grau de maturidade assinalado em cada subquestão e $(n)$ é o número de subquestões pertencentes a $(q)$. Conforme a fórmula abaixo.

$$
q(x)=\frac{x_{1}+x_{2}+x_{3}+\cdots+x_{n}}{n}=\frac{1}{n} \sum_{i=1}^{n} x_{i}
$$

Os resultados obtidos em cada questão $(q)$, quando plotados no gráfico radar da Figura 18, apresentam um panorama da situação atual do SSD, o qual pode facilitar a identificação dos pontos que necessitam de melhorias ou mesmo para comparar detalhadamente dois ou mais SSD.

Foi adotado este tipo de gráfico para auxiliar o avaliador na análise detalhada das questões, devido ao seu formato, que permite incluir e visualizar a escala de Likert (1932) 
de forma clara e os resultados obtidos em cada questão. Outro fator considerado foram os ótimos resultados obtidos a partir das análises realizadas nele, durante o processo de implantação da construção enxuta nas empresas voltadas para construção civil (CARVALHO, 2008; OLIVEIRA et al., 2010; VIEIRA; SOUZA; AMARAL, 2012).

O gráfico é dividido em quatro anéis, que representam o percentual considerado para cada nível de maturidade nas questões. O anel azul que está na extremidade é o melhor nível e o anel vermelho que esta no centro é o pior nível. Cada vértice que corta os anéis representa uma questão $(q)$. Ao plotar o resultado obtido na função $q(x)$ em seu respectivo vértice, obtêm-se uma visão geral das questões em relação ao nível de maturidade.

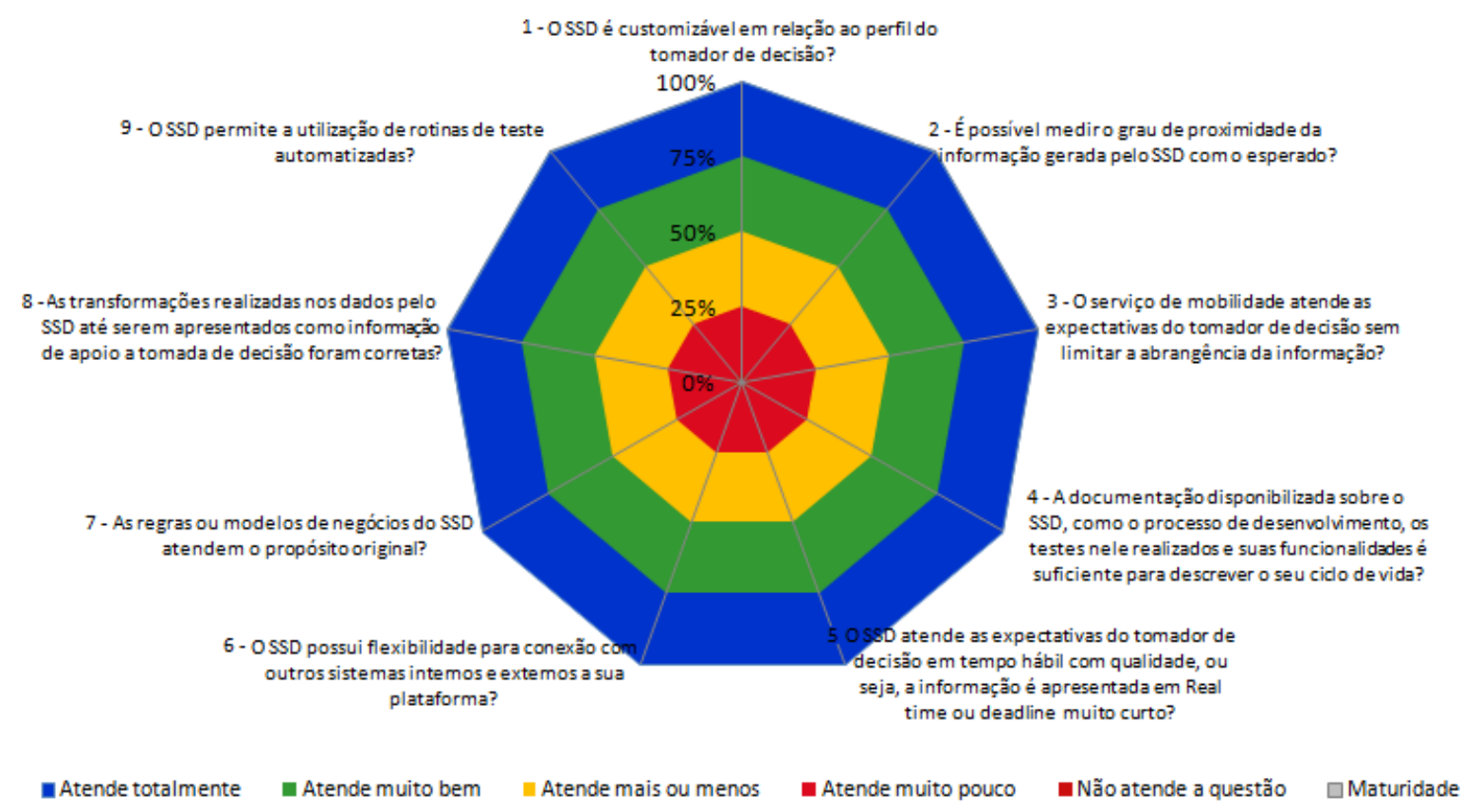

Figura 18 - Modelo para avaliação e mapeamento dos pontos fortes e fracos do SSD, adaptado de (CARVALHO, 2008).

A classificação geral do SSD é obtida com os resultados de todas as questões principais do questionário. Nesta pesquisa, todas as questões possuem o mesmo grau de importância; por isto, foi considerada a média aritmética dos resultados obtidos.

A expressão para calcular o nível de maturidade geral do SSD é composta por: $(Q)$ é o nível de maturidade alcançado, $q_{1}, q_{2}, q_{3}, \cdots, q_{m}=$ o grau de maturidade obtido na função $q(x)$ em cada questão e $(m)$ é o número de questões. Conforme a fórmula abaixo:

$$
Q(q)=\frac{q_{1}+q_{2}+q_{3}+\cdots+q_{m}}{m}=\frac{1}{m} \sum_{i=1}^{m} q_{i}
$$


Com o resultado obtido na função $Q(q)$ e transformado em percentual, é possível analisar o nível de maturidade atual do SSD. Para isto, a Tabela 6 fornece o nível mínimo e o nível máximo que pode ser alcançado pela avaliação do SSD.

A Tabela 6 apresenta uma régua com quatro níveis de maturidade em percentuais: A, B, C e D. Foram adicionadas cores a cada nível para facilitar a visualização entre o melhor nível, representada na cor azul e o pior nível destacado em vermelho. Cada uma das divisões possui três subníveis, por exemplo: o nível A possui os subníveis: AAA, AA e A, com o propósito de oferecer mais alternativas no momento da avaliação.

Tabela 6 - Classificação do SSD conforme o nível de maturidade, adaptado de (HOFACKER et al., 2008).

\begin{tabular}{|c|l|c|c|}
\hline Nível & Subnível & Percentual & Características \\
\hline \multirow{3}{*}{ A } & AAA & $95 \%$ a $100 \%$ & Alto nível de maturidade para atender as expectativas \\
& AA & $90 \%$ a $94 \%$ & do cliente e alto grau de testabilidade. \\
& A & $85 \%$ a $89 \%$ & \\
\hline \multirow{3}{*}{ B } & BBB & $80 \%$ a $84 \%$ & Nível de maturidade aceitável, mas necessita melhorias. \\
& BB & $75 \%$ a $79 \%$ & Consequentemente o grau de testabilidade também pode \\
& B & $70 \%$ a $74 \%$ & ser elevado com as melhorias. \\
\hline \multirow{3}{*}{ C } & CCC & $65 \%$ a $69 \%$ & Baixo nível de maturidade, atende muito pouco as ex- \\
& CC & $60 \%$ a $64 \%$ & pectativas do cliente, necessita de várias mudanças para \\
& C & $55 \%$ a $59 \%$ & elevar a qualidade. \\
\hline \multirow{2}{*}{ D } & DDD & $50 \%$ a $54 \%$ & O nível de maturidade é muito baixo ou não possui, \\
& DD & $45 \%$ a $49 \%$ & necessita rever o projeto e aplicar modificações. Conse- \\
& D & $0 \%$ a $44 \%$ & quentemente o grau de testabilidade é mínimo. \\
\hline
\end{tabular}

Outra forma de utilizar a régua de classificação é no processo de análise de vários SSD, como ilustrado na Figura 19, a qual permite visualizar graficamente o nível alcançado por cada sistema e sua posição na régua. Uma das vantagens deste modelo é a visão geral de todos os sistemas avaliados em relação a régua de classificação. 


\section{Modelo de Avaliação dos SSD}

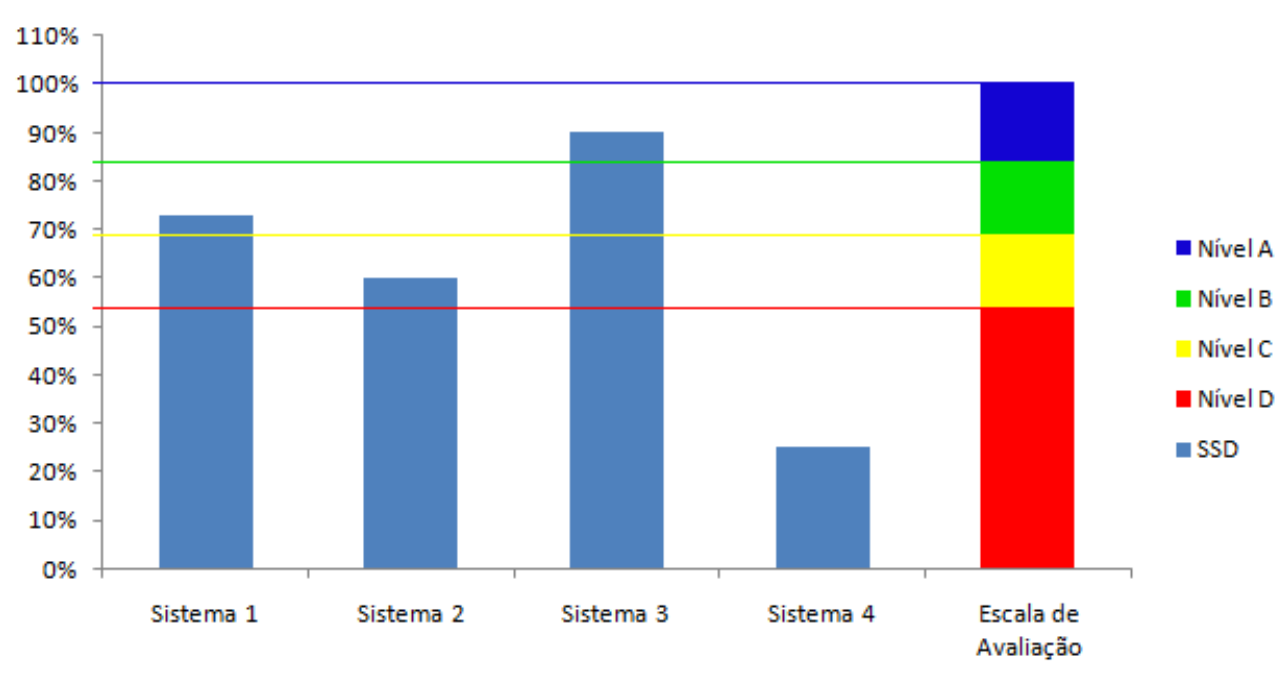

Figura 19 - Modelo gráfico para avaliação dos SSD, adaptado de (OLIVEIRA et al., 2010).

\subsection{Considerações finais}

Foi definido neste capítulo o método para coletar informações sobre um SSD em relação a sua testabilidade, tendo como foco algumas das expectativas do cliente. Este método de coleta é feito na forma de questionário, o qual se encontra no Apêndice A.

Além disso, foram definidas as métricas para avaliação do resultado obtido pelo questionário e os meios gráficos para auxiliar na análise dos pontos fortes e fracos do SSD. Também foi ressaltada a importância da qualidade da informação no processo de tomada de decisão e identificados os fatores de testabilidade que podem influenciar na atividade de teste nos SSD.

No próximo capítulo serão apresentados alguns testes de aplicabilidade do questionário em SSD já consolidados, com o propósito de verificar o quanto as questões são pertinentes ao domínio dos SSD. 


\subsection{Considerações iniciais}

Este capítulo descreve os testes de aplicabilidade do questionário realizados em SSD e a aplicação das métricas de análise e avaliação dos resultados coletados nos testes. Para a condução dos testes foram criados mais dois questionários de apoio. No Apêndice B encontra-se o questionário usado para coletar informações sobre o perfil do colaborador e no Apêndice C o questionário utilizado para coletar informações de qualidade sobre o teste aplicado, na visão do colaborador.

Apenas com o propósito de facilitar a análise dos resultados, os testes foram separados pelo porte das empresas e área de atuação. Na Seção 4.2, é feita uma breve explanação sobre o perfil dos colaboradores e na sequência são apresentados os testes realizados em empresas de médio e grande porte, pequeno porte e no meio acadêmico. Por fim, é apresentado um resumo dos testes de aplicabilidade.

\subsection{Teste de aplicabilidade do questionário}

O principal objetivo deste estudo de caso foi realizar testes com o questionário em Sistemas de Suporte à Decisão já consolidados no mercado, com o propósito de verificar o quanto as questões são relevantes neste contexto e identificar pontos fortes e fracos no questionário.

Foram enviados questionários para profissionais que trabalham com SSD e possuem experiência na área, bem como conhecimento sobre as necessidades dos clientes e dos pontos fortes e fracos das empresas de software. Os questionários encaminhados foram: (1) principal, (2) perfil do colaborador e o (3) de apoio, para avaliação da aplicabilidade do principal. 
No processo de teste do questionário, oito profissionais da área contribuíram com a pesquisa, os quais serão chamados de colaboradores neste trabalho. A ordem em que foram nomeados os profissionais não tem relação com a ordem dos sistemas.

Entre estes colaboradores apenas um possui instrução de nível técnico, os demais possuem nível superior ou pós-graduação. A experiência deles, no tema e no mercado, fica acima de 2 anos e alguns com 12, 25 e 27 anos, atuando como analista de sistemas, testador de software, consultores, pesquisador e coordenador de negócios.

Na expectativa de explorar o máximo das questões do questionário principal, os profissionais utilizaram alguns sistemas já consolidados no mercado implantados em empresas $^{1}$ de pequeno porte, médio e grande porte. A fim de ser mais abrangente na aplicabilidade do questionário, além destes sistemas voltados para a indústria, economia, varejo, atacado e setor de serviços, também foi considerado um sistema em desenvolvimento no meio acadêmico.

\subsubsection{Sistemas para empresas de médio e grande porte}

Espera-se com o teste de aplicabilidade do questionário nos sistemas voltados às empresas de médio e grande porte conseguir responder o maior número de questões possíveis. Desta forma, será possível analisar o quanto as questões são direcionadas para os SSD. Para este teste os profissionais utilizaram os sistemas:

- SAP Business Warehouse ${ }^{2}$ : trata-se de um sistema de data warehousing, que permite extrair, transformar e armazenar dados de negócio para fins analíticos. Este módulo é parte da plataforma global SAP NetWeaver;

- SAP Business Objects Business Intelligence ${ }^{3}$ : é uma ferramenta de gerenciamento de relatórios, que permite aos administradores implantar e padronizar suas implementações de Business Intelligence;

- Oracle Business Intelligence ${ }^{4}$ : sistema de auxílio à tomada de decisão que permite criar cubos com dados armazenados, pode ser utilizado para avaliação de situação, análise de tendências entre outros;

Para facilitar a análise dos resultados obtidos com o teste de aplicabilidade, no decorrer do trabalho os sistemas utilizados foram chamados de:

1 Os critérios de classificação das empresas quanto seu porte ou receita bruta anual, podem ser verificados com mais detalhes em (SEBRAE, 2015).

2 http://help.sap.com/nwbw?current=netweaver

3 http://help.sap.com/bobi?current=analytics

4 http://www.oracle.com/us/solutions/business-analytics/business-intelligence/overview/index.html 
Sistema 1, os módulos SAP Business Warehouse e SAP Business Objects Business Intelligence; $\mathrm{e}$

Sistema 2, o módulo Oracle Business Intelligence;

O sistema 1 foi avaliado por três colaboradores, cada um com uma visão diferente deste sistema, devido as suas profissões e experiência com ele. As Figuras 20, 21 e 22 apresentam os resultados de cada avaliação, já convertidos em nível de maturidade, conforme método definido no Capítulo 3.

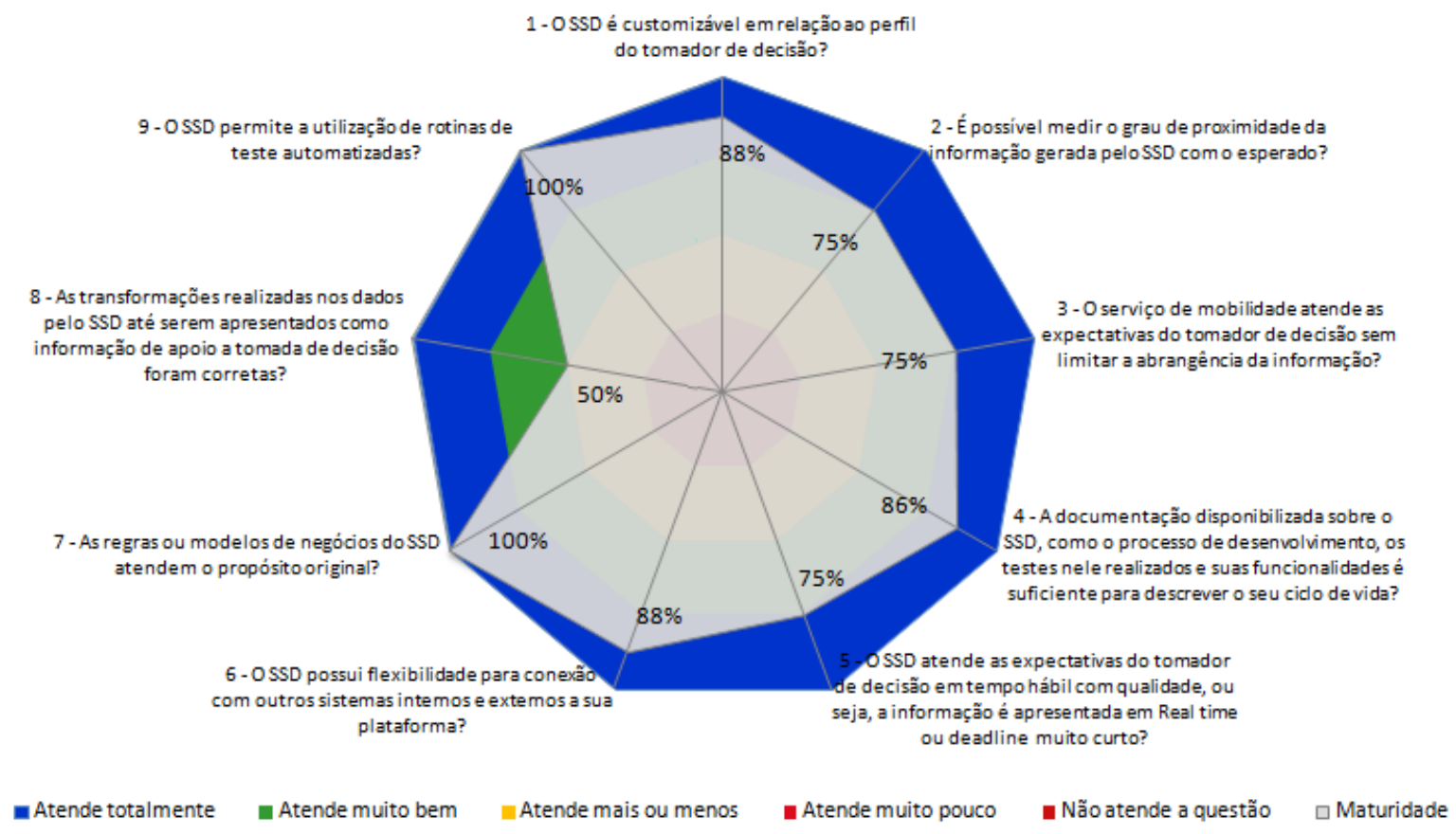

Figura 20 - Classificação por questão da primeira avaliação do sistema 1.

A Figura 20 apresenta o nível de maturidade alcançado pelo sistema 1 em cada questão, na primeira avaliação. A área plotada no gráfico com os níveis em percentuais, permite verificar que as questões sobre as expectativas do cliente foram bem classificadas. Essa classificação pode indicar que as questões são, na sua maioria, relacionadas a SSD, pois a área ocupada chega até o anel azul, que é definido entre $75 \%$ e 100\%, considerado o melhor nível.

Apesar da questão 8 ser classificada como média, ou seja, 50\% do nível máximo que poderia alcançar, o resultado obtido com esta primeira avaliação foi satisfatório, pois todas as questões foram classificadas acima da média. Esta questão, em particular, tem o propósito de verificar se o sistema oferece meios de analisar as informações apresentadas ao tomador de decisão desde a sua origem. Para isto, a sua subquestão foi elaborada de forma a verificar se é possível testar cada ponto de processamento desta informação. 
Para conseguir realizar este tipo de teste os atributos de testabilidade como observabilidade, controlabilidade, rastreabilidade e compreensibilidade podem facilitar esta atividade. Por exemplo, o princípio de rastreabilidade, ou seja, conseguir percorrer nos dois sentidos todo caminho de processamento dos dados em informação, permite realizar testes de conformidade retrocedendo a cada ponto de processamento. Assim, quanto maior for o nível da questão oito, maior poderá ser o grau de testabilidade destes atributos.

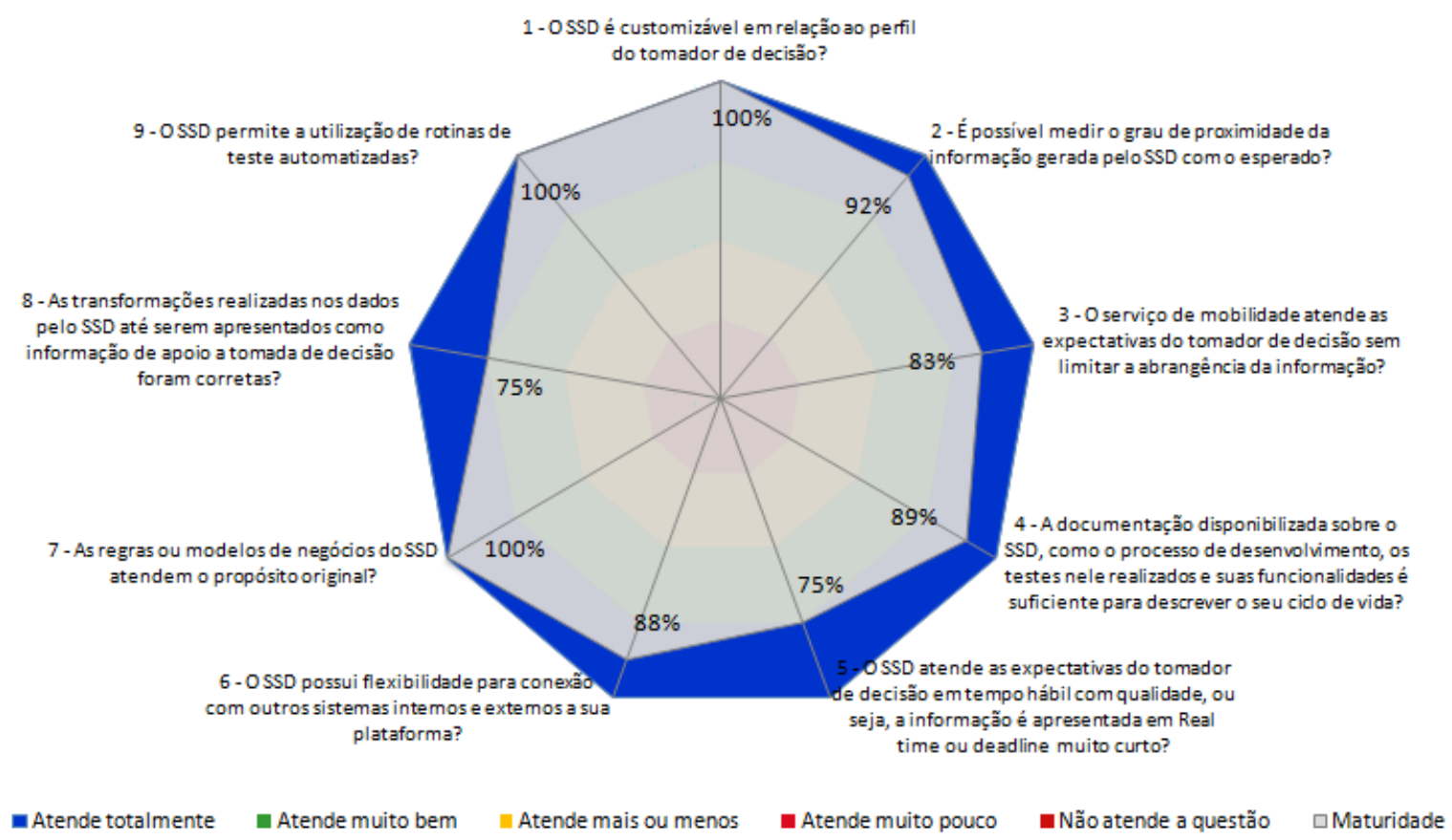

Figura 21 - Classificação por questão da segunda avaliação do sistema 1.

A Figura 21 apresenta o resultado obtido na segunda avaliação do sistema 1. Nesta avaliação o questionário também foi bem classificado em todas as questões, sua área plotada ocupa somente o anel azul, inclusive a questão oito que tinha sido classificada como média na primeira avaliação.

Um possível fator que pode ter contribuído nestas pequenas variações nos níveis de maturidade de cada questão, exceto a questão 8 que teve um aumento de $25 \%$ em seu nível, é o perfil do colaborador e suas restrições de acesso as funcionalidades do sistema. 


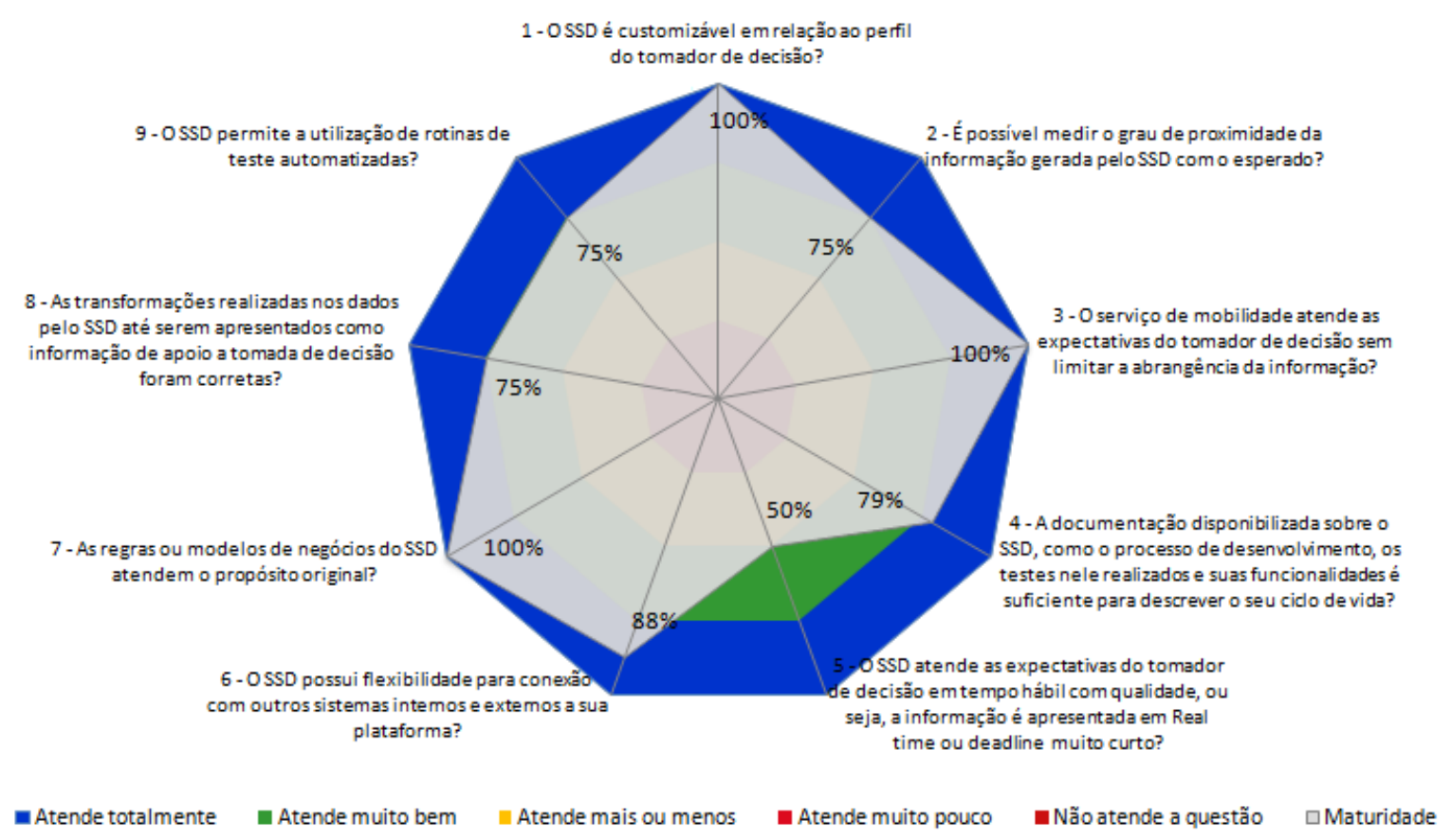

Figura 22 - Classificação por questão da terceira avaliação do sistema 1.

Na terceira avaliação do sistema 1, a questão 5 que vinha bem classificada com $75 \%$ nas outras duas avaliações, sofreu uma redução e foi classificada em 50\%, como pode ser verificado na Figura 22. Esta questão tem o objetivo de verificar se o sistema permite testar e avaliar o tempo de resposta entre a solicitação feita ao sistema pelo tomador de decisão e a saída da informação.

Este tipo de teste pode ser realizado com mais facilidade se forem adotados os princípios de observabilidade e compreensibilidade, na implementação e na documentação do sistema, ou seja, codificar o sistema de forma que permita observar ou registrar estes tempos, bem como documentar os tempos aceitáveis para cada processamento considerado complexo ou importante para os envolvidos. 


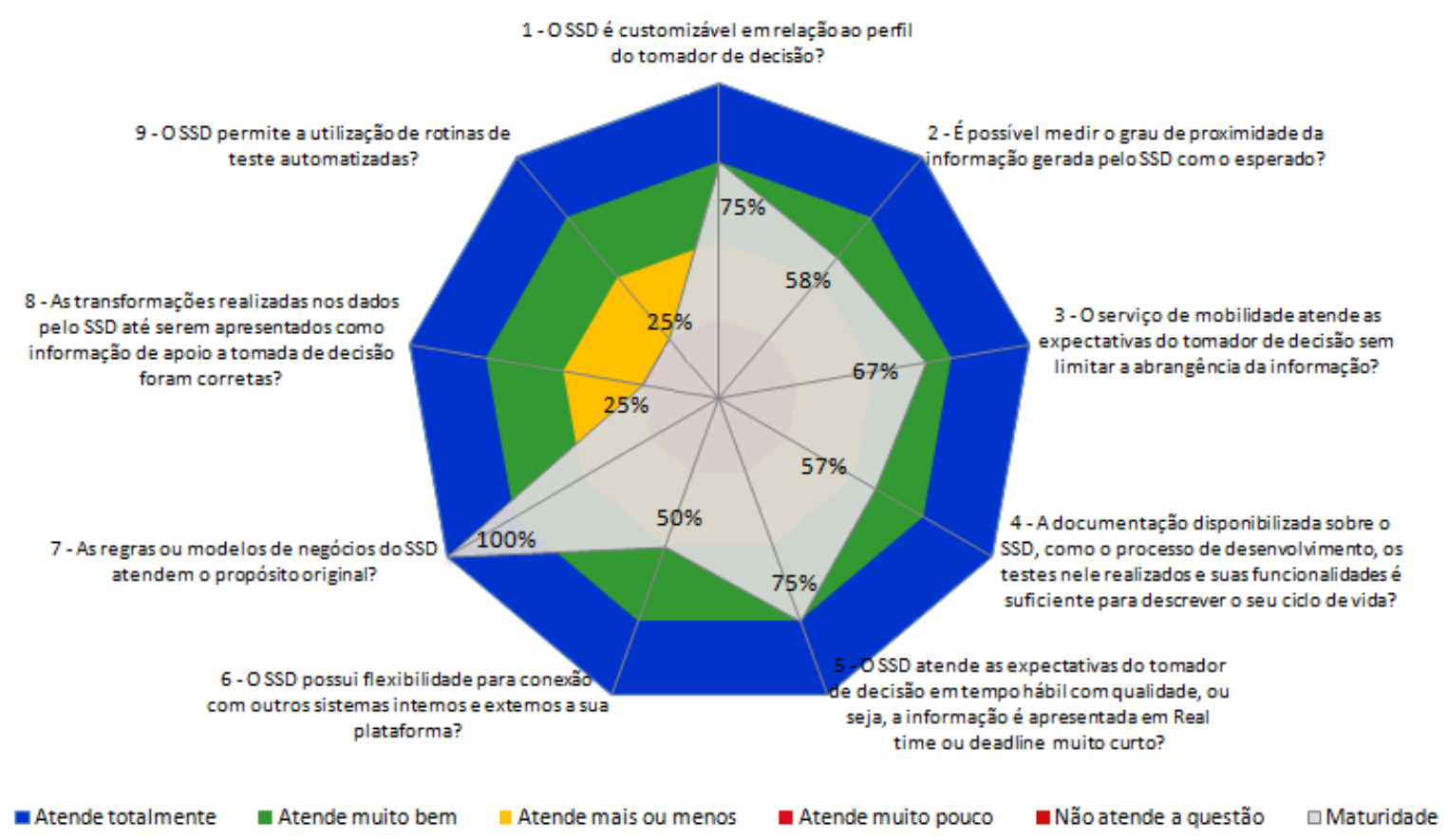

Figura 23 - Classificação por questão da avaliação do sistema 2.

A Figura 23 apresenta o resultado obtido na avaliação do sistema 2. A área plotada no gráfico apresenta indícios de alguns pontos fracos no questionário. Estes pontos são relacionados com as questões 6,8 e 9. A questão 6 tem como propósito verificar se o sistema possui interoperabilidade ${ }^{5}$ e meios para testar esta troca de informações entre os sistemas.

As questões 8 e 9 estão classificadas quase na região crítica do gráfico, em que somente algumas das funcionalidades consideradas nas questões foram atendidas, entretanto, as mesmas questões foram bem classificadas no sistema 1 . Um fator que pode ter contribuído para este resultado é o nível de acesso a estas funcionalidades do sistema pelo colaborador, ou seja não estão visíveis para ele.

\subsubsection{Sistemas para empresas de pequeno porte}

As próximas duas Figuras 24 e 25, são as avaliações realizadas em sistemas de informações já consolidados no mercado, atuando em segmentos distintos. Todas as suas funcionalidades são estruturadas em um único sistema, ou seja, não possuem um sistema para cada área da empresa. Outro ponto em comum é o baixo desenvolvimento das funcionalidades para o suporte à tomada de decisão. Estes sistemas são:

5 Capacidade em que dois ou mais sistemas, produtos ou componentes podem interagir entre si e utilizar as informações trocadas ISO/IEC 25010 (2010). 
- Sistema 3 - Sistema para Gestão de Cobrança: Sistema que auxilia nas atividades de cobrança de serviços e benefícios, realizados por uma entidade.

- Sistema 4 - Sistema de Gestão Imobiliário: Permite automatizar todas as tarefas de uma imobiliária. Com isto, agiliza o trabalho diário dos funcionários e favorece a geração e centralização das informações.

Um dos propósitos de ter aplicado o questionário nestes sistemas foi de analisar se as questões elaboradas não são genéricas, ou seja, se a essência de cada questão é realmente direcionada apenas aos sistemas de suporte a decisão.

A Figura 24 apresenta a avaliação do Sistema 3, ou seja, o Sistema de Gestão de Cobrança. Apesar do resultado ruim da avaliação, no qual somente as questões 1, 5 e 8 foram classificadas, o resultado foi ótimo, pois, trata-se de um indicativo de que as questões elaboradas são realmente voltadas para SSD. A classificação dessas três questões justifica-se pelo fato de possuírem natureza mais genérica em relação às demais questões do questionário.

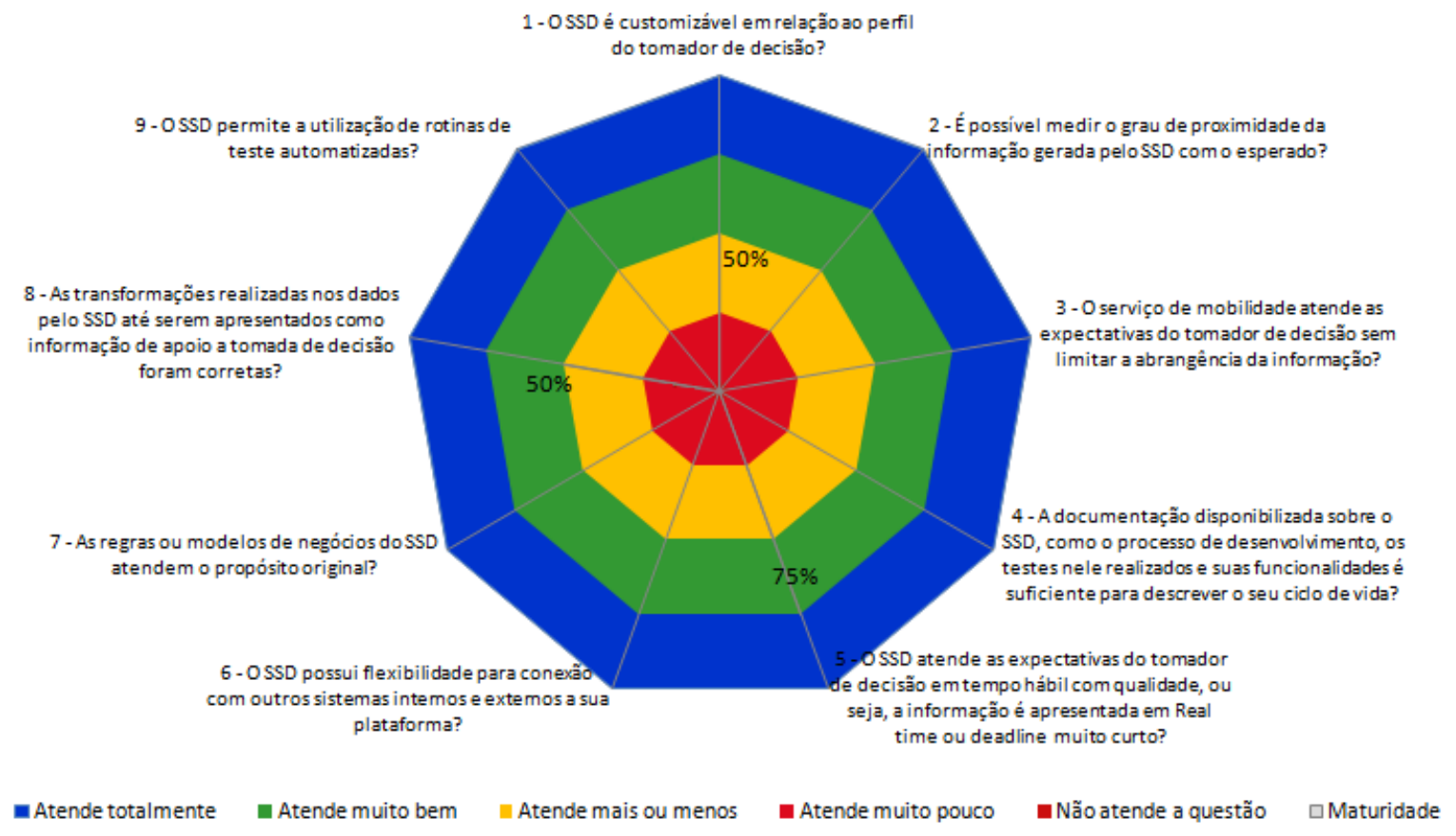

Figura 24 - Classificação por questão da avaliação do sistema 3. 


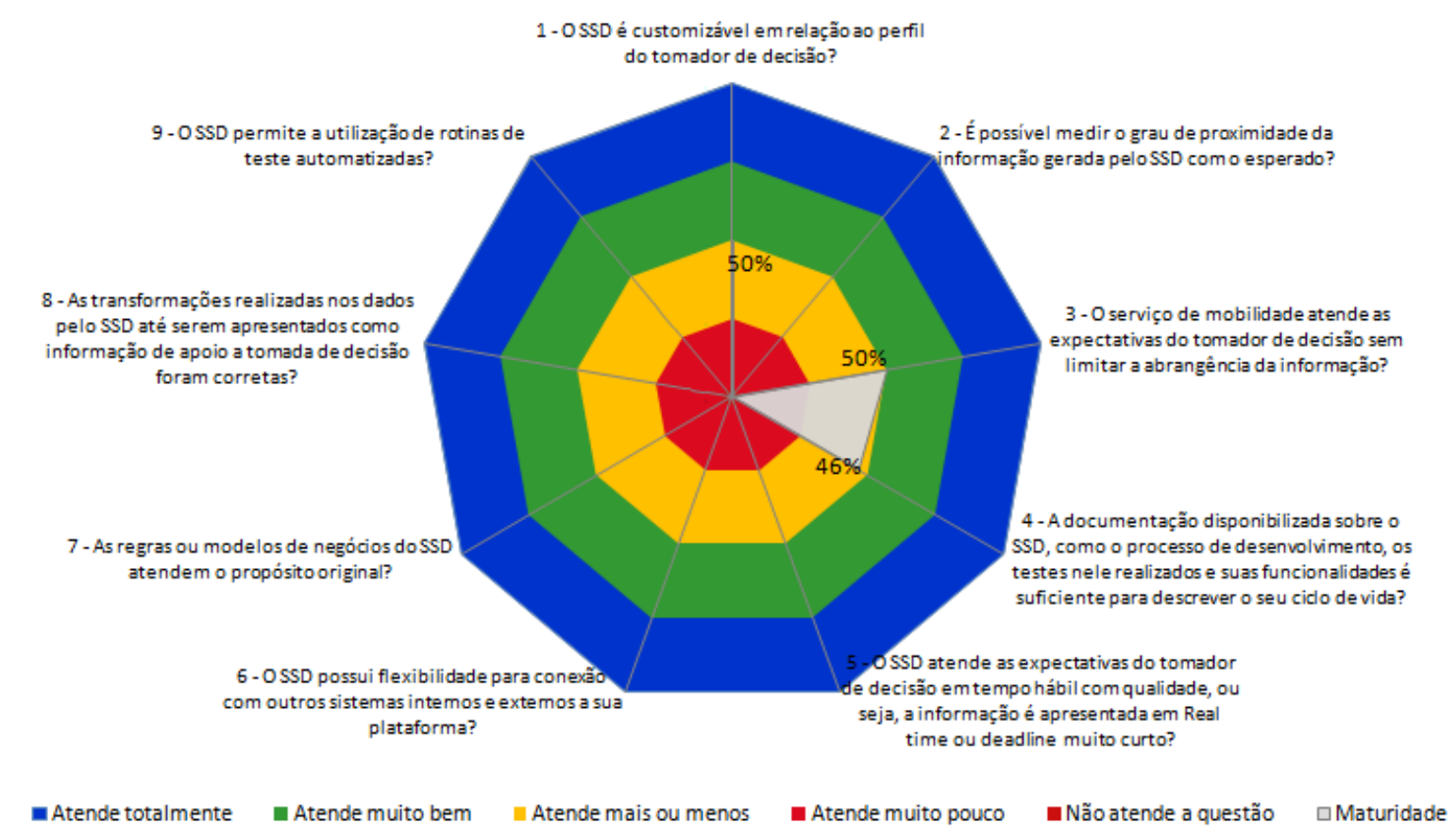

Figura 25 - Classificação por questão da avaliação do sistema 4.

O Sistema 4 é um sistema imobiliário com características parecidas com a do sistema 3, como já mencionado anteriormente, principalmente em relação às funcionalidades de suporte a decisão. O resultado apresentado na Figura 25 mostra uma situação crítica em relação aos recursos para atender às expectativas do tomador de decisão.

As avaliações realizadas com o sistema 4 e sistema 3, são fortes evidências de que as questões elaboradas são voltadas em sua maioria para os sistemas de suporte a decisão. No entanto, existem questões que podem ser respondidas considerando outros sistemas de informação, devido às particularidades de cada um. Este fato pode ser observado nos resultados obtidos entre esses dois sistemas, os quais conseguiram responder parcialmente algumas questões.

\subsubsection{Sistema no meio acadêmico}

Os sistemas avaliados até o momento atuam em vários setores do mercado, como: indústrias, serviços, área financeira, atacado, varejo e outros. Porém, com o dinamismo do mercado, avanços tecnológicos e mudanças nas necessidades da população, os SSD necessitam estar sempre evoluindo para conseguir fornecer informações relevantes ao tomador de decisão. Neste contexto, o meio acadêmico é uma das referências em inovações.

Entre as várias pesquisas desenvolvidas ou em andamento, há o projeto AGORA, que está em pleno desenvolvimento. O projeto AGORA ( $\boldsymbol{A} \boldsymbol{G}$ eospatial $\boldsymbol{O}$ pen collabo $\boldsymbol{R}$ ative Architecture for Building Resilience against Disasters and Extreme Events) tem como foco desenvolver soluções tecnológicas para apoiar comunidades vulneráveis na construção 
de resiliência ou melhora-lá contra desastres naturais e eventos extremos. Nesse contexto, resiliência pode ser entendida como a capacidade de um sistema, comunidade, sociedade ou indivíduo de resistir, absorver e se recuperar de situações de alto estresse, impacto de sistemas opressivos, exposição a riscos (NORRIS et al., 2008). Para execução desse projeto foi selada uma parceria entre grupos de pesquisa do Instituto de Ciências Matemáticas e Computação da Universidade de São Paulo (Brasil) e do GIScience Research Group da Universidade de Heidelberg (Alemanha).

Entre os tipos de desastres naturais e eventos extremos, as inundações são o foco desse projeto, pois são responsáveis por aproximadamente 30\% dos desastres naturais e também causadoras de muitos danos estruturais, econômicos e mortes. No entanto, conseguir aumentar a resiliência nos ambientes propícios a este tipo de evento depende da combinação de vários fatores. Visando essa combinação, o projeto AGORA está sendo desenvolvido através de conhecimentos transdisciplinares, os quais envolvem especialistas de várias áreas e grupos formados na comunidade, que discutem a melhor solução para os problemas, aproximando a ciência das necessidades da sociedade.

A característica transdisciplinar do projeto e de ser voltada para resolução de problemas, faz da informação um elemento essencial na tomada de decisão do grupo. Entretanto, o grande desafio é conseguir informações atuais e detalhadas do local, para estimativa de risco ou mapeamento desses pontos, bem como informações em tempo real sobre o grau de exposição e vulnerabilidade a inundações. Para minimizar essa e outras limitações, será realizada a integração de várias fontes de dados em uma plataforma, utilizando métodos que fornecerão indicadores da qualidade dos dados, para serem avaliados conforme o grau de confiança.

Com essa arquitetura, o sistema AGORA poderá oferecer suporte na construção de resiliência ou melhora-lá contra inundações, para isso, será criada uma plataforma de gestão de conhecimento que dará subsídios para as tomadas de decisão, relacionadas às questões de planejamento, preparação para risco de enchentes, além de oferecer apoio a novos eventos de inundação. No entanto, o AGORA vai além de sua premissa original, não só terá ferramentas de suporte a tomada de decisão, mas disponibilizar dados relevantes e padronizados a quem necessitar. 


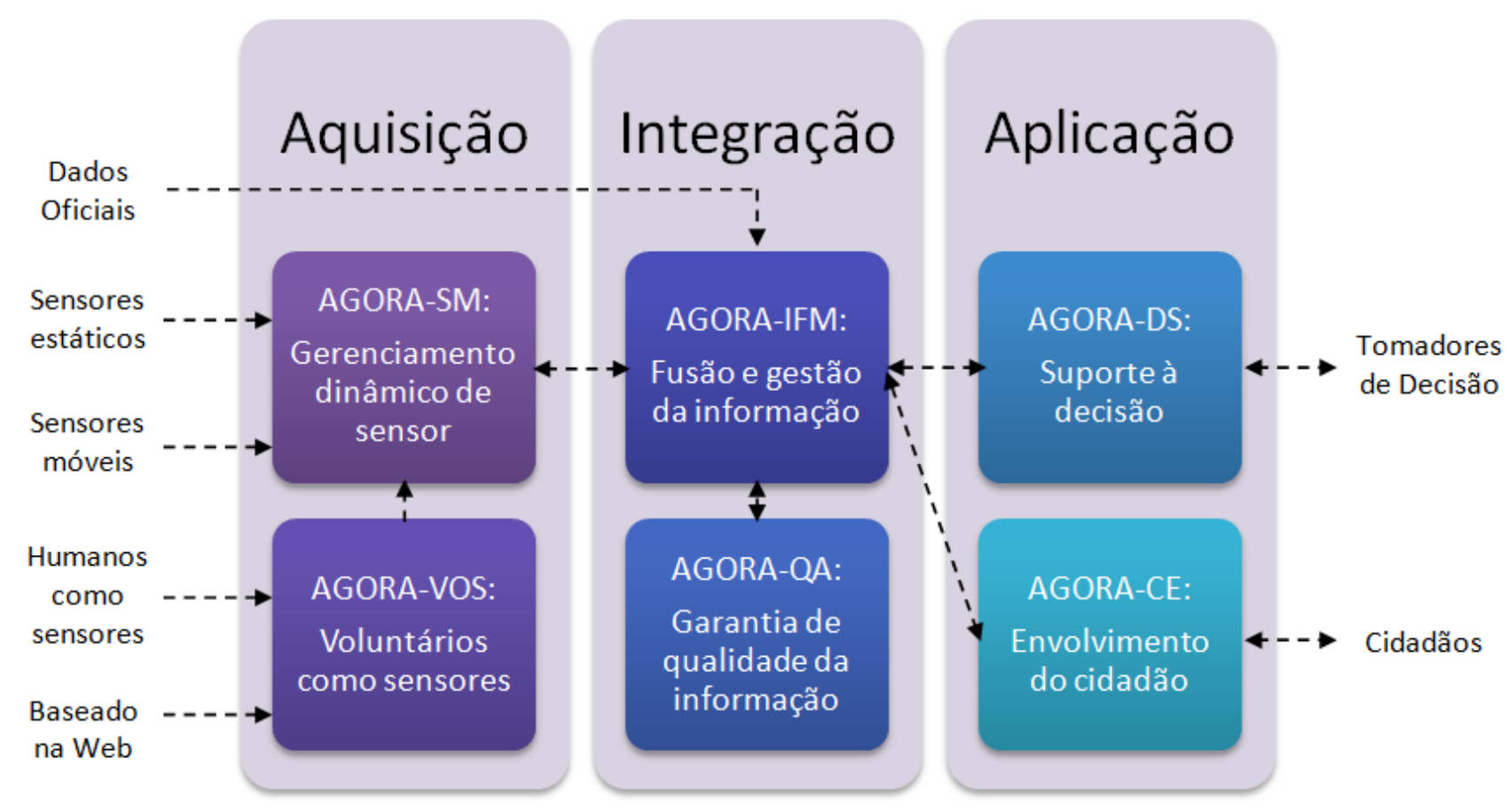

Figura 26 - Componentes da arquitetura do AGORA.

A Figura 26 mostra uma representação da arquitetura e onde cada componente relacionado ao projeto vai atuar. A princípio esta arquitetura é composta por três camadas:

1. Camada de Aquisição dos dados, composta por dois módulos principais:

- Agora-VOS: Volunteer As Sensor, que recebe os dados enviados pelos sensores baseados na web e humanos.

- Agora-SM: Dynamic Sensor Management, que recebe os dados enviados pelos sensores estáticos e móveis.

2. Camada de Integração dos dados, composta por dois módulos principais:

- Agora-IFM: Information Fusion and Management, responsável pela fusão dos dados recebidos da primeira camada e das bases de dados oficiais.

- Agora-QA: Information Quality Assurance, responsável pela avaliação e análise de confiança dos dados que vão ser integrados pelo módulo Agora-IFM.

3. Camada de Aplicação, composta por dois módulos principais:

- Agora-DS: Decision Support, responsável por fornecer ferramentas de suporte a tomada de decisão.

- Agora-CE: Citizen Engagement, responsável por coletar dados de redes sociais e enviar informativos/alertas à população. 
Entre as várias pesquisas relacionadas ao projeto AGORA e voltadas ao suporte à tomada de decisão, pode-se destacar o trabalho dos autores Rocha et al. (2014) que propõe um componente chamado AGORA-PL, baseado no conceito Linha de Produto de Software (LPS) com foco na LPS Orientada a Serviços (LPSOA), visto que, a integração dos dados no AGORA utiliza SOA e Web service. Esse componente é responsável por modelar as características comuns e variáveis de uma LPS, que servirá como modelo para geração de famílias de sistemas de apoio à decisão espacial (Spatial Decision Support Systems SDSS).

Outro trabalho importante é dos autores Horita et al. (2014) que apresentaram uma arquitetura chamada de AGORA-GeoDash, que possibilita trabalhar com dados em tempo real fornecidos por sensores sem fio, além de monitorar a situação de um rio em relação ao seu nível de água, por meios de um conjunto de indicadores de desempenho, os quais fornecem informações relevantes para a tomada de decisão no contexto da gestão dos riscos de inundações. Esta arquitetura é composta por três camadas: (i) das fontes de dados, (ii) de serviço e (iii) de visualização, sendo a integração entre elas realizada pela SOA, conforme ilustrado na Figura 27.

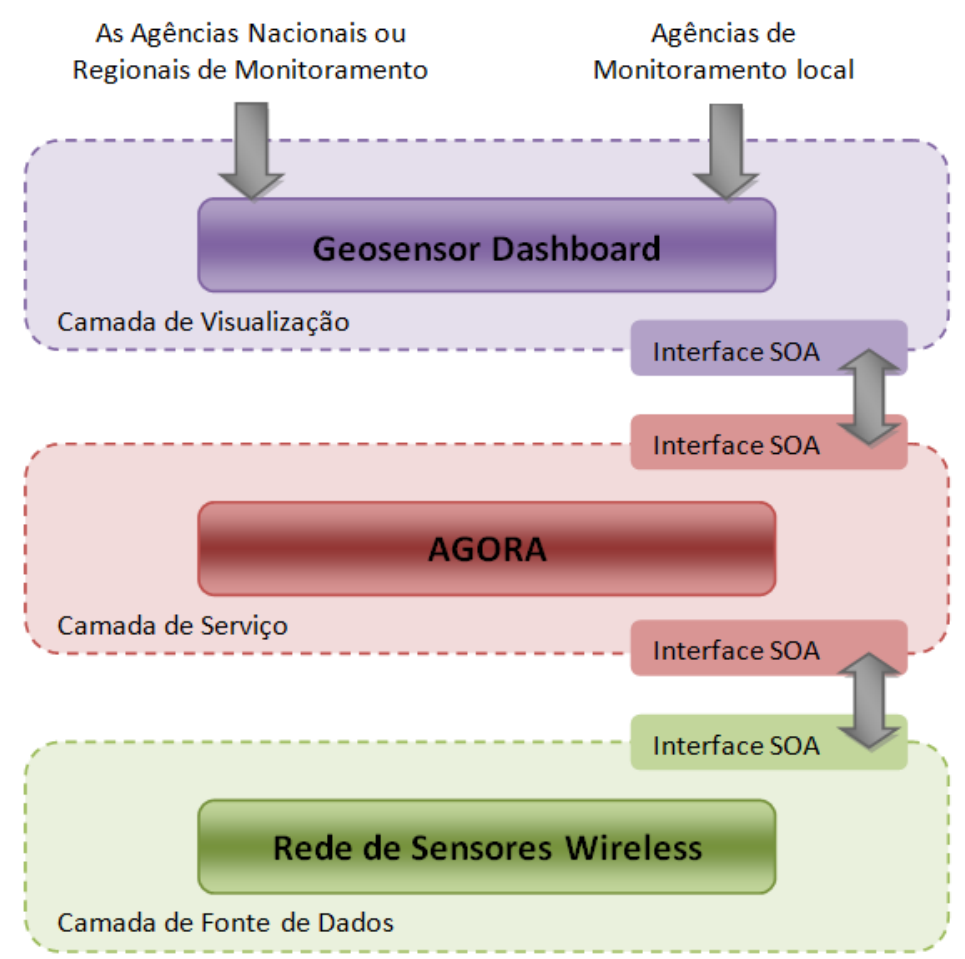

Figura 27 - Ilustração das camadas do AGORA-GeoDash, adaptado de (HORITA et al., 2014).

Com base na arquitetura e características do AGORA, o teste de aplicabilidade do questionário neste ambiente de pesquisa e desenvolvimento, será de grande importância, pois um dos propósitos deste trabalho é fornecer um guia para ser usado como metas a serem alcançadas durante o processo de desenvolvimento. Isto é, a cada questão classificada 
no sistema em desenvolvimento, significa uma meta alcançada e uma das expectativas dos tomadores de decisão atendida.

Outro fator pretendido ao desenvolver o sistema usando o guia é que, de forma direta ou indireta, os princípios dos atributos de testabilidade possam ser considerados no processo de desenvolvimento. Caso isto ocorra, o grau de testabilidade será maior, favorecendo a atividade de teste.

As Figuras 28 e 29 são resultados obtidos da aplicabilidade do questionário neste ambiente em desenvolvimento, o qual foi denominado como Sistema 5.

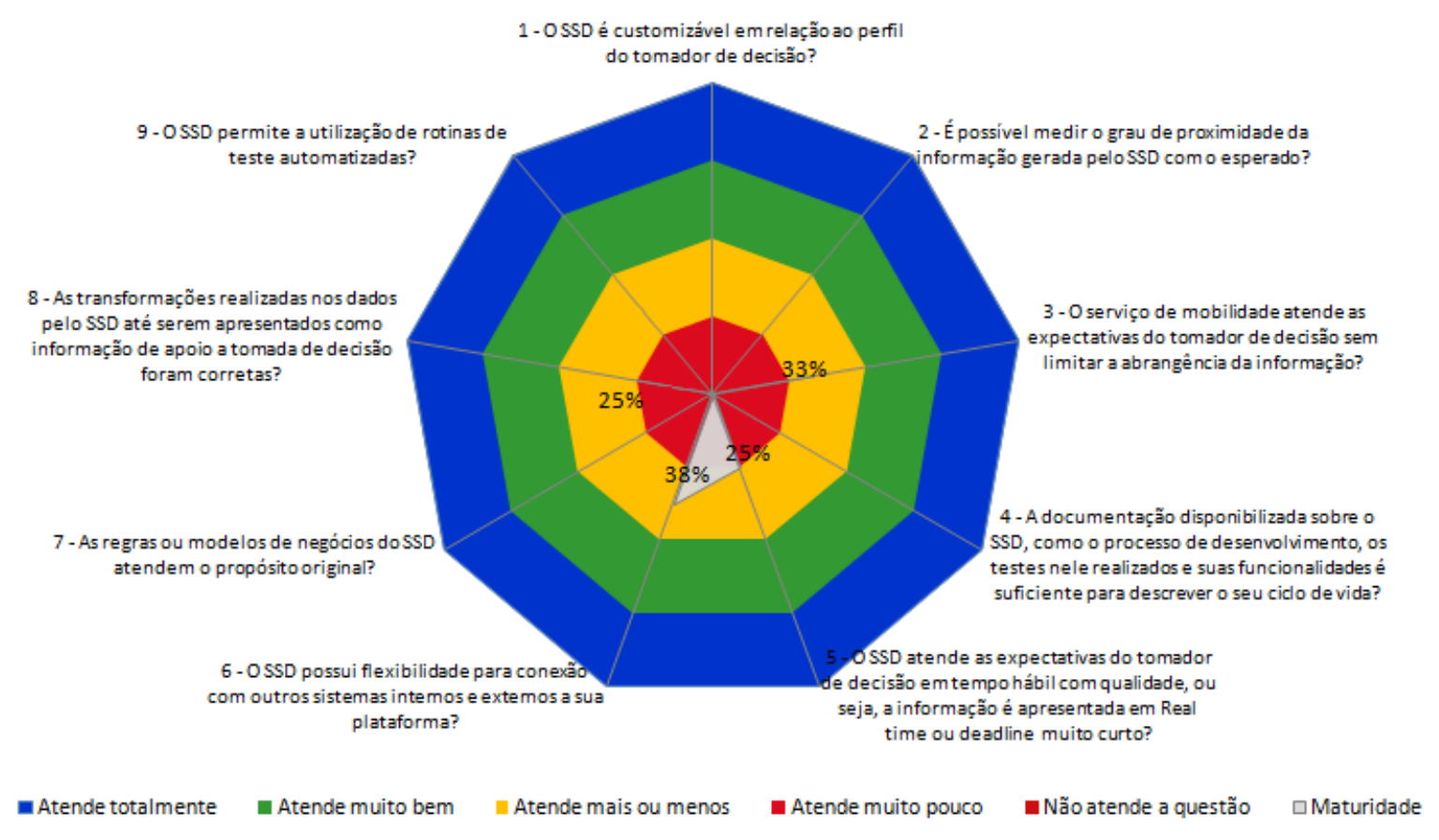

Figura 28 - Classificação por questão da primeira avaliação do sistema 5. 


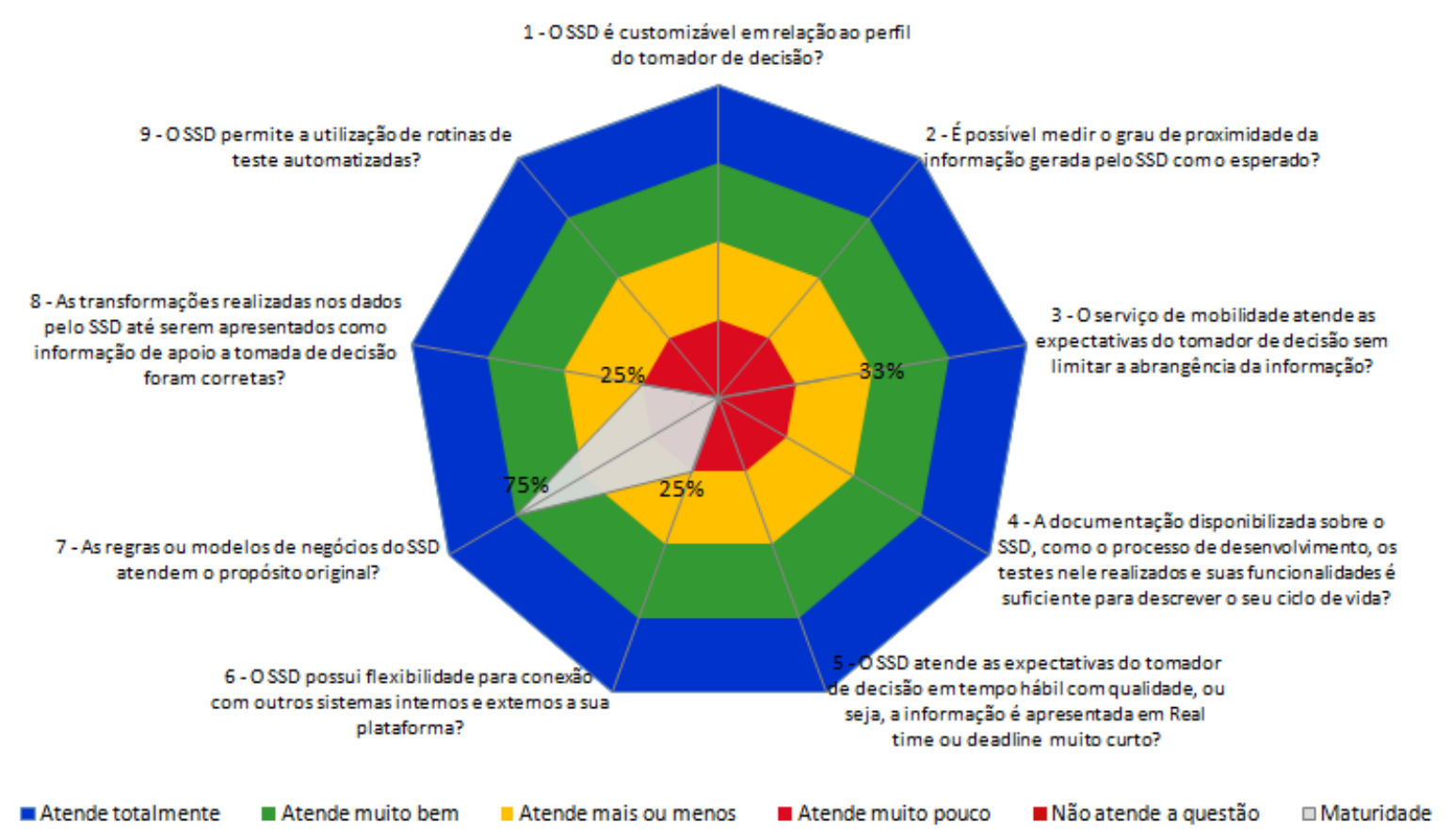

Figura 29 - Classificação por questão da segunda avaliação do sistema 5.

As poucas questões classificadas nos dois testes realizados pelos pesquisadores no Sistema 5, poderiam ser consideradas a primeira avaliação do sistema em desenvolvimento e, a cada evolução do sistema, seria aplicada outra avaliação. Desta forma, seria criado um mapa dos avanços no nível de maturidade do sistema até seu término.

\subsubsection{Resumo dos testes de aplicabilidade}

A Tabela 7 mostra o resumo de todas as avaliações realizadas pelos colaboradores em cada sistema. A tabela possui oito colunas, sendo as quatro primeiras dos sistemas totalmente voltados ao suporte à decisão. Nestas colunas, todas as questões receberam alguma classificação.

Um ponto interessante é que as questões 5, 6 e 7 tiveram classificações próximas entre os testes nos Sistema 1 e Sistema 2. Essas três questões analisadas em conjunto, têm como objetivo atender em tempo hábil as solicitações do tomador de decisão, com informações relevantes ao propósito original, geradas a partir de dados consistidos, independentemente da fonte ser interna ou externa.

As outras quatro colunas são os testes nos Sistemas 3, 4 e 5, as quais apresentam um panorama completamente diferente das outras, com várias questões zeradas, ou seja, sem classificação. Como já mencionado, os sistemas 3 e 4 agregam um pequeno módulo de suporte à decisão; talvez por isto, a maioria das questões não foi classificada.

O Sistema 5 encontra-se em desenvolvimento, o que explica as várias questões sem 
Tabela 7 - Classificação do nível de maturidade obtidos nos testes.

\begin{tabular}{|c|c|c|c|c|c|c|c|c|}
\hline \multirow{3}{*}{ Questão } & \multicolumn{8}{|c|}{ Nível de Maturidade em Percentual } \\
\hline & \multicolumn{3}{|c|}{ Sistema 1} & \multirow{2}{*}{$\begin{array}{l}\text { Sist. } 2 \\
\text { Teste } 1\end{array}$} & \multirow{2}{*}{$\begin{array}{l}\text { Sist. } 3 \\
\text { Teste } 1\end{array}$} & \multirow{2}{*}{$\begin{array}{l}\text { Sist. } 4 \\
\text { Teste } 1\end{array}$} & \multicolumn{2}{|c|}{ Sistema 5} \\
\hline & Teste 1 & Teste 2 & Teste 3 & & & & Teste 1 & Teste 2 \\
\hline 1 & 88 & 100 & 100 & 75 & 50 & 50 & 0 & 0 \\
\hline 2 & 75 & 92 & 75 & 58 & 0 & 0 & 0 & 0 \\
\hline 3 & 75 & 83 & 100 & 67 & 0 & 50 & 33 & 33 \\
\hline 4 & 86 & 89 & 79 & 57 & 0 & 46 & 0 & 0 \\
\hline 5 & 75 & 75 & 50 & 75 & 75 & 0 & 25 & 0 \\
\hline 6 & 88 & 88 & 88 & 50 & 0 & 0 & 38 & 25 \\
\hline 7 & 100 & 100 & 100 & 100 & 0 & 0 & 0 & 75 \\
\hline 8 & 50 & 75 & 75 & 25 & 50 & 0 & 25 & 25 \\
\hline 9 & 100 & 100 & 75 & 25 & 0 & 0 & 0 & 0 \\
\hline Total & 82 & 89 & 82 & 59 & 19 & 16 & 13 & 18 \\
\hline
\end{tabular}

classificação. Entretanto, possui um módulo com as funcionalidades de suporte à decisão bem definidas para atender o propósito do projeto.

A Figura 30 apresenta o nível de maturidade obtido com os testes realizados nos sistemas, conforme método definido na Subseção 3.6. O gráfico possui nove barras, sendo as oito primeiras o nível de maturidade obtido no teste em cada sistema e a última barra, a régua que determina se o nível alcançado no teste foi satisfatório.

Os três testes no Sistema 1 ocorreram em locais distintos e foram feitos por profissionais com visões diferentes sobre o mesmo sistema. Entretanto, o nível alcançado pelos três quase foram iguais, somente o segundo teste teve uma variação de $7 \%$. Isto significa que os colaboradores tiveram entendimento semelhante sobre o questionário, ou seja, as questões foram interpretadas da mesma forma. 


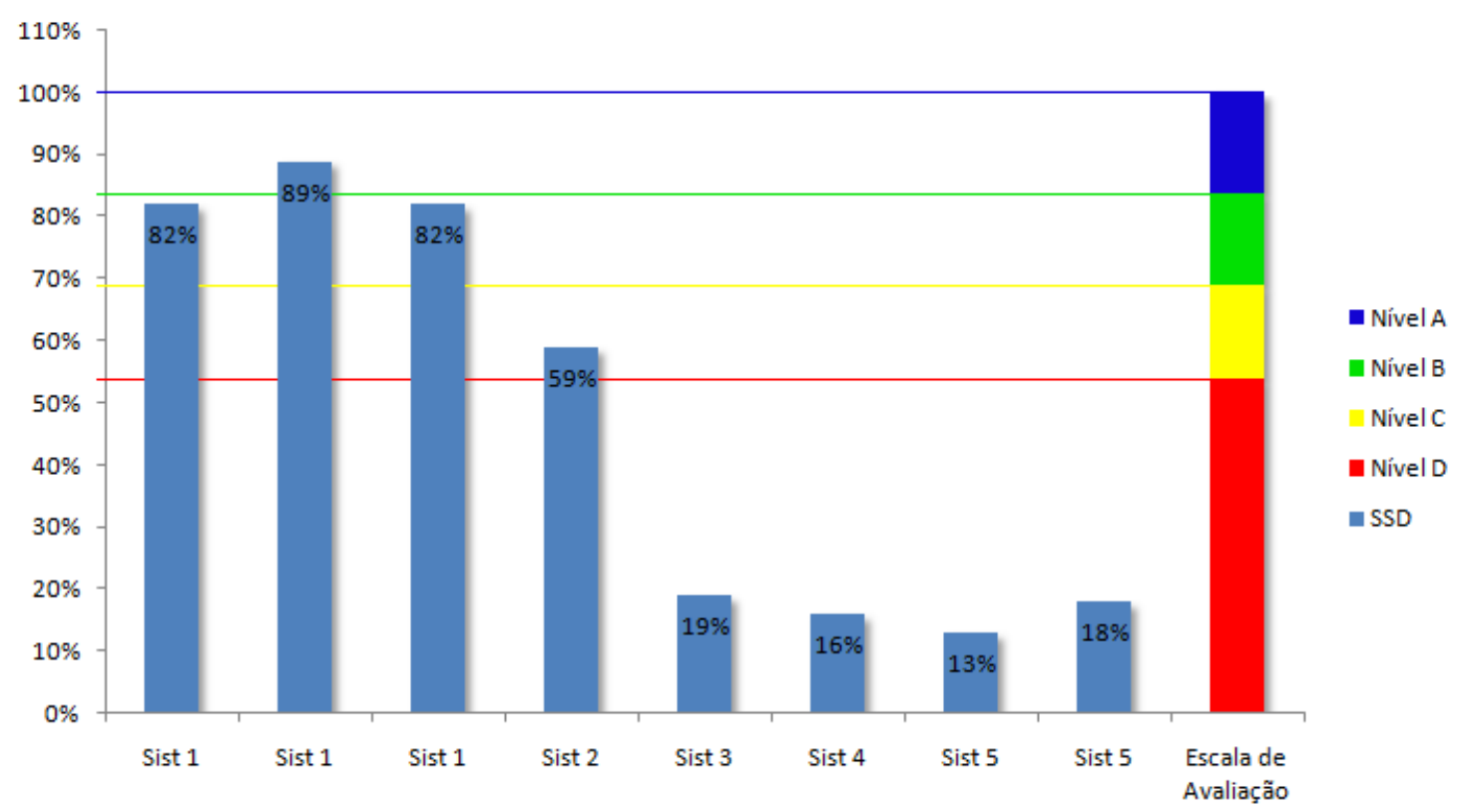

Figura 30 - Classificação geral obtidas nos testes.

Pressupondo um cenário de comparação entre os sistemas, para uma possível aquisição, o Sistema 1 foi o melhor avaliado, pois está posicionado na faixa verde da régua, que representa um nível de maturidade aceitável.

Os Sistemas 3, 4 e 5 estão posicionados na faixa vermelha, que representa uma área crítica, no que diz respeito às funcionalidades que atendem às expectativas do tomador de decisão. Já o sistema 2 está localizado em uma área de transição, na faixa amarela, que indica um sistema com capacidade de atender algumas necessidades do tomador de decisão.

\subsection{Considerações finais}

Apesar dos poucos testes de aplicabilidade realizados em SSD neste Capítulo, as particularidades de cada sistema e áreas distintas de atuação permitiram extrair várias conclusões sobre os testes, individualmente e agrupados pelo porte das empresas. No próximo Capítulo serão descritas estas conclusões e sobre a pesquisa desenvolvida neste trabalho, bem como os possíveis estudos que podem ser realizados a partir das contribuições desta dissertação. 

O desenvolvimento deste trabalho foi motivado pela importância dos SSDs nas organizações, os quais fornecem suporte aos tomadores de decisão para definirem as melhores estratégias de negócio frente ao dinamismo do mercado, e também pela complexidade que envolve o projeto de desenvolvimento, instalação e, principalmente, os testes de conformidade deste sistema com as especificações. Sendo assim, o objetivo desta pesquisa foi realizar o levantamento dos fatores ou atributos que possam elevar o grau de testabilidade do sistema e definir um método para mensurá-los, visando reduzir o tempo e os custos da atividade de teste, bem como elevar a qualidade do produto final.

Desta forma, as principais contribuições deste trabalho foram identificar fatores ou atributos relacionados à testabilidade; mostrar a relação direta ou indireta da qualidade da informação gerada na tomada de decisão e propor uma forma de analisar e avaliar o quanto o SSD está considerando os princípios destes fatores ou atributos em sua arquitetura.

Na revisão da literatura foram identificados vários trabalhos ao longo do tempo, os quais permitiram selecionar os principais fatores que podem influenciar o grau de testabilidade de um software. Os fatores selecionados foram compreensibilidade, observabilidade, rastreabilidade, controlabilidade e capacidade de suporte ao teste.

Para determinar um meio de avaliar e analisar os princípios destes fatores nos SSDs, o mapa elaborado a partir de vários estudos sobre qualidade da informação e o impacto na tomada de decisão foi fundamental, pois mostra como é importante a informação estar em conformidade com as especificações do sistema e estar atendendo às expectativas do cliente.

Com base nestes elementos foram realizados oito estudos de caso, com o propósito de testar a aplicabilidade do método de análise e avaliação, ou seja, do questionário. Os testes foram realizados em empresas de pequeno, médio e grande porte, bem como no meio acadêmico. 
Em relação aos testes de aplicabilidade do questionário, foi observado que os colaboradores que atuam como consultores nas empresas conseguiram extrair informações importantes das questões sem ficar em dúvida sobre seus propósitos. No entanto, o colaborador de nível técnico teve dificuldades em compreender os conceitos e objetivos de cada questão.

Por isso, recomenda-se que o questionário seja utilizado por pessoas que tenham conhecimento sobre SSD e dos conceitos básicos sobre teste de software. Assim, poderá diminuir as dúvidas que possam surgir durante a execução do questionário e consequentemente obter resultados mais próximos da realidade em que o SSD se encontra.

Para tornar o questionário mais compreensível a ponto de permitir que pessoas com o mínimo de conhecimento sobre o assunto possam utilizá-lo, seria necessário aumentar o número de subquestões, tornando-as mais diretas. A consequência desta mudança é o número elevado de questões que poderia inviabilizar sua aplicação.

Outro fato observado nos estudos de caso foi a especificidade das questões com o SSD. Para isso, foram analisados os testes realizados nas empresas de médio e grande porte, às quais utilizam sistemas totalmente voltados ao suporte à tomada de decisão e nas empresas de pequeno porte, que utilizam apenas alguns módulos de suporte à decisão.

Após análise destes testes, verificou-se que a maioria das questões só foi considerada nos sistemas totalmente voltados ao suporte à tomada de decisão. Já as questões consideradas em todos os sistemas, foram aquelas com características mais abrangentes no contexto de sistemas de informação. Este panorama é um forte indício de que o questionário é específico para SSD.

Por último, os testes realizados no meio acadêmico serviram para verificar a aplicabilidade do questionário em um projeto que está em desenvolvimento, pois um dos objetivos do questionário é servir como um guia, com metas a serem atendidas durante o projeto. No entanto, para testar se esse objetivo realmente eleva o grau de testabilidade do sistema, seria necessário desenvolver dois sistemas idênticos e utilizar o guia em um deles. Somente no término dos dois sistemas seria possível mensurar o grau de testabilidade dos dois e avaliar se o guia fez diferença.

Apesar dos poucos testes realizados, o questionário se comportou dentro do esperado nas diversas situações em que foi submetido. Desta forma, reforça-se a hipótese de que o questionário pode auxiliar na análise e avaliação de SSD.

\subsection{Dificuldades e Limitações}

As principais dificuldades e limitações que podem ameaçar a validade dos resultados obtidos neste trabalho são: 


\section{A falta de atributos ou fatores de testabilidade:}

Na pesquisa por estudos envolvendo testabilidade e principalmente seus atributos, não foi adotado nenhum fator limitante durante as buscas realizadas nas fontes de consulta. No entanto, apesar dos esforços para identificar o maior número de estudos, é possível não ter sido considerado algum trabalho relevante.

\section{Na extração das principais expectativas dos clientes em relação aos SSDs:}

O processo de extrair das licitações públicas algumas das principais exigências e expectativas dos clientes em relação aos SSDs não foi uma tarefa trivial, pois análise e a extração dos dados foram feitos manualmente. Dessa forma, uma vez que nem todas as informações eram óbvias sobre SSD, alguns dados tiveram que ser interpretados. A fim de assegurar a validade das questões elaboradas a partir das exigências e expectativas extraídas, foi elaborado um questionário para avaliar a qualidade destas questões, conforme o Apêndice C.

\section{No teste de aplicabilidade do questionário usado para avaliar o nível de ma- turidade do SSD:}

Importante destacar sobre os estudos de caso, a dificuldade em encontrar colaboradores com conhecimento e contato direto com SSDs, principalmente nas grandes empresas. Por conta disso, têm-se um número reduzido de testes, consequentemente, os resultados obtidos não têm realidade estatística. Mas, possibilitaram analisar e avaliar a aplicabilidade do questionário.

\subsection{Trabalhos Futuros}

Dentre as atividades que podem ser realizadas a partir deste trabalho, destacam-se:

- No desenvolvimento do questionário foi considerado apenas o atributo testabilidade do modelo de qualidade da (ISO/IEC 25010, 2010). Uma possível continuação deste trabalho seria elaborar novas questões envolvendo outros atributos do modelo, como: usabilidade, confiabilidade, reusabilidade, modificabilidade e outros. Isso tornaria o questionário mais completo a ponto de possibilitar seu uso como parâmetro no momento de desenvolver uma licitação pública ou um pedido de compra;

- Desenvolver um sistema informatizado com as questões, que permita aos avaliadores mais flexibilidade ao responder as subquestões; acesso ao histórico das avaliações, fornecer meios de análise e avaliação do SSD;

- Efetuar mais testes de aplicabilidade do questionário com o objetivo de validar a especificidade das questões com o SSD e analisar os resultados com o propósito de verificar se é necessária alguma melhoria; e 
- Com base na metodologia utilizada para desenvolver o questionário, método de análise e classificação do SSD, novos trabalhos podem ser desenvolvidos visando outros sistemas de software. Para tanto, seria necessário identificar as expectativas do cliente que são ligadas aos atributos de qualidade considerados no estudo. 
ADLA, A.; ZARATE, P. A cooperative intelligent decision support system. In: International Conference on Service Systems and Service Management (ICSSSM 2006). Troyes, France: IEEE, 2006. v. 1, p. 763-769. Citado 4 vezes nas páginas 17, 18, 28 e 29.

AIZENBUD-RESHEF, N.; NOLAN, B. T.; RUBIN, J.; SHAHAM-GAFNI, Y. Model traceability. IBM Systems Journal, v. 45, n. 3, p. 515-526, 2006. ISSN 0018-8670. Citado 2 vezes nas páginas 19 e 48 .

ARCHIBALD, R. D. Managing High-Technology Programs and Projects. 3. ed. Hoboken, NJ: John Wiley \& Sons, 2003. Citado 2 vezes nas páginas 18 e 31.

BASILI, V.; HEIDRICH, J.; LINDVALL, M.; MUNCH, J.; REGARDIE, M.; TRENDOWICZ, A. Gqm+ strategies - aligning business strategies with software measurement. In: International Symposium on Empirical Software Engineering and Measurement (ESEM 2007). Madrid, Spain: Journal of Empirical Software Engineering, 2007. v. 1, p. 488-490. Citado 3 vezes nas páginas 38, 56 e 92.

BASILI, V.; WEISS, D. A methodology for collecting valid software engineering data. IEEE Transactions on Software Engineering, SE-10, n. 6, p. 728-738, Nov 1984. Citado 3 vezes nas páginas 35, 36 e 37 .

BASILI, V. R. Software modeling and measurement: The Goal/Question/Metric paradigm. College Park, 1992. Citado na página 36.

BASILI, V. R.; CALDIERA, G.; ROMBACH, H. D. The goal question metric approach. In: Encyclopedia of Software Engineering. College Park, Maryland and Kaiserslautern, Germany: John Wiley, 1994. v. 2, p. 528-532. Citado na página 36.

BEAL, A. Gestão Estratégica da Informação: Como transformar a informação e a tecnologia da informação em fatores de crescimento e de alto desempenho nas organizações. São Paulo: Atlas, 2004. Citado na página 22.

BEHKAMAL, B.; KAHANI, M.; BAGHERI, E.; JEREMIC, Z. A metrics-driven approach for quality assessment of linked open data. Journal of Theoretical and Applied Electronic Commerce Research, Facultad de Ingeniería, Universidad de Talca, Talca, Chile, v. 9, n. 2, p. 64-79, May 2014. Citado na página 54.

BEUREN, I. M.; MARTINS, L. W. Sistema de informações executivas: Suas características e reflexões sobre sua aplicação no processo de gestão. Revista Contabilidade \& Finanças FIPECAFI - FEA - USP, v. 15, n. 26, p. 6 - 24, 2001. Citado 2 vezes nas páginas 18 e 28.

BINDER, R. V. Design for testability in object-oriented systems. Commun. ACM, ACM, New York, NY, USA, v. 37, n. 9, p. 87-101, Sep 1994. Citado 3 vezes nas páginas 19, 44 e 45. 
CARVALHO, B. S. Proposta de uma ferramenta de análise e avaliação das construtoras em relação ao uso da construção enxuta. Dissertação (Mestrado) - Universidade Federal do Paraná - UFPR, Dez 2008. Citado na página 60.

Chiavenato, I. Administração - Teoria, Processo e Prática. 4. ed. Rio de Janeiro: Editora Campus, 2006. Citado na página 22.

CNM. Confederação Nacional de Municípios - CNM. 2015. Online. Http://www.cidadecompras.com.br/1/Processos/. Citado na página 56.

DAVENPORT, T. H.; PRUSAK, L. Conhecimento empresarial. Rio de Janeiro: Campus, 1998. Citado na página 22.

DELAMARO, M. E.; MALDONADO, J. C.; JINO, M. Introdução ao Teste de Software. Rio de Janeiro: Elsevier, 2007. Citado 5 vezes nas páginas 19, 31, 32, 33 e 34.

ESTEndeR, A. C. O Novo Varejo São Paulo. 2005. Online. <http://www. institutosiegen.com.br/artigos/ARTIGO_ESTENDER01.pdf > - Acessado em 01/10/2015. Citado na página 17.

FRANKL, P. G.; WEYUKER, E. J. Testing software to detect and reduce risk. Jornal System Software, Elsevier Science Inc., New York, NY, USA, v. 53, n. 3, p. 275-286, set. 2000. Citado na página 33.

FREEDMAN, R. S. Testability of software components. IEEE Transactions on Software Engineering, IEEE Press, Piscataway, NJ, USA, v. 17, n. 6, p. 553-564, Jun 1991. Citado 6 vezes nas páginas 19, 34, 44, 46, 47 e 49.

GAO, J.; GUPTA, K.; GUPTA, h. Design for testability of software components. In: Proceedings of the 13th International Software/Internet Quality Week Conference (QW2000). San Francisco, California, USA: Software Research Institute (SR/Institute), 2000. Citado na página 47.

GAO, J. Z.; JACOB, T. H.-S.; WU, Y. Testing and Quality Assurance for Component-Based Software. Norwood, MA, USA: Artech House, Inc., 2003. Citado 6 vezes nas páginas 19, 47, 48, 49, 50 e 51.

GONCALVES, E. Quase metade do total de companhias em funcionamento do Brasil estão inadimplentes. 2015. Online. < http://veja.abril.com.br/noticia/economia/ com-a-crise-dispara-numero-de-empresas-caloteiras/> - Acessado em 01/10/2015. Citado na página 17.

GORLA, N.; SOMERS, T. M.; WONG, B. Organizational impact of system quality, information quality, and service quality. The Journal of Strategic Information Systems, v. 19, n. 3, p. 207-228, 2010. Citado 3 vezes nas páginas 51, 53 e 55.

GOTEL, O. C. Z.; FINKELSTEIN, A. C. W. An analysis of the requirements traceability problem. In: IEEE International Conference on Requirements Engineering (ICRE'94). Colorado Springs, CO, U.S.A.: IEEE, 1994. p. 94-101. Citado na página 48.

GUERRINI, F. M.; BELHOT, R. V. Modelagem da Produção - Modelos de referência, reflexões, técnicas e imlementações com TI. São Carlos: SEP-EESC-USP, 2008. Citado na página 28. 
GUPTA, S.; SINHA, M. Impact of software testability considerations on software development life cycle. In: First International Conference on Software Testing, Reliability and Quality Assurance (STRQA 1994). New Delhi, India: IEEE Comput. Soc. Press, 1994. p. 105-110. Citado 5 vezes nas páginas 34, 45, 46, 47 e 49.

HEIDRICH, J.; KOWALCZYK, M. Tutorial: Business it alignment using the gqm+strategies approach. In: DIESTE, O.; JEDLITSCHKA, A.; JURISTO, N. (Ed.). Product-Focused Software Process Improvement. Madrid, Spain: Springer Berlin Heidelberg, 2012, (Lecture Notes in Computer Science, v. 7343). p. 370-373. Citado 3 vezes nas páginas 38, 56 e 92 .

HOFACKER, A.; OLIVEIRA, B. F. d.; GEHBAUER, F.; FREITAS, M. C. D.; MENEZ JR., R.; SANTOS, A.; KIRSCH, J. Rapid Lean Construction-Quality Rating Model (LCR). In: TZORTZOPOUlOS, P.; KAGIOGLOU, M. (Ed.). 16th Annual Conference of the International Group for Lean Construction. Manchester, UK: IGLC.net, 2008. p. 241-250. Citado 2 vezes nas páginas 44 e 61.

HOFFMANN, A. W. Gestão do conhecimento: desafios de aprender. São Carlos: Compacta, 2009. Citado na página 22.

HORITA, F. E. A.; ALBUQUERQUE, J. P. An Approach to Support Decision-Making in Disaster Management based on Volunteer Geographic Information (VGI) and Spatial Decision Support Systems (SDSS). In: . Baden-Baden, Germany: 10th International Information Systems for Crisis Response and Management Conference (ISCRAM 2013), 2013. p. 301-306. Citado 2 vezes nas páginas 28 e 29.

HORITA, F. E. A.; FAVA, M. C.; MENDIONDO, E. M.; ROTAVA, J.; SOUZA, V. C.; UEYAMA, J.; ALBUQUERQUE, J. P. AGORA-GeoDash: A Geosensor Dashboard for Real-time Flood Risk Monitoring. In: 11th International Information Systems for Crisis Response and Management Conference (ISCRAM 2014). University Park - Pennsylvania, USA: The Pennsylvania State University, USA, 2014. p. 304-313. Citado 2 vezes nas páginas 11 e 73.

IEEE. Standard glossary of software engineering terminology. IEEE Std 610.12-1990, p. 1-84, 1990. Citado na página 31.

INDERAPERMANA, Y.; SUHARDI. Effect of information quality on decision performance at regency development priorities. In: International Conference on Rural Information \& Communication Technology and Electric-Vehicle Technology (rICT \& ICeV-T 2013). Bandung, Indonesia: IEEE, 2013. p. 1-6. Citado 3 vezes nas páginas 51, 53 e 55 .

ISHIKAWA, K. Introduction to Quality Control. 1. ed. Japan: JUSE Press Ltda., 1990. Citado na página 45.

ISO/IEC 25010. Systems and software engineering - Systems and software Quality Requirements and Evaluation (SQuaRE) - System and software quality models. Geneva, 2010. Citado 9 vezes nas páginas 18, 19, 21, 34, 35, 39, 44, 68 e 81.

ISO/IEC 9126-1. Software engineering - Product quality - Part 1: Quality model. Geneva, 2001. Citado na página 34. 
JARING, M.; KRIKHAAR, R.; BOSCH, J. Modeling variability and testability interaction in software product line engineering. In: Seventh International Conference on Composition-Based Software Systems (ICCBSS 2008). Madrid, Spain: IEEE, 2008. p. 120-129. Citado na página 34.

JHA, A. K.; MINER, T. W.; STANTON-GEDDES, Z. Building Urban Resilience: Principles, Tools, and Practice. NW, Washington: The Word Bank, 2013. Citado na página 30.

JIANJUN, L.; ZHISHU, L. Research on architecture of decision support system. In: 2nd IEEE International Conference on Computer Science and Information Technology (ICCSIT 2009). Beijing, China: IEEE, 2009. p. 199-202. Citado na página 29.

KAROUI, K.; GHEDAMSI, A.; DSSOULI, R. A study of some influencing factors in testability and diagnostics based on fsms. In: Proceedings IEEE International Symposium on Computers and Communications (ISCC 1999). Red Sea: IEEE, 1999. p. 109-115. Citado 2 vezes nas páginas 19 e 46.

KELly, G. C.; TANNER, M.; VALlELY, A.; CLEMENTS, A. Malaria elimination: moving forward with spatial decision support systems. Trends in Parasitology, v. 28, n. 7, p. 297 - 304, 2012. Citado 2 vezes nas páginas 18 e 30.

LAGARDE, C. Lagarde Calls for Policy Upgrade to Combat Uncertain Global Outlook. 2015. Online. <http://www.imf.org/external/pubs/ft/survey/so/2015/ NEW093015A.htm> - Acessado em 01/10/2015. Citado na página 17.

LAMBA, C. S. Testability models for structured programs. In: Second International Conference on Communication Software and Networks (ICCSN '10). Singapore: IEEE, 2010. p. 420-425. Citado na página 34.

LAUDON, K.; LAUDON, J. Sistemas de Informação Gerenciais. 9. ed. São Paulo: Pearson Prentice Hall, 2010. Citado 10 vezes nas páginas 18, 22, 23, 24, 25, 26, 27, 28, 30 e 31 .

LEE, S. H.; HAIDER, A. Identifying relationships of information quality dimensions. In: Technology Management in the IT-Driven Services (PICMET). San Jose, California, USA: PICMET, 2013. p. 1217-1228. Citado 4 vezes nas páginas 51, 53, 54 e 55 .

LI, M.; PENG, H. Research on building and management of model base of decision support system. In: Fifth World Congress on Intelligent Control and Automation (WCICA 2004). Hangzhou, China: IEEE, 2004. v. 3, p. 1895-1899. Citado 3 vezes nas páginas 18,28 e 29.

LIKERT, R. A technique for the measurement of attitudes. Archives of Psychology, v. 22, p. 1 - 55, 1932. Citado 3 vezes nas páginas 58, 59 e 92.

LIN, H. W.; NAGALINGAM, S. V.; KUIK, S. S.; MURATA, T. Design of a global decision support system for a manufacturing sme: Towards participating in collaborative manufacturing. International Journal of Production Economics, v. 136, n. 1, p. 1 12, 2012. Citado na página 29. 
LUO, F.; WANG, C.; XIAO, J.; GE, S.; YU, B.; WANG, J.; LI, Y.; WANG, S. A practical gis-based decision-making support system for urban distribution network expansion planning. In: International Conference on Sustainable Power Generation and Supply (SUPERGEN '09). Nanjing, China: IEEE, 2009. p. 1-6. Citado na página 29.

MYERS, G. J. A controlled experiment in program testing and code walkthroughs/inspections. Communications of the ACM, v. 21, n. 9, p. 760-768, 1978. Citado na página 31.

NAZIR, M.; KHAN, R. A. Software design testability factors: A new perspective. In: BHARTI VIDYA PEETH INSTITUTE OF COMPUTER APPLICATION AND MANAGEMENT. Proceedings, 3rd National Conference: INDIACom-2009. New Delhi, 2009. p. 26-27. Citado 4 vezes nas páginas 19, 34, 47 e 49.

NORRIS, F.; STEVENS, S.; PFEFFERBAUM, B.; WYCHE, K.; PFEFFERBAUM, R. Community resilience as a metaphor, theory, set of capacities, and strategy for disaster readiness. American Journal of Community Psychology, Springer US, v. 41, n. 1-2, p. 127-150, 2008. ISSN 0091-0562. Citado na página 71.

O'BRIEN, J. A. Sistemas de Informação e as Decisões Gerenciais na Era da Internet. 3. ed. São Paulo: Saraiva Ltda, 2011. Citado 2 vezes nas páginas 23 e 25.

OLIVEIRA, B. F.; FREITAS, M. C. D.; HOFACKER, A.; GHEBAUER, F.; JUNIOR, R. M. A model to evaluate the aplication degree of lean tools in contruction companys: The rapid lean contruction-quality rating model (lcr). Iberoamerican Journal of Industrial Engineering (IJIE), v. 2, p. 156 - 174, Dez 2010. Citado 3 vezes nas páginas 44, 60 e 62 .

OLIVEIRA, D. P. R. Sistemas De Informações Gerenciais: Estratégicas - Táticas - Operacionais. 14. ed. São Paulo: Editora Atlas S.A., 2011. Citado na página 27.

PARENTE, J. Varejo no Brasil: Gestão e Estratégia. 1. ed. São Paulo: Editora Atlas S.A., 2009. Citado na página 22.

PERRY, W. E. Effective Methods for Software Testing. 2. ed. Canadá: John Wiley \& Sons, Inc., 2000. Citado 2 vezes nas páginas 33 e 34.

PEZZè, M.; YOUNG, M. Teste e Análise de Software: processo, princípios e técnicas. Porto Alegre: Bookman, 2008. Citado 4 vezes nas páginas 18, 31, 33 e 34.

PRESSMAN, R. S. Software Engineering - A Practitioner's Approach. 7. ed. São Paulo: McGraw-Hill, 2010. Citado 5 vezes nas páginas 21, 31, 33, 34 e 48.

RCC. RCC Licitações Públicas. 2015. Online. Http://www.rcc.com.br/. Citado na página 56.

REZENDE, D. A.; ABREU, A. F. Tecnologia da Informação - Aplicada a Sistemas de Informação Empresariais. 3. ed. São Paulo: Editora Atlas S.A., 2003. Citado 4 vezes nas páginas 24, 26, 27 e 28.

REZENDE, S. O. Sistemas Inteligentes - Fundamentos e Aplicações. Barueri, SP: Editora Manole Ltda., 2003. Citado na página 22. 
ROCHA, R. d. S.; DEGROSSI, L. C.; HORITA, F. E. A.; ALBUQUERQUE, J. P. Agora-pl: Uma proposta para desenvolvimento de famílias de sistemas colaborativos baseados em vgi para a gestão do risco de inundação. In: Brazilian Symposium on Collaborative Systems. Curitiba, Brazil: Journal of Information and Data Management (JIDM), 2014. Citado na página 73.

RUIZ, M.; ROMERO, E.; PéREZ, M.; FERNáNDEZ, I. Development and application of a multi-criteria spatial decision support system for planning sustainable industrial areas in northern spain. Automation in Construction, v. 22, n. 0, p. 320 - 333, 2012. Citado 2 vezes nas páginas 18 e 30 .

SALMELA, H. From information systems quality to sustainable business quality. Information and Software Technology, v. 39, n. 12, p. 819 - 825, 1997. Information System Quality. Citado na página 51.

SALVADOR, V. F. M.; BRITTO, M.; MOURA, L. A.; A., J. J. R. Qualidade de Dados para Gestão de Conhecimento na Área de Saúde. 2013. Online. < http: //www.sbis.org.br/cbis/arquivos/758.pdf> - Acessado em 28/12/2013. Citado na página 24.

SANTOS, L.; COUTINHO-RODRIGUES, J. a.; ANTUNES, C. H. A web spatial decision support system for vehicle routing using google maps. Decis. Support Syst., Elsevier Science Publishers B. V., Amsterdam, The Netherlands, The Netherlands, v. 51, n. 1, p. 1-9, abr. 2011. Citado 2 vezes nas páginas 18 e 30.

SEBRAE. Critérios de classificação de empresas: MEI - ME - EPP. 2015. Online. <http://www.sebrae-sc.com.br/leis/default.asp?vcdtexto=4154> - Acessado em 17/08/2015. Citado na página 64.

SOLINGEN, R. v.; BERGHOUT, E. The Goal/Question/Metric Method: a practical quide for quality improvement of software development. London: McGraw-Hill, 1999. Citado 2 vezes nas páginas 35 e 36.

SOLINGEN, R. van; BASILI, V.; CALDIERA, G.; ROMBACH, H. D. Goal question metric (gqm) approach. Encyclopedia of Software Engineering, John Wiley \& Sons, Inc., Jan 2002. Citado na página 35.

SOMMERVILLE, I. Engenharia de Software. 9. ed. São Paulo: Pearson Prentice Hall, 2011. Citado 4 vezes nas páginas 18, 22, 31 e 33.

STAIR, R. M.; REYNOLDS, G. W. Princípios de Sistemas de Informação. 9. ed. São Paulo: Cengage Learning, 2011. Citado 9 vezes nas páginas 18, 22, 23, 24, 25, 26, 28, 29 e 30.

TAO, T.; HUIFENG, X. Architecture of an integrated environmental and resources legislation decision support system. In: 2nd Conference on Environmental Science and Information Application Technology (ESIAT). Wuhan, China: IEEE, 2010. v. 3, p. 43-46. Citado 2 vezes nas páginas 28 e 29.

TAYI, G. K.; BALlOU, D. P. Examining data quality. Commun. ACM, ACM, New York, NY, USA, v. 41, n. 2, p. 54-57, fev. 1998. Citado na página 24. 
TURBAN, E. Decision support and expert systems: management support systems. 4. ed. NJ, USA: Prentice Hall, 1995. Citado 2 vezes nas páginas 18 e 28.

VIEIRA, L. C.; SOUZA, L. O. D.; AMARAL, M. T. Application of the rapid lean construction-quality rating model to engineering companies. In: TOMMELEIN, I. D.; PASQUIRE, C. L. (Ed.). 20th Annual Conference of the International Group for Lean Construction. San Diego, USA: iglc.net, 2012. p. 18 - 20. Disponível em: <http://www.iglc.net/papers/details/859>. Citado 2 vezes nas páginas 44 e 60.

VIEIRA, S. Como Elaborar Questionários. 1. ed. São Paulo: Editora Atlas S.A., 2009. Citado na página 42.

VOAS, J.; MILLER, K. Software testability: the new verification. Software, IEEE, v. 12, n. 3, p. 17-28, 1995. Citado 3 vezes nas páginas 19, 34 e 46.

WANG, R. Y.; STRONG, D. M. Beyond accuracy: What data quality means to data consumers. J. Manage. Inf. Syst., M. E. Sharpe, Inc., Armonk, NY, USA, v. 12, n. 4, p. 5-33, mar 1996. Citado na página 51.

ZHAO, L. A new approach for software testability analysis. In: Proceedings of the 28th international conference on Software engineering. New York, NY, USA: ACM, 2006. (ICSE '06), p. 985-988. Citado na página 34.

ZHENGLI, L.; XIAOFENG, J. The architecture design of decision support system generator based on component technology. In: International Conference on E-Business and E-Government (ICEE 2011). Shanghai, China: IEEE, 2011. p. 1-4. Citado 2 vezes nas páginas 28 e 29. 

APÊNDICE

\section{A}

\section{QUESTIONÁRIO PARA AVALIAR O NÍVEL \\ DE MATURIDADE DO SSD}

O objetivo deste questionário é servir como um protocolo para avaliar o nível de maturidade do Sistema de Suporte a Decisão (SSD) em relação às expectativas do cliente ou como metas a serem alcançadas durante o processo de desenvolvimento de um SSD.

Os Sistemas de Suporte à Decisão (SSD) são considerados os de maior hierarquia entre os sistemas de informação. Foram projetados a partir da combinação entre os Sistemas de informações Executivas e os Sistemas de Apoio à Decisão, para dar suporte na solução de problemas mal estruturados ou sem nenhuma estruturação previamente conhecida, os quais necessitam da intuição e experiência do tomador de decisão para identificar qual solução é a mais apropriada.

A interação entre o SSD e o tomador de decisão, normalmente ocorre por ferramentas que permitem ao tomador adequar as saídas conforme suas necessidades e oferece recursos para analisar fatos não previsíveis à organização. Entre essas ferramentas temos: as de simulação, gerador de relatórios e gráficos. 


\section{Informações básicas sobre o sistema a ser avaliado}

1. Qual o nome do sistema?

2. Escreva uma breve descrição sobre o sistema a ser avaliado.

3. O sistema possui algum site, o qual, pode-se obter mais informações sobre ele? Qual é o link?

Instruções: O questionário é composto por uma pergunta principal com certo nível de abstração, ou seja, em uma linguagem mais voltada ao cliente. Para responder esta questão principal foram elaboradas subquestões mais técnicas, conforme os modelos apresentados pelos autores (BASILI et al., 2007; HEIDRICH; KOWALCZYK, 2012). A fim de oferecer flexibilidade ao participante, as respostas destas questões, estão organizadas de forma escalar com cinco alternativas, conhecidas como itens de Likert (LIKERT, 1932). 
Para responder as questões o participante deve assinalar apenas uma das alternativas, e para isto, deve considerar as seguintes declarações para cada opção de resposta:

0 Não atende a questão

1 Atende muito pouco

2 Atende mais ou menos

3 Atende muito bem

4 Atende totalmente a questão

Questionário para avaliação do nível de maturidade do SSD.

\begin{tabular}{|l|l|l|}
\hline Questão 1 & $\begin{array}{l}\text { O SSD é customizável em relação ao perfil do tomador de } \\
\text { decisão? }\end{array}$ & Nível de Maturidade \\
\hline
\end{tabular}

1.1 É possível desabilitar ou habilitar módulos do SSD?

\begin{tabular}{ll|l|l|l}
0 & 1 & 2 & 3 & 4
\end{tabular}

Nota Explicativa: Deve-se verificar se os recursos disponibilizados pelo SSD são dinamicamente ajustáveis conforme o usuário, exemplo: a mesma informação visualizada na forma de gráfico pela gerência, pode ser analisada na forma de tabela pela contabilidade.

1.2 A informação que foi adequada pela customização permanece sem distorção?

\begin{tabular}{lllll|l}
0 & 1 & 2 & 3 & 4
\end{tabular}

Nota Explicativa: Deve-se verificar se informações apresentadas em mais de um formato ou dispositivos diferentes permanecem sem alterações sintáticas ou semânticas.

\begin{tabular}{|l|l|c|}
\hline Questão 2 & $\begin{array}{l}\text { É possível medir o grau de proximidade da informação } \\
\text { gerada pelo SSD com o esperado? }\end{array}$ & Nível de Maturidade
\end{tabular}

2.1 O SSD possui ferramentas com capacidade de controlar o estado atual dos módulos envolvidos na geração da informação? 
Nota Explicativa: Deve-se verificar se o SSD permite parar a execução de um módulo ou reiniciá-lo, bem como, visualizar seu estado atual.

2.2 O SSD disponibiliza ferramenta que permita testar e observar individualmente cada um dos módulos envolvidos na \begin{tabular}{l|l|l|l|l|l}
0 & 1 & 2 & 3 & 4
\end{tabular} geração da informação previamente solicitada pelo tomador de decisão?

Nota Explicativa: Deve-se verificar se o SSD disponibiliza algum tipo de artefato que possibilite observar as entradas e saídas de cada módulo.

2.3 O SSD disponibiliza documentação sobre os requisitos funcionais e estrutura dos módulos envolvidos na geração $\begin{array}{llllll}0 & 1 & 2 & 3 & 4\end{array}$ da informação?

Nota Explicativa: Deve-se verificar se o SSD disponibiliza documentação sobre seus módulos e as funcionalidades de cada um.

\begin{tabular}{|l|l|c|}
\hline Questão 3 & $\begin{array}{l}\text { O serviço de mobilidade atende as expectativas do tomador } \\
\text { de decisão sem limitar a abrangência da informação? }\end{array}$ & Nível de Maturidade \\
\hline
\end{tabular}

3.1 O nível de detalhamento da informação é suficiente para o

\begin{tabular}{ll|l|l|l|l}
0 & 1 & 2 & 3 & 4
\end{tabular}
fácil entendimento por parte do tomador de decisão?

Nota Explicativa: Deve-se verificar se informações apresentadas em mais de um formato ou dispositivos diferentes, são suficientes, em termos de profundidade e abrangência para o objetivo em questão.

3.2 O serviço de mobilidade oferece segurança de acesso ao SSD, bem como das informações solicitadas, tudo isto, \begin{tabular}{ll|l|l|l|}
0 & 1 & 2 & 3 & 4
\end{tabular} independente da forma de acesso ou dispositivo?

Nota Explicativa: Deve-se verificar se o SSD tem módulos para controle de acesso ao sistema e do nível de detalhamento da informação, conforme o perfil do usuário. Tudo isto, nativo no próprio sistema, ou seja, independente do dispositivo utilizado para o acesso. 
3.3 A informação gerada pelo SSD está em conformidade com as especificações documentadas no projeto e livre de ambi\begin{tabular}{lllll|l}
0 & 1 & 2 & 3 & 4
\end{tabular} guidade?

Nota Explicativa: Deve-se verificar se o SSD disponibiliza documentação sobre as suas funcionalidades e comparar com o apresentado pelo SSD.

\begin{tabular}{|l|l|c|}
\hline Questão 4 & $\begin{array}{l}\text { A documentação disponibilizada sobre o SSD, como o } \\
\text { processo de desenvolvimento, os testes nele realizados e } \\
\text { suas funcionalidades é suficiente para descrever o seu ciclo } \\
\text { de vida? }\end{array}$ & Nível de Maturidade \\
\hline
\end{tabular}

4.1 A gestão da documentação do SSD é integrada a ponto de permitir visualizar seu histórico de manutenção, bem como, os módulos afetados por ela?

Nota Explicativa: Deve-se verificar se o SSD possui algum artefato que disponibiliza as ocorrências de manutenção, devidamente estruturadas com as informações do motivo da intervenção, módulos afetados e a alteração realizada.

4.2 O SSD oferece suporte para garantir a padronização da documentação, com modelos de documentos específicos para \begin{tabular}{ll|l|l|l|l}
0 & 1 & 2 & 3 & 4
\end{tabular} cada especialidade ou chamadas de manutenção, considerando os padrões definidos pela contratante ou contratada?

Nota Explicativa: Deve-se verificar se o SSD disponibiliza a gestão de chamadas de suporte, de forma a garantir o controle das ocorrências dentro do padrão previamente definido.

4.3 A documentação disponibilizada pelo SSD é de forma organizada, com índice, busca por assunto ou pela natureza do documento, por exemplo: modelos de negócio?

Nota Explicativa: Deve-se verificar se o SSD disponibiliza a sua documentação de forma organizada e com opções de classificação e busca por assunto.

4.4 A documentação do SSD descreve os modelos de negócio graficamente e textualmente? 
Nota Explicativa: Deve-se verificar se os modelos de negócio são apresentados graficamente, com detalhes dos pontos (nós) de processamento e suas respectivas entradas e saídas, bem como, explicados textualmente na documentação disponibilizada.

4.5 Os elementos tecnológicos necessários nos modelos de negócio são informados na documentação do SSD?

\section{$\begin{array}{llllll}0 & 1 & 2 & 3 & 4\end{array}$}

gócio são informados na dochmentac̃o do SSD?

Nota Explicativa: Deve-se verificar se há modelos de negócio que são dependentes de dispositivos tecnológicos fora da sua plataforma, e se os mesmos estão detalhados na documentação, juntamente com o grau de inferência no respectivo modelo.

4.6 O SSD disponibiliza tutoriais de treinamentos, guias com passo a passo para cada modelo de negócio e suporte \begin{tabular}{ll|l|l|l|}
0 & 1 & 2 & 3 & 4
\end{tabular} on-line?

Nota Explicativa: Deve-se verificar se o SSD possui algum canal de treinamento ou orientações sobre as suas funcionalidades, de forma que o usuário tenha o mínimo de conhecimento para utilizar seus recursos.

O SSD possui documentação complementar sobre a plataforma que utiliza (servidores, banco de dados, versões dos produtos e componentes de software de terceiros)?

Nota Explicativa: Deve-se verificar se na documentação do SSD está informando quais são os requisitos mínimos necessários para seu funcionamento e se existe a dependência de algum artefato fornecido por terceiros, ou seja, outra empresa.

\begin{tabular}{|l|l|l|}
\hline Questão 5 & $\begin{array}{l}\text { O SSD atende as expectativas do tomador de decisão } \\
\text { em tempo hábil com qualidade, ou seja, a informação é } \\
\text { apresentada em "Real time" ou "deadline" muito curto? }\end{array}$ & Nível de Maturidade \\
\hline
\end{tabular}

5.1 O tempo de resposta do SSD, após a solicitação do tomador de decisão, está dentro da faixa de tempo previamente especificada na documentação como aceitável? 
Nota Explicativa: Deve-se verificar se está documentado o tempo aproximado de resposta do SSD diante uma solicitação, ou seja, o intervalo entre a solicitação do usuário e saída do resultado, por exemplo: relatórios, consultas, simulações e outros que envolvem certa demanda de processamento.

\begin{tabular}{|l|c|c|}
\hline Questão 6 & $\begin{array}{c}\text { O SSD possui flexibilidade para conexão ou integração } \\
\text { com outros sistemas internos e externos a sua plataforma? }\end{array}$ & Nível de Maturidade \\
\hline
\end{tabular}

6.1 O serviço de conexão com outros sistemas é nativa no SSD e está documentada sua estrutura e procedimentos de como estabelecer a conexão entre os sistemas?

Nota Explicativa: Deve-se verificar se o SSD possui módulo para gestão da conexão com outros sistemas, tanto internos quanto externos a sua plataforma e se possui documentado como realizar esta integração.

6.2 A gestão da conexão com outro sistema é integrada, a ponto de permitir a consistência nas trocas de dados, observar o \begin{tabular}{lll|l|l|}
0 & 1 & 2 & 3 & 4
\end{tabular} tempo das transações e analisar o histórico delas?

Nota Explicativa: Deve-se verificar se o SSD possui formas de realizar a consistência dos dados ou informações compartilhadas entre os sistemas, a fim de bloquear pacotes com dados ou informações "quebradas" que possam levar o SSD a uma falha ou mesmo fornecer uma saída errada.

\section{Questão 7 As regras ou modelos de negócios do SSD atendem o propósito original?}

Nível de Maturidade

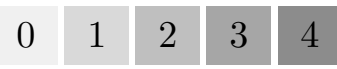

7.1 O comportamento do SSD diante de uma situação, ou seja, uma entrada, está em conformidade com o modelo de negócio mapeado na documentação?

Nota Explicativa: Considerando o fluxo do modelo de negócio previamente documentado, deve-se verificar se ao solicitar esta regra o SSD vai apresentar a saída conforme informada no modelo, por exemplo: ao solicitar um resumo das vendas no mês por vendedor, o SSD deve apresentar uma saída agrupada por vendedor e com a somatória do valor de suas vendas. 


\begin{tabular}{|l|l|c|}
\hline Questão 8 & $\begin{array}{l}\text { As transformações realizadas nos dados pelo SSD até se- } \\
\text { rem apresentados como informação de apoio a tomada de } \\
\text { decisão foram corretas? }\end{array}$ & Nível de Maturidade \\
\hline
\end{tabular}

8.1 O SSD possui artefato que permite mapear e visualizar todos os possíveis caminhos percorridos pelos dados entre os pontos de processamento (nós) do modelo de negócio e suas transformações desde a sua origem?

Nota Explicativa: Deve-se verificar se o SSD possui modos de visualizar o caminho dos dados desde a sua origem até a saída, bem como o ponto de processamento e a regra ou condição aplicada naquele ponto.

\begin{tabular}{|l|l|c|}
\hline Questão 9 & $\begin{array}{l}\text { O SSD permite a utilização de rotinas de teste automati- } \\
\text { zadas? }\end{array}$ & Nível de Maturidade \\
\hline
\end{tabular}

9.1 O SSD possui alguma ferramenta que disponibilize formas de gerenciar as rotinas de teste?

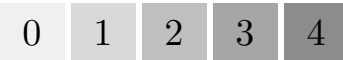

Nota Explicativa: Gerenciar rotinas de teste fica compreendido como: permitir editar rotinas de teste, agendar o início das rotinas, mapear os pontos de processamento (entrada/saída) e visualizar os resultados. 
APÊNDICE

B

\section{QUESTIONÁRIO PARA DEFINIR O PERFIL DO PARTICIPANTE}

\section{Questionário do Perfil do Participante}

"Validação experimental de uma abordagem baseada em questionário para avaliar Sistemas de Suporte a Decisão em relação as expectativas do cliente e seu grau de testabilidade"

Nas perguntas a seguir, marque com um $\mathrm{X}$ a alternativa que mais se aplica ao seu caso.

1. Qual o seu nível de formação?

Ensino Médio

Ensino Médio Técnico

Universitário

Pós-Graduação

2. Qual a sua profissão?

Analista de Sistema

Desenvolvedor de Software

Consultor na área de Informática

Outra - Qual: 


\section{Em qual setor atua?}

$\begin{array}{lll}{[} & ] & \text { Acadêmico } \\ {[} & ] & \text { Industrial } \\ {[} & ] & \text { Atacado e Varejo } \\ {[} & ] & \text { Outro - Qual: }\end{array}$

4. Quanto tempo possui de experiência na área em que atua?

[ ] Menos de 1 ano

[ ] Entre 1 e 2 anos

[ ] Entre 2 e 4 anos

[ ] Acima de 4 anos - Quantos: 
APÊNDICE

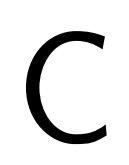

\section{QUESTIONÁRIO PARA AVALIAR A QUALIDADE DO QUESTIONÁRIO DO NÍVEL DE MATURIDADE DO SSD}

O questionário tem por objetivo obter as impressões do participante em relação a qualidade do questionário utilizado para avaliar o nível de maturidade do SSD, anteriormente aplicado.

Instruções: Este questionário é composto por cinco colunas, sendo a primeira delas preenchida com o número das questões do questionário principal e as outras quatro colunas são referentes a qualidade. Para cada uma das questões foi destinado um espaço para sugestões.

A fim de oferecer flexibilidade ao participante, as respostas destas questões estão organizadas de forma escalar com cinco alternativas em cada coluna, conhecidas como itens de Likert. Para responder às questões, o participante deve assinalar apenas uma das alternativas em cada coluna e para isto, deve considerar as seguintes declarações para cada opção de resposta em cada coluna:

A questão é de Fácil Entendimento e livre de ambiguidade?

0 Não é fácil de entender

1 Muito pouco

2 Razoável

3 Muito bom

4 Ótimo 
A Nota Explicativa foi útil para esclarecer dúvidas sobre a questão?
0 Não foi útil
1 Muito pouco útil
2 Razoável
3 Muito útil
4 Totalmente útil

A questão é Importante no contexto de Sistemas de Suporte a Decisão e para atender as expectativas do cliente?
0 Sem importância
1 De pouca importância
2 Mais ou menos importante
3 Importante
4 Muito importante

A questão é Objetiva quanto ao seu propósito?
0 Não é objetiva
1 Muito pouca objetiva
2 Mais ou menos objetiva
3 Muito objetiva
4 Totalmente objetiva

Questionário para avaliar a qualidade das questões aplicadas.

\begin{tabular}{|c|c|c|c|c|c|c|c|c|c|c|c|c|c|c|c|c|c|c|c|c|}
\hline Questão & $\begin{array}{l}\text { Fác } \\
\text { Ent }\end{array}$ & $\begin{array}{l}\text { il } \\
\text { end }\end{array}$ & ime & & & $\begin{array}{l}\text { Not } \\
\text { foi }\end{array}$ & $\begin{array}{l}\mathrm{a} \mathrm{E} \\
\text { átil }\end{array}$ & $\mathrm{xpli}$ & cat & & $\begin{array}{l}\text { Imp } \\
\text { o co }\end{array}$ & $\begin{array}{l}\text { ort } \\
\text { nte }\end{array}$ & $\begin{array}{l}\text { ante } \\
\text { xto }\end{array}$ & $\mathrm{pa}$ & & & Obje & tiv & dac & \\
\hline \multirow{2}{*}{1} & 0 & 1 & 2 & 3 & 4 & 0 & 1 & 2 & 3 & 4 & 0 & 1 & 2 & 3 & 4 & 0 & 1 & 2 & 3 & 4 \\
\hline & \multicolumn{20}{|c|}{ Sugestão: } \\
\hline
\end{tabular}




\begin{tabular}{|c|c|c|c|c|c|c|c|c|c|c|c|c|c|c|c|c|c|c|c|c|}
\hline Questão & $\begin{array}{l}\text { Fá } \\
\text { En }\end{array}$ & enc & $\mathrm{im}$ & nto & & $\begin{array}{l}\text { Not } \\
\text { foi }\end{array}$ & & $\mathrm{xpl}$ & cat & & & nte & $\begin{array}{l}\text { ante } \\
\text { xto }\end{array}$ & $\mathrm{pat}$ & & & Obje & tiv & dac & \\
\hline \multirow{3}{*}{1.1} & 0 & 1 & 2 & 3 & 4 & 0 & 1 & 2 & 3 & 4 & 0 & 1 & 2 & 3 & 4 & 0 & 1 & 2 & 3 & 4 \\
\hline & Suge & tã & & & & & & & & & & & & & & & & & & \\
\hline & 0 & 1 & 2 & 3 & 4 & 0 & 1 & 2 & 3 & 4 & 0 & 1 & 2 & 3 & 4 & 0 & 1 & 2 & 3 & 4 \\
\hline \multirow{2}{*}{1.2} & Suge & tã & & & & & & & & & & & & & & & & & & \\
\hline & 0 & 1 & 2 & 3 & 4 & 0 & 1 & 2 & 3 & 4 & 0 & 1 & 2 & 3 & 4 & 0 & 1 & 2 & 3 & 4 \\
\hline \multirow{2}{*}{2} & Suge & stã & & & & & & & & & & & & & & & & & & \\
\hline & 0 & 1 & 2 & 3 & 4 & 0 & 1 & 2 & 3 & 4 & 0 & 1 & 2 & 3 & 4 & 0 & 1 & 2 & 3 & 4 \\
\hline \multirow{2}{*}{2.1} & Suge & stã & & & & & & & & & & & & & & & & & & \\
\hline & 0 & 1 & 2 & 3 & 4 & 0 & 1 & 2 & 3 & 4 & 0 & 1 & 2 & 3 & 4 & 0 & 1 & 2 & 3 & 4 \\
\hline \multirow{2}{*}{2.2} & Suge & tã & & & & & & & & & & & & & & & & & & \\
\hline & 0 & 1 & 2 & 3 & 4 & 0 & 1 & 2 & 3 & 4 & 0 & 1 & 2 & 3 & 4 & 0 & 1 & 2 & 3 & 4 \\
\hline \multirow{2}{*}{2.3} & Suge & stã & & & & & & & & & & & & & & & & & & \\
\hline & 0 & 1 & 2 & 3 & 4 & 0 & 1 & 2 & 3 & 4 & 0 & 1 & 2 & 3 & 4 & 0 & 1 & 2 & 3 & 4 \\
\hline 3 & \multicolumn{20}{|c|}{ Sugestão: } \\
\hline
\end{tabular}


1DPAENDICE C. Questionário para avaliar a qualidade do questionário do nível de maturidade do SSD

\begin{tabular}{|c|c|c|c|c|c|c|c|c|c|c|c|c|c|c|c|c|c|c|c|c|}
\hline Questão & $\begin{array}{l}\text { Fác } \\
\text { Ent }\end{array}$ & end & ime & & & & $\begin{array}{l}\text { a E } \\
\text { átil }\end{array}$ & xpli & cati & & $\begin{array}{l}\mathrm{Im} \\
\text { O C }\end{array}$ & & & par & & & Obje & tivi & idad & \\
\hline \multirow{3}{*}{3.1} & 0 & 1 & 2 & 3 & 4 & 0 & 1 & 2 & 3 & 4 & 0 & 1 & 2 & 3 & 4 & 0 & 1 & 2 & 3 & 4 \\
\hline & Suge & tãc & & & & & & & & & & & & & & & & & & \\
\hline & 0 & 1 & 2 & 3 & 4 & 0 & 1 & 2 & 3 & 4 & 0 & 1 & 2 & 3 & 4 & 0 & 1 & 2 & 3 & 4 \\
\hline \multirow{2}{*}{3.2} & Suge & tãc & & & & & & & & & & & & & & & & & & \\
\hline & 0 & 1 & 2 & 3 & 4 & 0 & 1 & 2 & 3 & 4 & 0 & 1 & 2 & 3 & 4 & 0 & 1 & 2 & 3 & 4 \\
\hline \multirow{2}{*}{3.3} & Suge & tãc & & & & & & & & & & & & & & & & & & \\
\hline & 0 & 1 & 2 & 3 & 4 & 0 & 1 & 2 & 3 & 4 & 0 & 1 & 2 & 3 & 4 & 0 & 1 & 2 & 3 & 4 \\
\hline \multirow{2}{*}{4} & Suge & tãc & & & & & & & & & & & & & & & & & & \\
\hline & 0 & 1 & 2 & 3 & 4 & 0 & 1 & 2 & 3 & 4 & 0 & 1 & 2 & 3 & 4 & 0 & 1 & 2 & 3 & 4 \\
\hline \multirow{2}{*}{4.1} & Suge & tãc & & & & & & & & & & & & & & & & & & \\
\hline & 0 & 1 & 2 & 3 & 4 & 0 & 1 & 2 & 3 & 4 & 0 & 1 & 2 & 3 & 4 & 0 & 1 & 2 & 3 & 4 \\
\hline \multirow{2}{*}{4.2} & Suge & tãc & & & & & & & & & & & & & & & & & & \\
\hline & 0 & 1 & 2 & 3 & 4 & 0 & 1 & 2 & 3 & 4 & 0 & 1 & 2 & 3 & 4 & 0 & 1 & 2 & 3 & 4 \\
\hline 4.3 & \multicolumn{20}{|c|}{ Sugestão: } \\
\hline
\end{tabular}




\begin{tabular}{|c|c|c|c|c|c|c|c|c|c|c|c|c|c|c|c|c|c|c|c|c|}
\hline Questão & & enc & $\mathrm{im}$ & nto & & & & $\mathrm{xpl}$ & cati & & & $\begin{array}{l}\text { orta } \\
\text { ntex }\end{array}$ & $\begin{array}{l}\text { ante } \\
\text { xto }\end{array}$ & pa & & & bj & tivi & dad & \\
\hline \multirow{3}{*}{4.4} & 0 & 1 & 2 & 3 & 4 & 0 & 1 & 2 & 3 & 4 & 0 & 1 & 2 & 3 & 4 & 0 & 1 & 2 & 3 & 4 \\
\hline & Suge & stã & & & & & & & & & & & & & & & & & & \\
\hline & 0 & 1 & 2 & 3 & 4 & 0 & 1 & 2 & 3 & 4 & 0 & 1 & 2 & 3 & 4 & 0 & 1 & 2 & 3 & 4 \\
\hline \multirow{2}{*}{4.5} & Suge & stã & & & & & & & & & & & & & & & & & & \\
\hline & 0 & 1 & 2 & 3 & 4 & 0 & 1 & 2 & 3 & 4 & 0 & 1 & 2 & 3 & 4 & 0 & 1 & 2 & 3 & 4 \\
\hline \multirow{2}{*}{4.6} & Suge & stã & & & & & & & & & & & & & & & & & & \\
\hline & 0 & 1 & 2 & 3 & 4 & 0 & 1 & 2 & 3 & 4 & 0 & 1 & 2 & 3 & 4 & 0 & 1 & 2 & 3 & 4 \\
\hline \multirow{2}{*}{4.7} & Suge & stã & & & & & & & & & & & & & & & & & & \\
\hline & 0 & 1 & 2 & 3 & 4 & 0 & 1 & 2 & 3 & 4 & 0 & 1 & 2 & 3 & 4 & 0 & 1 & 2 & 3 & 4 \\
\hline \multirow{2}{*}{5} & Suge & stã & & & & & & & & & & & & & & & & & & \\
\hline & 0 & 1 & 2 & 3 & 4 & 0 & 1 & 2 & 3 & 4 & 0 & 1 & 2 & 3 & 4 & 0 & 1 & 2 & 3 & 4 \\
\hline \multirow{2}{*}{5.1} & Suge & stã & & & & & & & & & & & & & & & & & & \\
\hline & 0 & 1 & 2 & 3 & 4 & 0 & 1 & 2 & 3 & 4 & 0 & 1 & 2 & 3 & 4 & 0 & 1 & 2 & 3 & 4 \\
\hline 6 & \multicolumn{20}{|c|}{ Sugestão: } \\
\hline
\end{tabular}


1ABEENDICE C. Questionário para avaliar a qualidade do questionário do nível de maturidade do SSD

\begin{tabular}{|c|c|c|c|c|c|c|c|c|c|c|c|c|c|c|c|c|c|c|c|c|}
\hline Questão & $\begin{array}{l}\text { Fác } \\
\text { Ent }\end{array}$ & end & ime & & & & $\begin{array}{l}\text { a E } \\
\text { átil }\end{array}$ & xpli & cati & & $\begin{array}{l}\mathrm{Im} \\
\mathrm{OC}\end{array}$ & & & par & & & Obje & tivi & idad & \\
\hline \multirow{3}{*}{6.1} & 0 & 1 & 2 & 3 & 4 & 0 & 1 & 2 & 3 & 4 & 0 & 1 & 2 & 3 & 4 & 0 & 1 & 2 & 3 & 4 \\
\hline & Suge & tãc & & & & & & & & & & & & & & & & & & \\
\hline & 0 & 1 & 2 & 3 & 4 & 0 & 1 & 2 & 3 & 4 & 0 & 1 & 2 & 3 & 4 & 0 & 1 & 2 & 3 & 4 \\
\hline \multirow{2}{*}{6.2} & Suge & tãc & & & & & & & & & & & & & & & & & & \\
\hline & 0 & 1 & 2 & 3 & 4 & 0 & 1 & 2 & 3 & 4 & 0 & 1 & 2 & 3 & 4 & 0 & 1 & 2 & 3 & 4 \\
\hline \multirow{2}{*}{7} & Suge & tãc & & & & & & & & & & & & & & & & & & \\
\hline & 0 & 1 & 2 & 3 & 4 & 0 & 1 & 2 & 3 & 4 & 0 & 1 & 2 & 3 & 4 & 0 & 1 & 2 & 3 & 4 \\
\hline \multirow{2}{*}{7.1} & Suge & tãc & & & & & & & & & & & & & & & & & & \\
\hline & 0 & 1 & 2 & 3 & 4 & 0 & 1 & 2 & 3 & 4 & 0 & 1 & 2 & 3 & 4 & 0 & 1 & 2 & 3 & 4 \\
\hline \multirow{2}{*}{8} & Suge & tãc & & & & & & & & & & & & & & & & & & \\
\hline & 0 & 1 & 2 & 3 & 4 & 0 & 1 & 2 & 3 & 4 & 0 & 1 & 2 & 3 & 4 & 0 & 1 & 2 & 3 & 4 \\
\hline \multirow{2}{*}{8.1} & Suge & tãc & & & & & & & & & & & & & & & & & & \\
\hline & 0 & 1 & 2 & 3 & 4 & 0 & 1 & 2 & 3 & 4 & 0 & 1 & 2 & 3 & 4 & 0 & 1 & 2 & 3 & 4 \\
\hline 9 & \multicolumn{20}{|c|}{ Sugestão: } \\
\hline
\end{tabular}




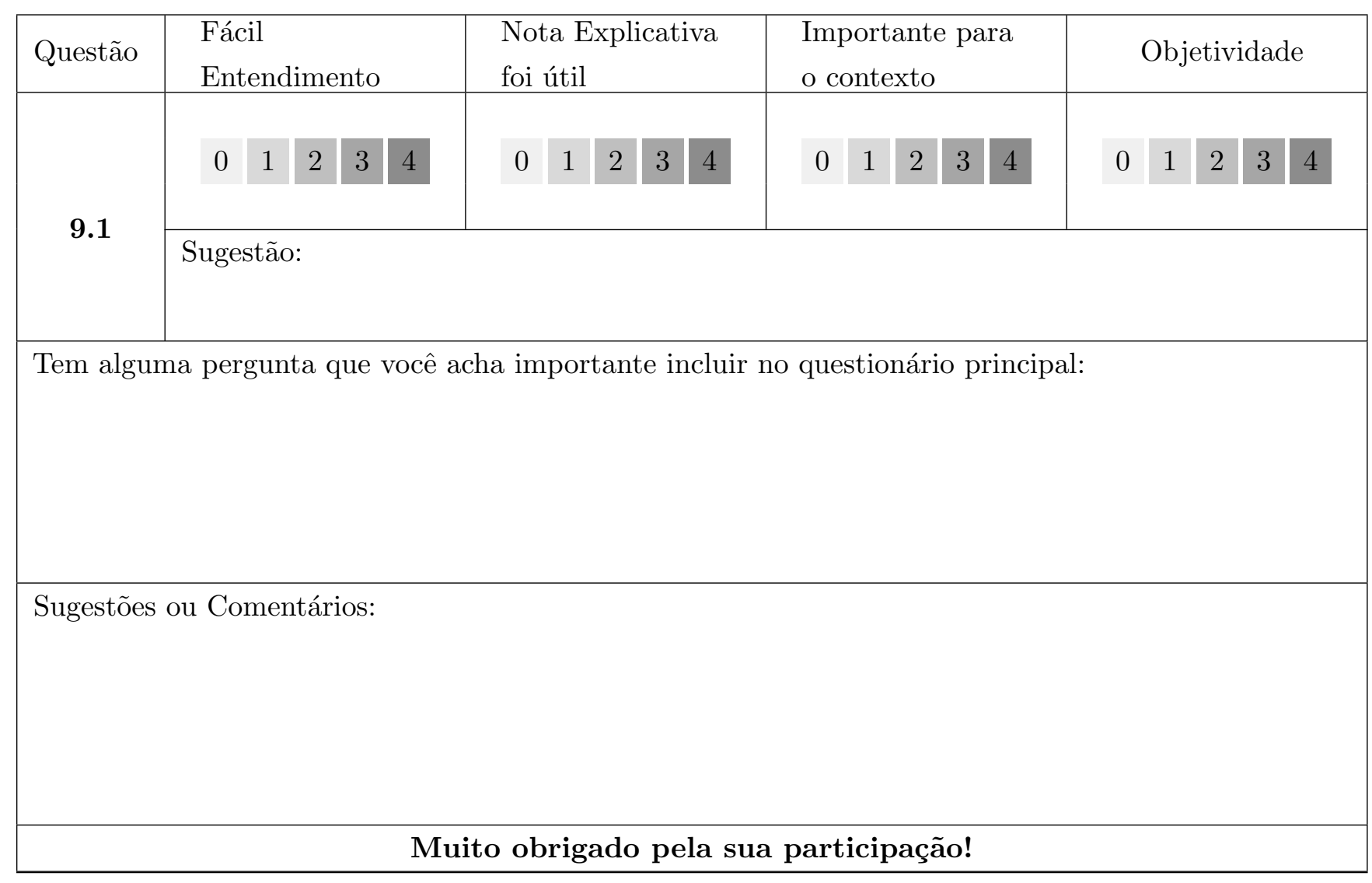

